\title{
VIVECA WALLIN BENGTSSON PERIODONTITIS, CAROTID CALCIFICATIONS AND FUTURE CARDIOVASCULAR DISEASES IN OLDER INDIVIDUALS
}
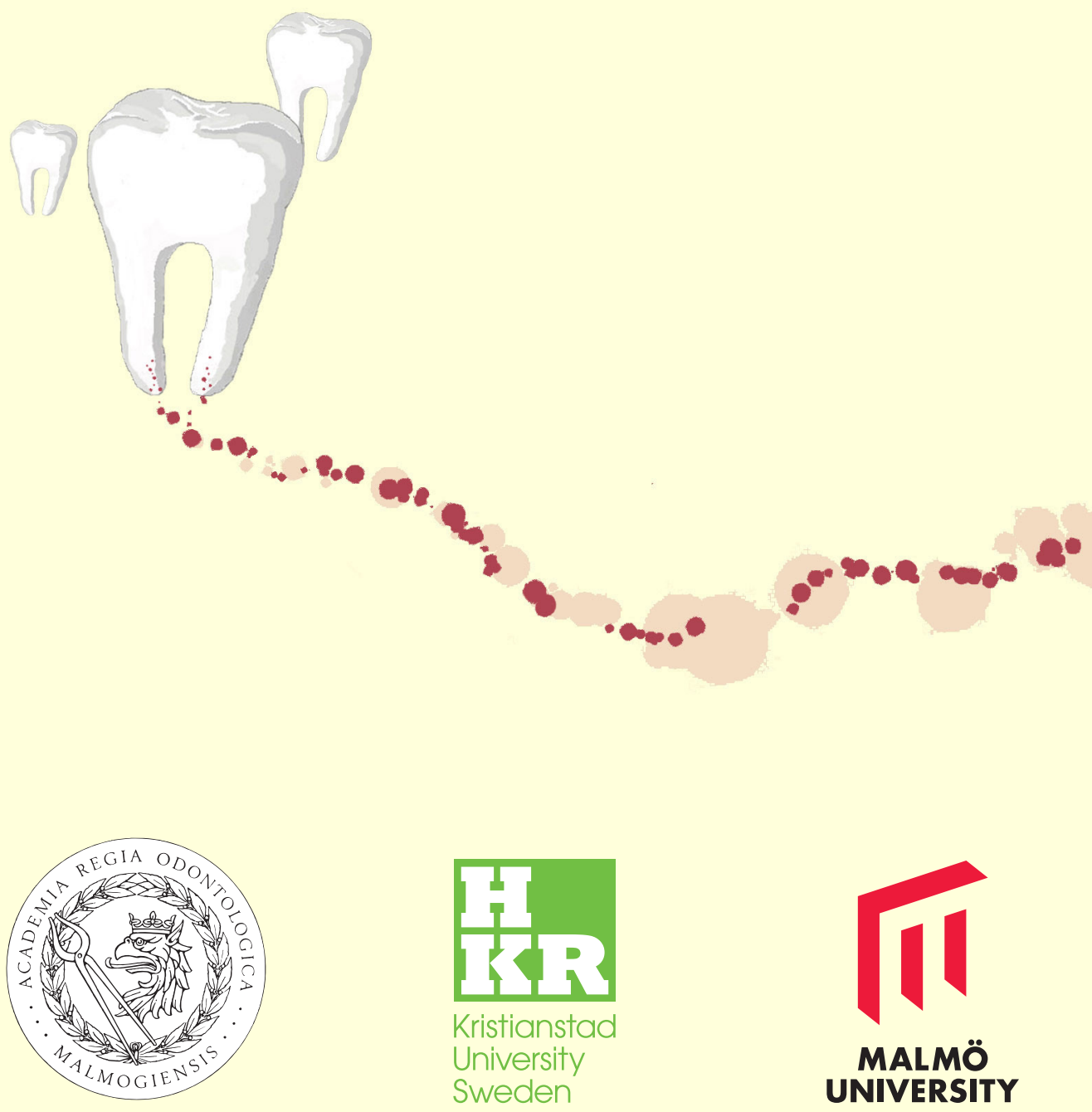

PERIODONTITIS, CAROTID CALCIFICATIONS AND FUTURE

CARDIOVASCULAR DISEASES IN OLDER INDIVIDUALS 
Malmö University, Faculty of Odontology
Doctoral Dissertation in Odontology, 2019

(C) Copyright Viveca Wallin Bengtsson 2019

Coverpage Marie Jönsson

ISBN 978-91-7877-020-5 (Malmö) (print)

ISBN 978-91-7877-021-2 (Malmö) (pdf)

ISBN 978-91-87973-41-3 (Kristianstad)

Holmbergs, Malmö 2019 


\section{VIVECA WALLIN BENGTSSON PERIODONTITIS, CAROTID CALCIFICATIONS AND FUTURE CARDIOVASCULAR DISEASES IN OLDER INDIVIDUALS}

Malmö University, 2019 Faculty of Odontology Department of Periodontology

Kristianstad University, 2019 Faculty of Health Sciences 
The publication is available in electronic format at: doi.org/10.24834/978-91-7877-021-2 
To Andreas, Alexander, Ludwig and Victoria 



\section{CONTENTS}

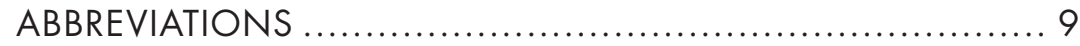

LIST OF PAPERS ............................................... 12

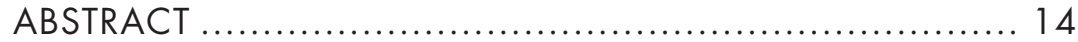

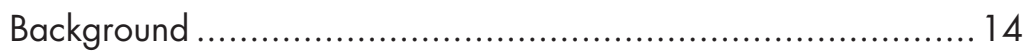

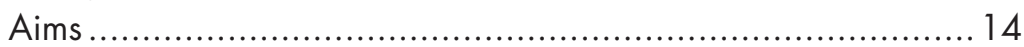

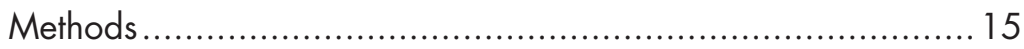

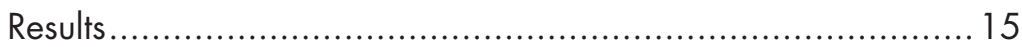

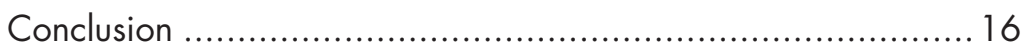

POPULÄRVETENSKAPLIG SAMMANFATTNING ............... 18

INTRODUCTION ................................................ 20

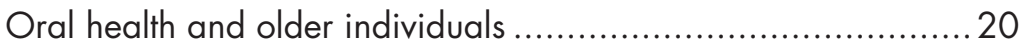

Periodontitis and older individuals ........................................... 21

Periodontitis, systemic diseases and older individuals............... 22

Periodontitis, cardiovascular diseases (CVDs), mortality

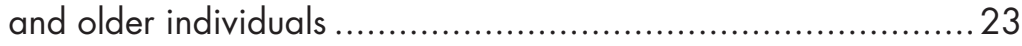

Carotid calcifications, atherosclerotic lesions on

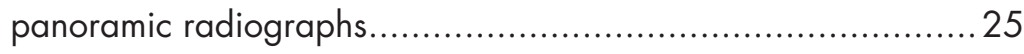

AIMS .............................................................. 27

MATERIAL AND METHODS ................................. 28

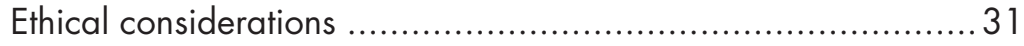

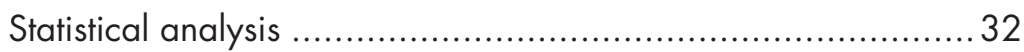

RESULTS ......................................................... 34

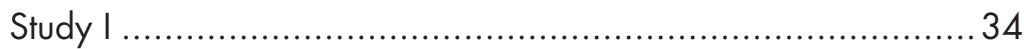

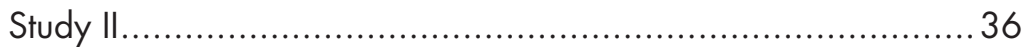

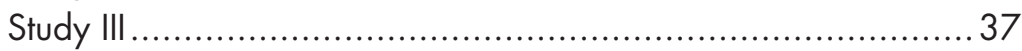

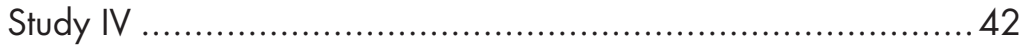


DISCUSSION ............................................... 45

CONCLUSIONS ............................................... 53

FUTURE RESEARCH............................................ 55

CLINICAL IMPLICATIONS ......................................... 56

ACKNOWLEDGEMENTS .................................. 57

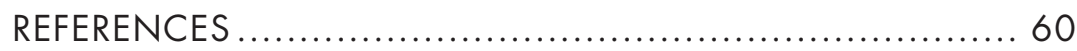

PAPERS I - IV .................................................... 71 


\section{ABBREVIATIONS}

ACS- Acute coronary syndromes

AMI- Acute myocardial infarction

BMI- Body mass index

BL- Bone loss

BOP- Bleeding on probing

CC- Carotid calcification

CAL- Clinical attachment level

CEJ-Cementoenamel junction

CI- Confidence Interval

C3- Cervical vertebra 3

C4- Cervical vertebra 4

CVDs- Cardiovascular diseases

DS- Doppler Sonography 
FDI- World Dental Federation

HR- Hazard ratio

ICC- Intraclass correlation

ICD- International classification of diseases

JB- Johan Sanmartin Berglund

MI- Myocardial infarction

OR- Odds ratio

OO- Old old age cohort 78-96 years

PASW- Predictive Analytics Soft Ware

PC- Personal computer

PD- Probing depth

PMX- Panoramic radiograph

REP- Rigmor Persson

SD- Standard deviation

SNAC- Swedish National Study of Aging and Care

SPP- Statistical Package for the Social Sciences

SWEAH- The Swedish National Graduate School for Competitive Science on Ageing and Health

TIA- Transient ischemic contact 
UN- United Nations

WHO- World Health Organization

WMA- World Medical Association

YO- Young old age cohort $60-72$ years 


\section{LIST OF PAPERS}

This thesis is based on the following four papers, which will be referred to in the text by the Roman numerals I-IV as listed below.

I. Bengtsson VW, Persson GR, Renvert S. Assessment of carotid calcifications on panoramic radiographs in relation to other used methods and relationship to periodontitis and stroke: a literature review. Acta Odontol. Scand. 2014;72(6):401-12.

II. Bengtsson VW, Persson GR, Berglund J, Renvert S. A cross-sectional study of the associations between periodontitis and carotid arterial calcifications in an elderly population. Acta Odontol. Scand. 2016;74(2):115-20.

III. Bengtsson VW, Persson GR, Berglund J, Renvert S. Carotid calcifications on panoramic radiographs are associated with future stroke or ischemic heart diseases: a long-term follow-up study. Clin Oral Investig. 2019;23(3):11711179 .

IV. Periodontitis related to cardiovascular events and mortality, a long-time longitudinal study. In manuscript.

Reprints of articles I and II were made with kind permission of the publishers. Article III is distributed under the terms of the Creative Commons Attribution 4.0 International License. 


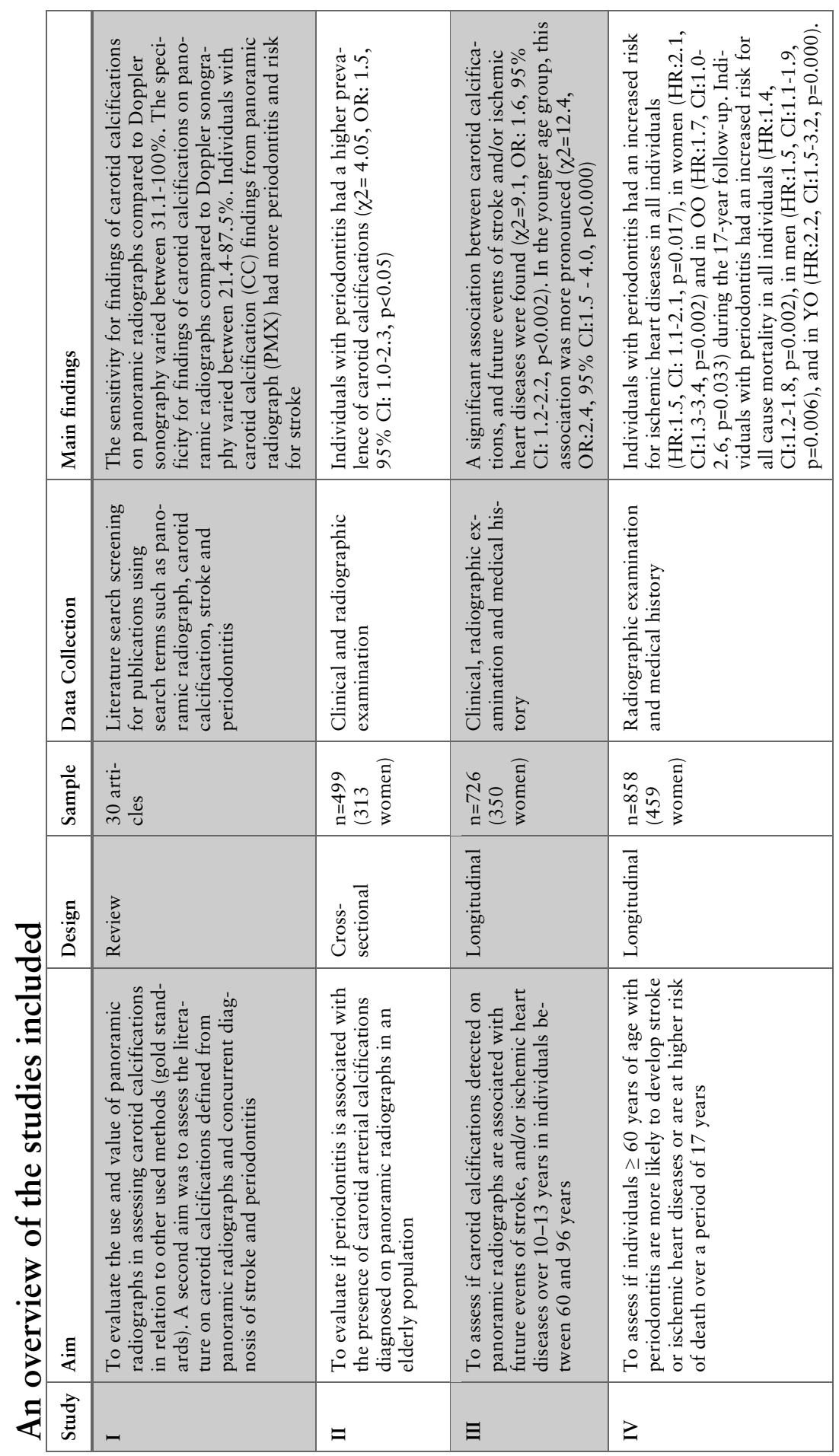




\section{ABSTRACT}

\section{Background}

Periodontitis is a chronic inflammatory disease with a microbiological etiology affecting the supporting tissues of the tooth. The disease affects approximately $50 \%$ of the adult population. The prevalence of periodontitis increases with age. The complex bacterial infection, as well as an exaggerated host inflammatory reaction, may trigger subclinical atherosclerosis.

\section{Aims}

The overall aim of the present thesis was to study the associations between periodontitis, cardiovascular diseases and mortality. The specific aims were: I) to evaluate the use and value of panoramic radiographs in assessing carotid calcifications in relation to other used methods (gold standards) and to assess the literature on carotid calcifications defined from panoramic radiographs and concurrent diagnosis of stroke and periodontitis, II) to evaluate if periodontitis is associated with the presence of carotid arterial calcifications diagnosed on panoramic radiographs in an elderly population, III) to assess if carotid calcifications detected on panoramic radiographs are associated with future events of stroke, and/or ischemic heart diseases over 10-13 years in individuals between 60 and 96 years, IV) to assess if individuals $\geq 60$ years of age with periodontitis are more likely to develop stroke or ischemic heart diseases or are at higher risk of death over a period of 17 years. 


\section{Methods}

A literature review based on peer-reviewed studies was performed evaluating the use of panoramic radiographs in assessing carotid calcifications compared to other methods. In study II, III, IV older individuals, 60 years and older participating in the Swedish $\mathrm{Na}$ tional Study of Aging and Care (SNAC) were included in the studies. A dental hygienist performed a dental clinical and radiographic examination. Probing depths (PD) and bleeding on probing (BOP) was registered. From radiographic panoramic images, the distances between the alveolar bone level and the cement enamel junction (CEJ) were measured. In study II, a diagnosis of periodontitis was declared, using a composite definition; if a distance between the alveolar bone level and the $\mathrm{CEJ} \geq 5 \mathrm{~mm}$ on panoramic radiographs at $>10 \%$ of sites and $\mathrm{PD} \geq 5 \mathrm{~mm}$ at one or more teeth and with BOP $>20 \%$ of teeth. In study IV, an indicator of a history of periodontal disease was declared if a distance between the alveolar bone level and the CEJ $\geq 5 \mathrm{~mm}$ on panoramic radiographs at $\geq 30 \%$ of sites. Evidence of a radiopaque nodular mass in the intervertebral space at or below the vertebrae C3-C4 was identified as carotid calcification. In addition, a medical research team performed the medical examinations, and a medical doctor (JB) reviewed all medical records for information about events of stroke and ischemic heart diseases. Stroke and ischemic heart diseases were registered according to the ICD 10 codes: ICD 60-69 for stroke and ICD: 20-25 for ischemic heart diseases. Study I was a review of the literature, in study II, a cross-sectional study design was employed. In studies III and IV, a longitudinal prospective study design was used.

\section{Results}

On the use of panoramic radiographs in assessing carotid calcifications in relation to other used methods, the sensitivity and specificity varied between studies published. Furthermore, only a small number of studies were found concerning carotid calcifications and stroke. These studies were primarily retrospective. Four studies were found on the association between periodontitis and carotid calcification. 
Study II identified that older individuals with periodontitis had a significantly higher prevalence of carotid calcifications than individuals who did not have a diagnosis of periodontitis. In study III, a significant association was found between carotid calcifications on panoramic radiographs and 13- year incidence of stroke using a logistic regression analysis adjusted for confounders (BMI, diabetes type 2, hypertension) in the 60-72 years. A statistically significant crude association between radiographic evidence of carotid calcifications and incidence of ischemic heart diseases was found in individuals between 60-72 years. Such an association was, however, not identified among individuals older than 72 years.

In study IV, Cox regression analysis was used, adjusted for confounders (age group, BMI $>30$, diabetes type 2, gender, hypertension, history of AMI, history of stroke, periodontitis, smoking) and with a definition of periodontitis as having a distance between the alveolar bone level and the CEJ $\geq 5 \mathrm{~mm}$ in panoramic radiographs at $\geq 30 \%$ of sites. Periodontitis increased the risk for ischemic heart diseases in all individuals, in women and in the 78-96 years age group (OO). Associations between periodontitis, and mortality were found in all individuals, in men and in the 60-72 years age group (YO) in the long term follow-up.

\section{Conclusions}

1.

Study I identified that there are studies which have assessed the value of panoramic radiographs in relation to other used methods (gold standards). The sensitivity and the specificity varied, with the specificity being more often higher. Few studies have considered the relationship between radiographic evidence of carotid calcifications and stroke. Four studies identified a relationship between a diagnosis of periodontitis and carotid calcifications on panoramic radiographs. 
2.

Study II identified a significant association between periodontitis and carotid calcification in individuals 60-96 years.

3.

Study III identified that signs of carotid calcifications assessed from panoramic radiographs from the 60-96-year-old individuals were consistent with an incident of stroke and/or ischemic heart diseases over 13 years follow-up.

4.

Study IV identified that periodontitis was associated with future ischemic heart diseases in all individuals, in women and in the 7896 years age group. Periodontitis was associated with mortality in all indviduals, in men and in the 60-72 years age group. 


\title{
POPULÄRVETENSKAPLIG SAM- MANFATTNING
}

\begin{abstract}
Munnen är en del av kroppen. Processer och sjukdomar som påverkar munhålan kan även påverka övriga delar av kroppen. Tandlossning är en kronisk inflammatorisk sjukdom som startar med bakterier. Bakterieprodukter och inflammatoriska produkter orsakar en destruktion av tandens stödjevävnader (parodontit). Om sjukdomen, genom behandling, inte kan stoppas leder det till att tanden lossnar, därför används ibland ordet tandlossning i allmänt tal. Parodontit drabbar en stor del av befolkningen och ökar med stigande ålder. De bakterier, bakterieprodukter och inflammatoriska produkter som är involverade vid parodontit har påträffats $i$ blodkärlen. Det finns många andra sjukdomar som också är inflammationsdrivna så som hjärtkärlsjukdomar där ateroskleros anses vara den huvudsakliga orsaken.
\end{abstract}

Det övergripande målet med denna avhandling var att studera samband mellan parodontit och hjärtkärlsjukdomar respektive död över tid. Mer specifika mål var att i en övergripande allmän litteraturstudie studera användning och värde av panoramaröntgen för att identifiera karotisförkalkningar. I samma litteraturstudie studerades karotisförkalkningar i relation till stroke och parodontit. Med hjälp av röntgenundersökning studerades karotisförkalkningar liksom bennivån runt tänderna. Kliniskt undersöktes förekomsten av tandköttsfickor och blödning vid ficksondering. Förhållandet mellan karotisförkalkning och parodontit studerades. Vidare studerades om karotisförkalkningar, som identifierats på röntgen, 
kunde sättas i samband med insjuknande i stroke och/eller hjärtsjukdomar över en uppföljningstid på 13 års. Ytterligare ett mål var att undersöka om individer med parodontit hade större sannolikhet att utveckla stroke, hjärtsjukdom eller död, under en uppföljningstid på 17 år. Individer 60 år och äldre boende i Karlskrona kommun rekryterades inom projektet "Swedish National Study of Aging and Care" (SNAC). Två tandhygienister utförde kliniska och röntgenologiska undersökningar. En läkare granskade medicinska journaler för att identifiera eventuella stroke eller hjärtsjukdomar.

Träffsäkerheten med panoramaröntgen jämfört med andra metoder varierade kraftig mellan analyserade studier. Ett fătal studier påträffades avseende samband mellan karotisförkalkning på panoramaröntgen och stroke liksom karotisförkalkning och parodontit. I flertalet studier som rörde stroke hade man granskat samband mellan karotisförkalkning och en historia av stroke men inte framtida insjuknande i stroke.

Hos individer 60-72 år upptäcktes ett starkt samband mellan karotisförkalkning på panoramaröntgen och insjuknande i stroke och/eller hjärtsjukdomar. Individer med parodontit visade sig ha en ökad risk att dö under den 17 åriga uppföljningstiden jämfört med individer utan parodontit. Parodontit visade sig ha ett samband med ökad risk för hjärtsjukdomar.

Slutsatsen av denna avhandling är att;

Äldre individer med parodontit har ökad risk att dö och har oftare karotisförkalkning, jämfört med de som inte har parodontit.

Karotisförkalkning på panoramaröntgen har ett samband med insjuknande i hjärtkärlsjukdomar.

Individer med parodontit utvecklar oftare hjärtsjukdomar. 


\section{INTRODUCTION}

\section{Oral health and older individuals}

Oral health is part of the overall health, well-being and quality of life (Glick et al. 2017). For older individuals, oral health is vital to avoid discomfort and pain, tooth loss, and being able to chew food properly to avoid malnutrition (Eke et al. 2016). WHO defines oral health as "a state of being free from chronic mouth and facial pain, oral and throat cancer, oral infection and sores, periodontal (gum) disease, tooth decay, tooth loss, and other diseases and disorders that limit an individual's capacity in biting, chewing, smiling, speaking, and psychosocial "well-being" (Fisher et al. 2018). A similar definition by the World Dental Federation (FDI) has been declared, "oral health is multi-faceted and includes the ability to speak, smile, smell, taste, touch, chew, swallow and convey a range of emotions through facial expressions with confidence and without pain, discomfort and disease of the craniofacial complex" (Glick et al. 2017).

Life expectancy worldwide has increased, and most individuals can expect to live beyond 60 years. The proportion of the world's population $>60$ years is predicted to change from $12 \%$ to $22 \%$ between 2015 and 2050 (WHO 2018). The demographic shift concerns particularly older adults of the developed countries in North America, Western Europe and northeast Asia (Lamster 2016). The definition of the older adult has been debated, but in 2017, the United Nations (UN) agreed to use 60 years as a definition (United Nations Ageing 2017). 
In older individuals the presence of complete dentures and partial dentures has steadily decreased over 40 years and the older population has more remaining teeth at older age (Norderyd et al. 2015, Tonetti et al. 2017, Schwendicke et al. 2018, Wahlin et al. 2018). Wahlin et al. (2018) demonstrated that the number of teeth significantly increased in a population between 20 to 80 years of age, especially in individuals with severe periodontitis. A decrease in the number of caries affected teeth has also been demonstrated, and this trend is expected to continue (Jordan et al. 2019). Accordingly, the number of filled and decayed teeth has increased in older individuals and will be expected to continue to increase (Norderyd et al. 2015, Jordan et al. 2019).

More remaining teeth and better oral health is considered a result of progress in the prevention and treatment of caries and periodontitis (Tonetti et al. 2017). The growing aging population and the increasing expectations of good oral health-related quality of life in older individuals will, however, provide a considerable challenge to the healthcare systems (Tonetti et al. 2017).

\section{Periodontitis and older individuals}

Periodontitis is a mixed bacterial infection, triggering inflammatory destruction of the teeth supporting tissues (Hajishengallis et al. 2012). The transition from gingivitis, a reversible inflammation in the gingiva, to periodontitis is caused by a disruption in the homeostasis between genetic (host immune system), environmental and bacterial virulence factors (Harvey et al. 2017). Epidemiologic studies performed in different parts of the world have shown that colonization by certain species of periodontal bacteria, including Aggregatibacter actinomycetemcomitans (A.a), Porphyromonas gingivalis (P.g), Tannerella forsythia (T.f) and Campylobacter rectus are detected in destructive periodontitis (Papapanou et al. 2014). If untreated, periodontitis may result in tooth loss and accounts for one of the biggest reasons to lose teeth in adulthood (Natto et al. 2014). 
Until now, periodontitis has been classified as: 1) chronic periodontitis, 2) aggressive periodontitis, and 3) periodontitis as a manifestation of systemic disease (Armitage, 2004). Recently a new classification has been adopted. Periodontitis is grouped into one single category and based on a multi-dimensional staging based on the severity and complexity and assessment of progression of the disease (Papapanou et al. 2018). Periodontitis is a chronic and cumulative disease that affects more often older individuals (Castrejón-Pérez et al. 2014). Data from The NHANES study in US 2009 and 2010, demonstrated that $47 \%$ of the population, representing 64.7 million adults 30 years and older in the US, had periodontitis. The prevalence of periodontitis increased with increasing age (Eke et al. 2012). The prevalence of severe periodontitis in individuals 80 years and older was in a Swedish population of $50 \%$ (Holm-Pedersen et al. 2006). Another Swedish study identified periodontitis in $38 \%$ of men $\geq 81$ years of age (Renvert et al. 2013). In a Norwegian population 67 years and older, $33 \%$ of the subjects had periodontitis, and out of those, $12 \%$ had severe periodontitis (Norderyd et al. 2012).

\section{Periodontitis, systemic diseases and older individuals}

During the last 30 years, a new research field, periodontal medicine has been launched. In this field, researchers have studied how periodontal disease may influence the individual's systemic health and vice versa (Williams et al. 2000). Periodontitis has not only local effects on the tooth-supporting tissues. Oral bacteria may also enter the bloodstream through the ulcerated periodontal pockets and cause infections in other organs (e.g. endocarditis, lung abscess and pneumonia) (Lockhart et al. 2009, Zhang et al. 2013). Bacteria from the periodontal lesions may cause inflammatory reactions that could influence the progression of systemic diseases, such as diabetes mellitus, atherosclerosis, adverse pregnancy outcomes, rheumatoid arthritis and neurodegenerative diseases (Genco et al. 2010, Glick et al. 2014). Associations between periodontitis and diabetes are well established (Chavarry et al. 2009, Borgnakke et al. 2013, Sanz et al. 2018) and periodontitis is associated with im- 
paired glycemic control in individuals with diabetes (Borgnakke et al. 2013).

\section{Periodontitis, cardiovascular diseases (CVDs), mortality and older individuals}

Development of atherosclerosis is a lifelong process, starting in early childhood, with clinical manifestations many years after (Niinikoski et al. 2012). Atherosclerosis is the main cause of CVDs (Gasbarrino et al. 2016, Chapman et al. 2017) and CVDs are the most common cause of death in the US (Xu et al. 2016). CVDs include all conditions associated with the heart and blood vessels, such as coronary heart disease, stroke and heart failure (Waters et al. 2013).

Periodontitis has been associated with an increased risk for CVDs (Scannapieco et al. 2003, Kinane et al. 2008, Lockhart et al. 2012, Cullinan et al. 2013, Dietrich et al. 2013). The etiopathogenic link between periodontitis and CVDs is considered to be the results of systemic inflammation (Aoyama et al. 2017). Through the ulcerated periodontal pockets oral bacteria may enter the bloodstream (Lockhart et al. 2009) resulting in systemic inflammatory and immunologic responses (Scannapieco et al. 2016) that could trigger the initiation and progression of atherosclerosis (Ross et al. 1999, Libby et al. 2009). Individuals with a diagnosis of acute coronary syndrome (ACS) have demonstrated a significantly higher total oral bacterial load and increased number of species associated with periodontitis, such as Porphyromonas gingivalis, Tanerella forsythia and Treponema denticola (Renvert et al. 2006). High-sensitivity serum C-reactive protein levels, a mediator for inflammation, have in several studies demonstrated associations to periodontitis (Persson et al. 2005, Kumar et al. 2014). Data exist suggesting that periodontitis is associated with subclinical atherosclerosis (Desvarieux et al. 2003, Söder et al. 2005, Lockhart et al. 2012).

Having periodontitis increased the risk for stroke (Reyes et al. 2013, Schenkein et al. 2013, Tonetti et al. 2013). In a review of the literature, periodontitis was reported to be associated with the oc- 
currence of stroke (Lafon A et al. 2014) especially in men and in younger subjects (Grau et al. 2004). Periodontitis has also been associated with myocardial heart infarction (Rydén et al. 2016).

Few prospective longitudinal studies on the association between periodontitis and CVDs have been reported. In a 3-year follow-up study, periodontitis was predictive of a future ACS event (Renvert et al. 2010). Another 3-year follow-up study demonstrated that individuals with severe periodontitis and a diagnosis of coronary vascular disease attained the combined endpoint (myocardial infarction, stroke/transient ischemic attack, cardiovascular death and death caused by stroke) more often, although not significant, compared to individuals without periodontitis (18.9\% versus $14.2 \%)$ (Reichert et al. 2016). Patients with periodontitis were reported to have an increased risk of CVDs in a Danish nationwide cohort study with a 15 -year follow-up period (Hansen et al. 2016). In the same study by Hansen et al. (2016) it was reported that periodontitis increased the risk of all-cause mortality within 15 years. Individuals (30-40 years) with periodontitis and missing molars have been reported to have an increased risk for death from diseases of the circulatory system, over 16 years (Söder et al. 2007). Contradictory to the results by Hansen et al. (2016) and Söder et al. (2007) survival statistics from a 6-year longitudinal study failed to show that periodontitis predicted mortality in older individuals (Renvert et al. 2015). Missing teeth have been proposed as a surrogate marker for current or past periodontitis as it reflects an accumulation of oral inflammation to which an individual has been experienced throughout life (Holmlund et al. 2012). In a Korean nationwide cohort follow-up study of 7.6 years, tooth loss was associated with an incident of myocardial infarction, heart failure or ischemic stroke, especially in individuals with periodontitis (Lee et al. 2019). A population-based survey over 13 years, demonstrated that $\geq 5$ missing teeth were significantly associated with an event of coronary heart disease and acute myocardial infarction whereas no association with stroke was observed (Liljestrand et al. 2015). In another longitudinal study, with a median follow- up time 15.8 years, the number of teeth was significantly related to myocardial 
infarction and heart failure but not to an event of stroke (Holmlund et al. 2017). In the study by Liljestrand et al. (2015), missing teeth $\geq 9$ was associated with mortality.

\section{Carotid calcifications, atherosclerotic lesions on panoramic radiographs}

Atherosclerotic disease is common in the area where the carotid artery bifurcates into the internal and external carotid arteries (Cheng et al. 2006). Both invasive and non-invasive methods are used to assess the presence and extent of arterial calcifications (Bos et al. 2015). Intravascular ultrasound and intravascular optical coherence tomography are examples of invasive diagnostic methods, and they may be the most predictable methods in identifying elevated risks for stroke or other cardiovascular events (Denzel et al. 2004). Non-invasive diagnostic methods are Doppler sonography (DS), computed tomography (CT) and magnetic resonance imaging (MRI), all able to identify carotid calcifications (Huibers et al. 2015).

Panoramic radiography is a frequently performed radiographic diagnostic method in dentistry. Carotid calcifications are usually localized in the bifurcation area, posterior, inferior to the mandibular angle, and adjacent to the space between the third or fourth cervical vertebrae (C3 and C4). When the area of the carotid bifurcates is visible, panoramic radiography can also be utilized to identify carotid artery calcifications (Friedlander et al. 1994, Cohen et al. 2002, Persson et al. 2002, Ravon et al. 2003, Tanaka et. al 2006, Kumagai et al. 2007, Lee et al. 2014, Friedlander et al. 2015). In $3-15 \%$ of the adult population, these calcifications can be identified on panoramic radiographs (Friedlander et al. 1994, Carter et al. 1997, Ohba et al. 2003, Johansson et al. 2011). Signs of carotid calcifications are more frequently found in older individuals compared to younger individuals (Bengtsson et al. 2016). A high level of agreement in intra-examiner assessments of carotid calcification signs on panoramic radiographs has been reported (Persson et al. 2002). Asymptomatic carotid stenosis of $50 \%$ is a risk marker for 
future vascular events (Venketasubramanian et al. 2013, Brott et al. 2011). Guidelines recommend secondary vascular prevention and treatment of higher preventive intensity, for individuals with $50 \%$ carotid stenosis, even in the absence of vascular events (Venketasubramanian et al. 2013, Brott et al. 2011). Carotid stenosis of $50 \%$ or more can be detected in $75 \%$ of cases on panoramic radiographs (Garoff et al. 2014). 


\section{AIMS}

I. To evaluate the use and value of panoramic radiographs in assessing carotid calcifications in relation to other used methods (gold standards). A second aim was to assess the literature on carotid calcifications defined from panoramic radiographs and concurrent diagnosis of stroke and periodontitis

II. To evaluate if periodontitis is associated with the presence of carotid arterial calcifications diagnosed on panoramic radiographs in an elderly population

III. To assess if carotid calcifications detected on panoramic radiographs are associated with future events of stroke, and/or ischemic heart diseases over 10-13 years in individuals between 60 and 96 years

IV. To assess if individuals $\geq 60$ years of age with periodontitis are more likely to develop stroke or ischemic heart diseases or are at higher risk of death over a period of 17 years 


\section{MATERIAL AND METHODS}

The first study I, included in this thesis is a review assessing carotid calcifications on panoramic radiographs in relation to other used methods and the relationship to periodontitis and stroke. Studies II, III, IV are based on material from the Swedish National Study on Aging and Care (SNAC) in Blekinge Sweden.

\section{Study I}

Study 1 was performed as a literature review based on a literature search in PubMed (Medline) up to November 2012. The search was based on the following search terms; (I) (panoramic radiography and carotid calcification) OR (panoramic radiography and carotid calcifications) OR (panoramic radiography and carotid artery atheroma); (II) (carotid calcifications and stroke and panoramic radiography) OR (carotid calcification and dental) OR (carotid calcification and stroke and panoramic radiography) OR (carotid calcification and stroke panoramic radiography) and (III) (calcifications and periodontitis and panoramic radiography) OR (carotid calcification and periodontitis and panoramic radiography) OR (carotid calcification and periodontal disease and panoramic radiography) OR (periodontitis and carotid calcification) OR (periodontitis and carotid calcifications). Hard copy search of additional references was also employed. Only literature published in English was considered. The literature review included studies on the relationship between carotid calcifications identified on panoramic radiographs and other methods of assessments and studies on the association between carotid calcification and stroke and between ca- 
rotid calcification and periodontitis. Case reports, review papers and animal research were excluded.

Study II, III and IV

Studies II, III and IV are based on data from the Swedish National Study on Aging and Care (SNAC) in Blekinge. SNAC a national, multidisciplinary project includes four participating areas: SNACBlekinge, SNAC Kungsholmen, SNAC Nordanstig, and SNAC Skåne (GÅS). In all four study areas, research centers conduct a population study. In an older population, 60 years and over, data are obtained through repeated medical examinations, tests, interviews, and questionnaires regarding health, illness, functional capability and social situation. In SNAC-Blekinge, an oral health examination is also incorporated. The study has a longitudinal design and uses a common type of study design.

Study individuals in study II, III and IV

Study individuals were randomly selected from the Swedish population database representing the ageing population (60-96 years) in Karlskrona municipality (The Swedish Tax Agency electronic database), Sweden. At baseline (2001), an equal number of randomly selected individuals in age cohorts of $60,66,72$ and 78 years were included. In the age cohorts of 81, 84, 87, 90, 93 and 96 years, all inhabitants were invited, representing the older population in Karlskrona, Sweden. All individuals were invited by regular mail, and the enrolment occurred between 2001-2003 (baseline). At baseline, the response rate was $62 \%$ representing approximately $10 \%$ of the population $\geq 60$ years. More individuals in the older age cohorts declined participation.

\section{Clinical examination in study II}

During the enrolment, at baseline 2001-2003, two dental hygienists performed the clinical examinations. The examinations were performed in a dental chair at the research clinic. Probing depth (PD) was measured with a periodontal probe (CP-12, Hu-Friedy Inc. Chicago, IL) at four sites (mesial, mid-buccal, distal and mid- 
lingual) per tooth. The deepest PD value of each tooth was used to calculate the proportions of teeth with a probing depth $\geq 5 \mathrm{~mm}$. Reliability measurements between randomly selected cases for double assessments regarding the inter-observer agreement of PD values between the two clinicians performing the examinations was 0.76 (Cronbach's of (95\% CI:0.67-0.82; p<0.001). The proportion of teeth with bleeding on probing (BOP) was registered as bleeding or not per tooth and calculated on an individual level. In study II, periodontitis was defined by the extent of bone loss, PD and BOP.

\section{Radiographic examination in study II, III and IV}

At baseline in 2001-2003, analogue panoramic radiographs (Orthopantomograph, OP 100 Instrumentarium Tuusula Finland) were taken with a standard exposure of $75 \mathrm{kV}$ and $10 \mathrm{~mA}$. An experienced independent examiner (REP) performed the radiographic measurements blind to medical and dental information, age, gender and survival status. A millimeter graded plastic ruler, a magnification viewer (x 2) and a lightbox source, was used to measure the distances between the alveolar bone level and cement enamel junction (CEJ). Alveolar bone loss was measured at the mesial and distal aspect of the existing teeth. The number of interproximal sites with a distance $\geq 5 \mathrm{~mm}$ between the alveolar bone level and CEJ was used. Reliability measurements were made for a second reading of the panoramic radiographs. The intra-class correlation coefficient (ICC) between the intra-observer measurements for the distance between CEJ and the apex was 0.93 (95\% CI:0.91-0.96, $\mathrm{p}<0.01$ ). In study II, a diagnosis of periodontitis was made if a distance between the alveolar bone level and the CEJ $\geq 5 \mathrm{~mm}$ on panoramic radiographs was detected at $>10 \%$ of sites and $\mathrm{PD} \geq 5 \mathrm{~mm}$ at one or more teeth and with BOP $>20 \%$ of teeth. In study IV, periodontitis was defined if a distance between the alveolar bone level and the CEJ $\geq 5 \mathrm{~mm}$ on panoramic radiographs was detected at $\geq$ $30 \%$ of sites.

In study II and study III, evidence of a radiopaque nodular mass in the intervertebral space at or below the vertebrae C3-C4 was identified as carotid calcification. Reliability measurements of carotid 
calcifications were made through intra-examiner assessments from 100 randomly selected panoramic radiographs resulting in Cronbach's alpha of 0.91 with an interval between the two sets of readings approximately one year.

\section{Medical examination in study III and IV}

Information about events of stroke (cerebrovascular diseases) and ischemic heart diseases were collected from the electronic medical database at the research center of the general hospital in Karlskrona, Sweden. A physician (JB) annually reviewed the medical records for all individuals in the study. According to the world health organization (WHO), diseases were classified into "the statistic classification of diseases and related health problems, 10th revision" (ICD 10) (WHO 2019). These classifications are, for ischemic heart diseases (including myocardial infarction) classified ICD 10: 20-25 and for cerebrovascular diseases (including stroke) ICD 10: 60-69.

\section{Ethical considerations}

The included studies comply with the ethical regulations for research described by the World Medical Association (WMA), The Declaration of Helsinki with amendments (WMA 2013). All the four different ethical considerations were fulfilled: the information, the consent, the confidentiality and the utility requirement. The studies were based on voluntary participation. All study individuals signed an informed consent to the registration of collected information. All information was anonymized, coded and stored in order to protect the integrity of the study individuals. The principal investigator was the only one having access to the unique code key. Permission for the studies has been requested and granted by the Regional Research Ethics Committee at the Lund University (LU dnr LU-604-00 and 744-00). All the authors had full access to the data set. 


\section{Statistical analysis}

Statistical computations were carried out using Statistical Package for the Social Sciences (SPSS) Predictive Analytics Software (PASW) (version 22.0, 23.0 and 25.0 SPSS Inc., Chicago, IL, USA) for Windows.

\section{Study II}

Descriptive statistics were used to analyze the data. Independent ttests (equal variance not assumed) and non-parametric tests (Mann-Whitney U-test) were performed to assess group differences. Pearson's $\chi^{2}$ test and Mantel-Haenzel common odds ratio were also used. Significance was declared at $p<0.05$. The SPSS PASW version 22.0 for an Apple computer was used in the analysis.

\section{Study III}

The SPSS PASW version 23.0 for Personal Computer (PC) computer was used in the analysis. The data were analyzed using descriptive and inferential statistics. The data were assumed not to follow a normal distribution pattern, and therefore, both independent ttest (equal variance not assumed) and nonparametric tests (MannWhitney U test) was performed to assess group differences. Pearson $\chi 2$ test and Mantel-Haenzel odds ratio were used to analyze dichotomous data. The data were also studied by binominal logistic regression and adjusted for BMI, diabetes type 2, and hypertension. The Kaplan-Meier estimator (log rank Mantel-Cox) was used to study events of stroke and ischemic heart diseases in study individuals with or without radiographic evidence of carotid calcifications during the study period. Significance was set with $\alpha$ at $\mathrm{p}<0.05$.

\section{Study IV}

The SPSS PASW version 25.0 for PC was used in the analysis. The data were analyzed using descriptive and inferential statistics. Dichotomous data were analyzed using Pearson $\chi 2$ test, and Mantel- 
Haenszel common odds ratio. Cox regression analysis, using the enter method, was used to study adjusted associations (age group, BMI, diabetes type 2, gender, hypertension, history of AMI, history of stroke, periodontitis). Proportional hazards assumption was evaluated graphically with "log-log" plots. Time was defined as months from inclusion (dental examination) to either death, stroke, ischemic heart diseases outcome or censoring due to emigration, death or end of follow-up. Statistical significance was declared at $\mathrm{p}<0.05$. 


\section{RESULTS}

\section{Study I}

Panoramic radiographs in assessing carotid calcifications in relation to other used methods

Most of the studies were case series. Doppler sonography (the gold standard) is often used to identify carotid calcifications and was compared to panoramic radiographs in 12 out of the 16 studies. The sensitivity for findings of carotid calcifications on panoramic radiography compared to a finding by Doppler sonography varied from $31.1-100 \%$ and the specificity varied from $21.4-87.5 \%$ on a patient level. Two studies compared panoramic radiography to anterior-posterior projection radiography, and both were in total concordance to panoramic radiographs (Friedlander 1995, Friedlander et al. 2001). One study compared panoramic radiographs with computer tomography with a sensitivity of $22 \%$ and a specificity of $90 \%$ (carotid artery level) (Yoon et al. 2008). Digital subtraction angiography versus panoramic radiographs was studied in one study with a sensitivity of $60 \%$ and a specificity of $48 \%$ (carotid artery level) (Damaskos et al. 2008).

Carotid calcifications defined on panoramic radiographs and diagnosis of stroke

Associations between findings of carotid calcifications on panoramic radiographs and stroke were reported in 10 studies. Most of the information was based on case series. In the majority of stud- 
ies, the frequency of carotid calcifications on panoramic radiographs differed but was mostly low. Three of the studies investigated individuals with a history of stroke. One of them showed that all 14 individuals had carotid calcifications on panoramic radiographs (Christou et al. 2010). In the other two studies, 7/19 (Friedlander et al. 1994), and 8/40 (Kumagai et al. 2007), individuals with a history of stroke showed carotid calcifications on panoramic radiographs. Four studies focused on individuals with carotid calcifications on panoramic radiographs and if they had a history of stroke. The figures varied considerably, 1/42 (Carter et al. 1997), 29/71 (Cohen et al. 2002), 5/29 (Ravon et al. 2003), 3/33 (Tanaka et al. 2006). In one study, no individuals with carotid calcification on panoramic radiograph had a history of stroke (Lewis et al. 1999). One study assessed a history of stroke in individuals with carotid calcifications on panoramic radiographs both at baseline and at 5 years follow-up. At baseline 5/46, individuals with signs of carotid calcification had a history of stroke and 5 years later, another five individuals had developed stroke (Friedlander et al. 2007). In individuals 80 years old, one study showed that $2 / 106$ individuals with carotid calcifications died from cardiovascular diseases within 3.5 years (Tamura et al. 2005).

\section{Carotid calcifications defined on panoramic radiographs and concurrent diagnosis of periodontitis}

Relationships between carotid calcifications and a concurrent diagnosis of periodontitis were reported in four studies (Persson et al. 2002, Ravon et al. 2003, Beckström et al. 2007, Tiller at al. 2011). The definition of periodontitis varied between these studies. One of the studies focused on periodontitis risk (Tiller et al. 2011). When periodontitis was defined as alveolar bone loss $\geq 4 \mathrm{~mm}$ between the CEJ and the bone level at $\geq 30 \%$ of sites, an association was shown with carotid calcification on panoramic radiographs (Persson et al. 2002, Ravon et al. 2003) and a dose-response relationship between the size of the carotid calcification and the severity of periodontitis has been reported (Ravon et al. 2003). If periodontitis was defined as $>1 \mathrm{~mm}$ bone loss, $25.7 \%$ of individuals with bilateral carotid calcifications had periodontitis compared to 
$10.4 \%$ in individuals without carotid calcifications on panoramic radiographs (Beckström et al. 2007). Measuring periodontitis risk and radiographic evidence of carotid calcification, no associations were found when multivariate regression analysis was performed (Tiller et al. 2011).

\section{Study II}

In the study, 714 individuals with $\geq 10$ teeth as assessed from the panoramic radiographs were included. The area of interest for identifying carotid calcifications was not readable from 215 panoramic radiographs $(30.1 \%)$, leaving 499 individuals in the study (313 women; 62.7\%). When separating the individuals into a young-old (YO) age cohort, 60-72 years, $293(58.7 \%)$ individuals were included and in the old-old (OO) age cohort 78-93 years, 206 $(41.3 \%)$ were included. Individuals had on average 21.3 remaining teeth $(\mathrm{SD} \pm 5.1)$. Teeth with bleeding on probing $(\mathrm{BOP})$ was on average $25.3 \%$ ( $\mathrm{SD} \pm 22.6 \%$ ). A combined definition for periodontitis was used (if a distance between the alveolar bone level and the CEJ $\geq 5 \mathrm{~mm}$ could be identified on the panoramic radiographs at $>10 \%$ of sites and $\mathrm{PD} \geq 5 \mathrm{~mm}$ at one tooth or more and with bleeding on probing at $>20 \%$ of teeth). Using this definition of periodontitis 91 out of the 499 (18.4\%) study individuals were diagnosed as periodontitis patients. A diagnosis of periodontitis was more frequent in men (Pearson $\chi 2=12.9 ; \mathrm{p}<0.001$ ) with an OR of 2.0 (95\% CI: 1.4$2.9, \mathrm{p}<0.001)$. The prevalence of periodontitis was higher in the OO age cohort with an OR of 1.8 (Pearson $\chi^{2}=10.1,95 \%$ CI: $1.3-2.6, \mathrm{p}<0.001)$. No statistical differences were found in BOP between the two age cohorts.

Radiographic signs of carotid calcification identified from panoramic radiographs were found in 195/499 individuals (39.1\%). Men had more radiographic signs of carotid calcifications compared to women (Pearson $\chi_{2}=4.6, \mathrm{p}<0.05$ ), with an OR of 1.5 (95\% CI:1.0-2.2, p <0.05). When comparing the age cohorts, the OO had significantly more signs of carotid calcifications with an OR of 1.7 (95\% CI:1.1-2.4, p <0.01). In the younger age cohort, the prevalence of carotid calcifications was significantly higher 
among men (Pearson $\chi_{2}=5.2, \mathrm{p}<0.05$ ) with a likelihood of 1.8 (95\% CI:1.1- 2.9, p <0.05).

Statistical analysis demonstrated that individuals with periodontitis had a higher prevalence of carotid calcification (Pearson $\chi 2=4.05$ $\mathrm{p}<0.05)$ and with an OR of 1.5 (95\% CI: 1.0-2.3, p <0.05).

\section{Study III}

The study included 726 individuals with a readable panoramic radiograph. The participants were divided into young-old (YO) 6072 years, including 350 study participants and old-old (OO) 78-96 years including 376 participants. During the follow-up period (2001-2014) 66/350 (18.9\%) in the YO and 285/376 (75.8\%) in the $\mathrm{OO}$ age group had died.

In all individuals, a significant association between signs of carotid calcifications on panoramic radiographs at baseline and a future event of stroke and/or ischemic heart diseases was identified $\left(\chi_{2}=\right.$ 9.1, OR:1.6, 95\% CI:1.2-2.2, p <0.002). Specifically, in the younger age group this was more pronounced $\left(\chi_{2}=12.4\right.$, OR:2.4, 95\% CI:1.5-4.0, $\mathrm{p}<0.000)$. In the same group, a significant association between carotid calcifications and an event of stroke was found ( $\chi_{2}$ $=4.5$, OR:2.3, 95\% CI:0.9-6.2, $\mathrm{p}=0.03$ ).

At the baseline examination, a history of stroke and/or ischemic heart diseases was reported in 91/726 (14.3\%) individuals. Radiographic signs of carotid calcifications were found in 45/91 (49.5\%) of these individuals. The gender distribution of such signs was $13 / 45(28.9 \%)$ in women and $32 / 45(71.1 \%)$ in men.

Data on the remaining 635 individuals who reported no previous event of stroke and/or ischemic heart diseases at the baseline examination is described in a sub-analysis. Carotid calcification was identified in 238/635 (37.5\%) of the study individuals. Carotid calcifications were more frequent in the OO age group 135/319 $(42.3 \%)$ as compared to the $\mathrm{YO}$ age group $103 / 316(32.6 \%)(\chi 2=$ 6.4 , OR:1.5, 95\% CI:1.1-2.1, p = 0.01). Independent of age, radi- 
ographic signs of carotid calcifications were more frequently identified in men $(\chi 2=11.1$, OR:1.8, 95\% CI:1.3-2.5, p = 0.001). During 2001-2014, first events of stroke and/or ischemic heart diseases were identified in 195/635 (30.7\%) individuals. Men in the YO age group had a higher OR for a stroke event than women (OR:3.1, $95 \%$ CI:1.0-8.3, $\mathrm{p}=0.02)$. There was no gender difference for ischemic heart diseases (OR: 1.3, 95\% CI:0.7-2.4, p = 0.4) in the same YO group. Data analysis also failed to demonstrate gender differences in the $\mathrm{OO}$ age group for the incidence of stroke (OR:1.0, 95\% CI:0.6-1.8, $\mathrm{p}=0.9$ ) or for the incidence of ischemic heart diseases (OR:1.4, 95\% CI: 0.9-2.4, $\mathrm{p}=0.12$ ).

A significant association was identified by logistic regression, crude and adjusted (BMI, diabetes type 2, hypertension), in the YO between carotid calcifications on panoramic radiographs and stroke and/or ischemic heart diseases crude (OR:2.4, 95\% CI:1.5-4.0, p= 0.000), and adjusted (OR:1.9, 95\% CI:1.1-3.5, p = 0.03) (Table I). In the OO group, only a history of hypertension was significantly associated with future stroke and/or ischemic heart diseases.

Table 1. Associations between 10-13 year incidence of stroke and/or ischemic heart diseases and different independent variables. Logistic regression in 60-72 years without a history of stroke and/or ischemic heart diseases reported at baseline

\begin{tabular}{|l|l|l|l|}
\hline Independent variables at baseline & OR & $95 \% \mathrm{CI}$ & p-value \\
\hline BMI & 1.0 & $1.0-1.1$ & 0.14 \\
\hline Carotid calcifications & 1.9 & $1.1-3.5$ & $0.03^{*}$ \\
\hline Diabetes mellitus type 2 & 2.1 & $0.7-5.9$ & 0.16 \\
\hline Hypertension & 1.7 & $0.9-3.2$ & 0.08 \\
\hline
\end{tabular}

BMI $=$ Body mass Index

* $=\mathrm{p}<0.0 .5$ 
Data on causes of death was not available. Among those who died during the course of the study, $47.0 \%$ had positive signs of radiographic carotid calcifications compared to $31.2 \%$ in the material that were survivors. For those with signs of carotid calcifications at baseline, the OR of death before the endpoint was 2.0 (95\% CI: 1.4-2.7, $\mathrm{p}<0.001$ ).

Relationships between positive or negative signs of carotid calcification and cumulative events of a first event of stroke and/or the first event of ischemic heart diseases were illustrated by KaplanMeier survival analysis (Figures 1 and 2). Study participants YO with baseline radiographic carotid calcifications and no previous history of an event had a mean cumulative stroke and/or ischemic heart diseases survival time of 12.1 years compared to those without carotid calcifications (mean cumulative survival time 13.0 years) ( $\log$ rank Mantel-Cox $\chi 2=10.7, p=0.001)$. YO individuals with baseline radiographic evidence of carotid calcifications and no history of an ischemic event had a mean cumulative ischemic heart diseases survival time 12.5 years compared to those without carotid calcifications (mean survival time was 13.2 years) (log rank Mantel-Cox $\chi 2=9.5, \mathrm{p}=0.002$ ). 


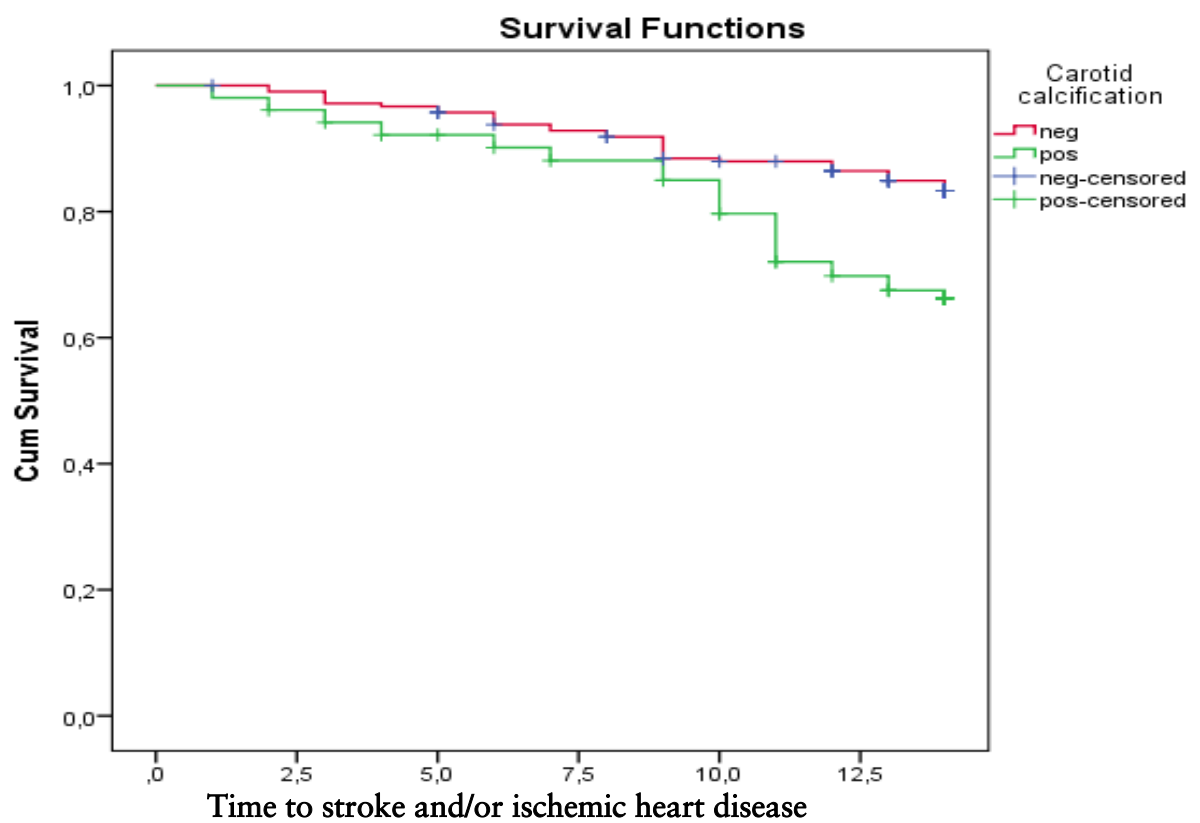

Figure 1. Kaplan-Meier curves of 60-72 year old individuals with no history of stroke and/or ischemic heart diseases, comparing individuals with and without carotid calcification. 13 year cumulative stroke and/or ischemic heart diseases survival 


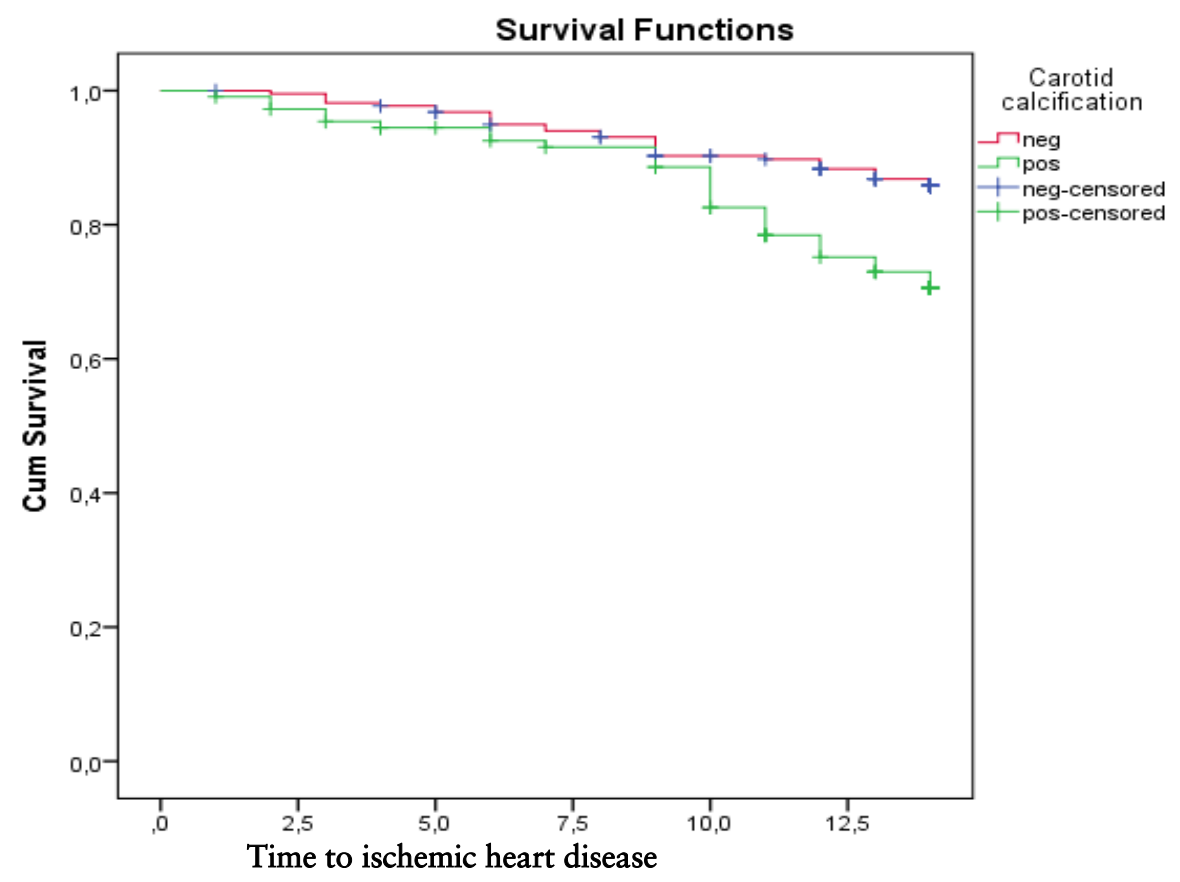

Figure 2. Kaplan-Meier curves of 60-72 year old individuals with no history of ischemic heart diseases, comparing individuals with and without carotid calcification. 13 year cumulative ischemic heart diseases survival. 


\section{Study IV}

Data were derived from 858 individuals (women $53.5 \%$ ). The ages at baseline varied between 60-93 years with a median age 72.0 years (SD: \pm 9.3 ). Individuals had, on average, 18.6 remaining teeth (SD: \pm 7.5 ). Approximately half of the individuals 428/838 (51.1\%) reported that they did not or had never smoked. During the 17year follow-up $492 / 858(57.3 \%)$ died, and $51 / 858$ (5.9\%) of the individuals moved away from the Karlskrona area. Periodontitis was defined as bone loss $\geq 5 \mathrm{~mm}$ at $\geq 30 \%$ of sites. At the baseline examination, periodontitis was diagnosed in $212 / 858$ (24.7\%). Periodontitis was more frequent among men (57.1\%) (OR:1.8, $95 \%$ CI:1.3-2.4, $\mathrm{p}=0.000)$. If dividing into a young-old ( $\mathrm{YO}$ ) age cohort (60-72 years), 471/858 (54.9\%) were included, and in an old-old (OO) age cohort (78-96 years), $387 / 858$ (45.1\%) were included.

The cumulative incidence of at the least one stroke during the 17year follow-up was $118 / 858(13.8 \%)$, and for at the least one ischemic heart disease episode, the cumulative incidence was 203/858 (23.7\%). Concerning gender, men and women almost equally developed stroke $60 / 118(50.8 \% \mathrm{men})$ and ischemic heart diseases $102 / 203$ (50.2\% men). The incidence of stroke per year was 24.86, which corresponds to 2898 strokes per 100000 persons and year. The same figures for ischemic heart diseases was 57.2 incidents per year and 6668 per 100000 and year.

Cox regression analysis was used with periodontitis as an independent variable. Incidence of death, the first event of a stroke or ischemic heart diseases as the dependent variables were used, adjusted for independent variables: age group, BMI $>30$, diabetes type 2 , gender, hypertension, a history of acute myocardial infarction (AMI), a history of stroke and smoking. Periodontitis increased the risk for ischemic heart diseases in all individuals (HR:1.5, CI:1.1-2.1, $\mathrm{p}=0.017$ ) (Figure 3). If having periodontitis and being a woman (HR:2.1, CI:1.3-3.4, $\mathrm{p}=0.002$ ) or having periodontitis and being in the $\mathrm{OO}$ age group (HR:1.7, CI:1.0-2.6, $\mathrm{p}=0.033$ ) there was also an increased risk for ischemic heart diseas- 
es. In men and in the $\mathrm{YO}$ age group no association between periodontitis and ishemic heart diseases could be demonstrated (HR:1.1, CI:0.7-1.7, $\mathrm{p}=0.749$ ) respectively (HR:1.3, CI:0.8-2.2, $\mathrm{p}=0.229$ ). No association between periodontitis and stroke could be identified. Concerning death periodontitis increased the risk for all cause mortality in all individuals (HR:1.4, CI:1.2-1.8, $\mathrm{p}=0.001$ ) (Figure 4). If having periodontitis and being a man (HR:1.5, CI:1.1-1.9, $\mathrm{p}=0.006$ ) or in the $\mathrm{YO}$ age group (HR:2.2, CI:1.5-3.2, $\mathrm{p}=0.000$ ), the risk for death was also increased.

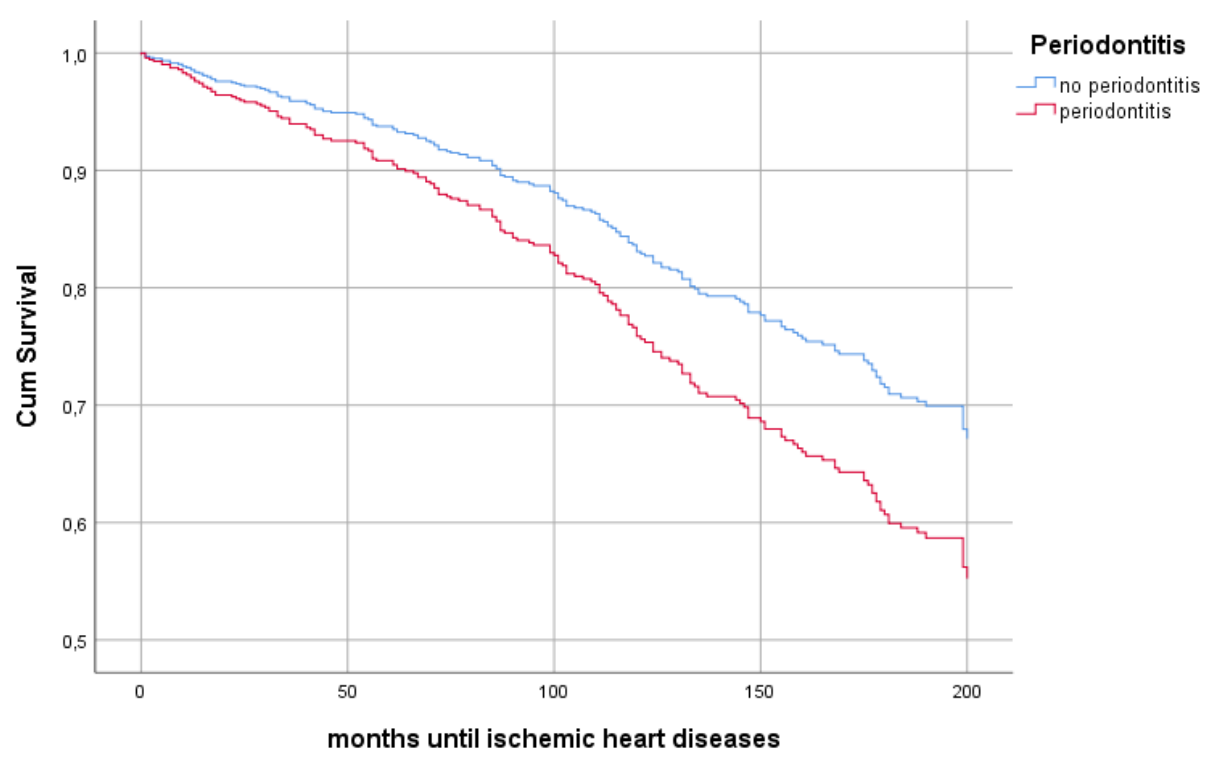

Figure 3. Cox regression curves: 17 year cumulative ischemic heart diseases survival of the total population, comparing individuals with and without periodontitis. 


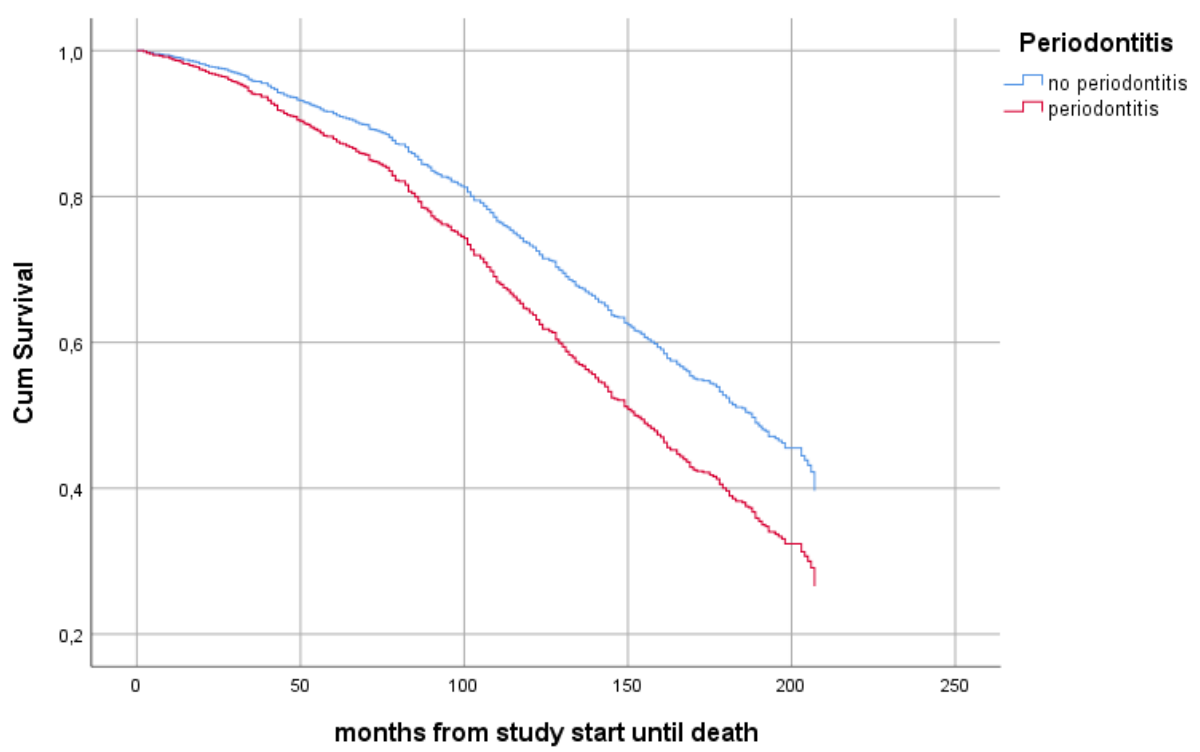

Figure 4. Cox regression curves: 17 year cumulative death survival of the total study population, comparing individuals with and without periodontitis. 


\section{DISCUSSION}

Periodontitis and cardiovascular diseases are both chronic diseases. It is therefore not surprising that such conditions are more common in older individuals. In part, increasing longevity can be attributed the extensive research resulting in better interceptive care. Nevertheless, in most cases medical and dental clinicians can alleviate symptoms, prolonging the disease processes and consequences of disease over an extended time. Changes in diagnostic criteria over time, changes in therapies, changes in life-style, changes in socio-economic factors, and other confounding factors that may affect the clinical expression of both periodontitis and cardiovascular diseases are challenging to control for using statistical modelling alone. Until health sciences have identified a majority of the etiological factors and effects of confounding factors, it may be difficult to go beyond studies considering associations between different disease complexes.

Periodontitis driven by inflammation, like many other diseases, including CVDs (Christodoulidis et al. 2014), has been shown to trigger subclinical atherosclerosis through an inflammatory process. Atherosclerosis is the main reason for CVDs (Cheng et al. 2006, Desvarieux et al. 2003). One type of atherosclerotic lesion is the carotid calcification (van Gils et al. 2012), which most often is identified in Doppler sonography (Denzel et al. 2004). The carotid calcification can be identified on panoramic radiographs (Friedlander et al. 1994, Cohen et al. 2002, Persson et al. 2002, Ravon et al. 2003, Tanaka et al. 2006, Kumagai et al. 2007, Lee et al. 2014, 
Friedlander et al. 2015, Bengtsson Wallin et al. 2016, Bengtsson Wallin et al. 2019) and more often in older individuals (Bengtsson Wallin et al. 2016, Bengtsson Wallin et al. 2019). In study I, it could be concluded, that there are only a few well-designed studies in older individuals investigating carotid calcifications on panoramic radiographs and associations with periodontitis and associations with a history of stroke. The specificity, when identifying carotid calcifications was in most studies high, meaning that the absence of radiographic evidence of carotid calcifications on panoramic radiographs is consistent with negative findings using Doppler sonography. To identify carotid calcifications against Doppler sonography the sensitivity varied between the different studies. There was a shortage of longitudinal or clinical follow-up studies, specifically beyond assessments with Doppler sonography. It is, therefore, no surprise that one significant meta-analysis 2012 identified that an association between periodontitis and atherosclerotic heart disease exists independent of known confounders. No studies have, however, identified a causative relationship (Lockhart et al. 2012).

In a cross-sectional study (Study II) an association between periodontitis and carotid calcifications on panoramic radiographs was shown. Similar results have been shown in other studies (Persson et al. 2002, Ravon et al. 2003, Beckström et al. 2007). In two of the studies (Persson et al. 2002, Ravon et al. 2003), the definition of periodontitis was; alveolar bone loss $>4 \mathrm{~mm}$ between the cementoenamel junction (CEJ) and bone level at $\geq 30 \%$ of sites. In our study a composite definition of periodontitis was used. Although using different definitions of periodontitis, the results indicate a statistical association between periodontitis and carotid calcifications.

In study III, it was demonstrated that individuals with carotid calcifications on panoramic radiographs at baseline, over 10-13 years developed events of stroke and/or ischemic heart diseases more often than individuals without carotid calcifications and this was especially true in the younger age cohort (YO), 60-72 years. These 
associations also remained when adjusted for confounders. Men 60-72 years, without previous events, had a higher OR of 3.1 to develop stroke, compared to women. This association may be related to the finding of more carotid calcifications on panoramic radiographs in men. There are several studies demonstrating associations between carotid calcifications on panoramic radiographs and a history of stroke (Friedlander et al. 1994, Carter et al. 1997, Lewis et al. 1999, Ravon et al. 2003, Kumagai et al. 2007, Christou et al. 2010). A few prospective studies have also demonstrated an association between presence of carotid calcifications and stroke (Cohen et al. 2002, Friedlander et al. 2007, Johansson et al. 2015). Two studies with a follow-up of approximately 3 years studied male veterans $>55$ years, and found associations between carotid calcifications on panoramic radiographs and an incidence of MI, stroke, TIA, revascularization, and angina (Cohen et al. 2002, Friedlander et al. 2007). Another recent study over 5 years demonstrated that the risk of future vascular events was higher in individuals with carotid calcifications on panoramic radiographs compared to individuals without such signs (Johansson et al. 2015). This is in line with the results of our study with a follow-up of 1013 years. Our study is, as far as we know, the only long-term-study with a follow-up time of 10 or more years in individuals 60 years and older investigating associations between carotid calcifications on panoramic radiographs and new events of medically diagnosed stroke and/or ischemic heart diseases. In the YO age cohort with carotid calcifications, the mean cumulative stroke and/or ischemic heart disease survival time was approximately 1 year lower and should be considered clinically significant. Among individuals with carotid calcifications, more individuals died over time, with an OR of 2.0 for reasons not known but most likely many died due to CVD events.

According to the result in study IV, individuals 60 years and older with periodontitis had a higher risk to die in the 17-year follow-up period compared to individuals without periodontitis. Approximately half of the individuals died during the long-term follow-up period, but we do not have access to the reasons for death. The 
main reason for death in the US is coronary heart diseases, and the second reason is stroke (Benjamin et al. 2018). Accordingly, it is likely that some individuals in the study had CVD events that resulted in a lethal outcome and therefore no cardiovascular event was registered and likewise deaths due to CVDs could never be clarified. In a registerbased study it was demonstrated that periodontitis increased the risk for all cause mortality within 15 years (Hansen et al. 2016). An association between periodontitis and mortality in the 60-72 years (YO) was also shown in our study. Söder et al. (2007) demonstrated that young individuals (30-40 years) with periodontitis and missing molars had an increased risk for early death over 16 years. Some of the studies have used missing teeth as a proxy for periodontitis since if periodontitis is not treated or arrested the consequence will be missing teeth and missing teeth due to periodontitis may in a way reflect an inflammatory burden (Holmlund, \& Lind, 2012). Lee et al. (2019) demonstrated that edentulous individuals had the highest cardiovascular risk. Periodontitis has been reported as one of the major causes for tooth loss in adulthood (Natto et al. 2014). It is, however, difficult to be sure of the reason for missing teeth unless it is clearly reported in the dental record. Bone loss as used in the present study to define periodontitis is, however, a very strong indicator of that the patient have had periodontal inflammation and using periodontal bone loss instead of missing teeth as a proxy of inflammatory burden over time seems more relevant.

The second main finding in study IV was that periodontitis increased the risk for ischemic heart diseases in the total population over the 17-year. In women with periodontitis, the OR for the incidence of ischemic heart disease was 2.1. This is in agreement with data from Stramba et al. (2006) reporting that women after the menopause, have a higher incidence of MI compared to agematched men. There are few other longitudinal studies investigating associations between periodontitis and CVDs. In a 3-year follow-up study by Renvert et al. (2010), including individuals that already had been diagnosed with ACS, an association between periodontitis and recurrent ACS was shown (Renvert et al. 2010). In 
study IV individuals were randomly selected from the population. A register-based study with a 15 -year follow-up identified that patients with periodontitis reported an increased risk of CVDs (Hansen et al. 2016). In this study, individuals $>18$ years were consecutively included. A hospital diagnosis of chronic or acute periodontitis, based on ICD codes was registered and also the subsequent incidents of CVDs. Compared to our study the included ages differed and the definition of periodontitis was more vague with no information regarding the severity. In a Korean nationwide cohort follow-up study of 7.6 years, a dose-dependent association between missing teeth and incidence of myocardial infarction, heart failure and ischemic stroke was found, especially in individuals with periodontitis (Lee et al. 2019). The definition of periodontitis was in the study by Lee et al. (2019) not mentioned and the study individuals included were from 20 years with a history of a CVD event. Those differences makes this study not comparable to our study.

In study IV the distance between the alveolar bone level and the $\mathrm{CEJ} \geq 5 \mathrm{~mm}$ at $\geq 30 \%$ of sites on panoramic radiographs was used as the definition of periodontitis. This definition reflects the effects of periodontitis. It is reported that progressive periodontitis among older individuals includes bone loss, attachment loss and progressive gingival recession rather than deep periodontal pockets (Dietrich et al. 2006).

With the above mentioned definition $24.7 \%$ of the individuals were diagnosed as having periodontitis. In other studies the prevalence of periodontitis varies from $33 \%-70 \%$ in older individuals, all with different criteria for periodontitis and different ages (Holm-Pedersen et al. 2006, Eke et al. 2012, Norderyd et al. 2012, Renvert et al. 2013). The prevalence of periodontitis in this study with an older population was low. Our definition of periodontitis included a more severe stage of periodontitis as a bone loss of $\geq 5$ $\mathrm{mm}$ from the CEJ to the alveolar bone level indicates a definitive bone loss even accounting for the measurement error. A requirement in our definition was also that the bone loss should be present at $\geq 30 \%$ of sites, which corresponds to a general disease dis- 
tribution. Other reasons for the low prevalence of periodontitis can be that the very sick and immobile individuals were not included in the study as it was not possible to obtain a panoramic radiograph at the research centre. While periodontitis is a cumulative disease, more individuals develop periodontitis with age (Eke et al. 2016). A prerequisite to having a diagnosis of periodontitis in the present study was the presence of teeth. An inclusion criterion for being included in the present study was presence of one tooth or more. Individuals affected by periodontitis in younger ages are the most sensitive individuals with a hyperactive responsive immune and inflammatory system (Fine et al. 2018). The most susceptible individuals with the rapid form of periodontitis progression are often younger and have probably fewer teeth or are even edentulous with older ages and therefore were not included in the study. A stronger association between periodontitis and CVDs has been shown in younger individuals compared to older individuals (Lee et al. 2019, Schenkein et al. 2013). This could be one explanation for the lack of association between periodontitis and incidence of stroke in the present study, as it concerns older individuals.

A strength with the comprehensive SNAC study is that it has a long-term follow-up of the individuals. It is valuable that both a medical and a dental examination were performed with the same time intervals. The clinical examinations were performed as a full mouth examination and not as partial examinations of specific teeth or areas. Partial mouth examinations have been shown to underestimate the disease (Kingman et al. 2008). Most of the published studies so far are cross-sectional studies. Several other studies have identified associations between periodontitis and CVDs (Persson et al. 2003, Scannapieco et al. 2003, Renvert et al. 2006, Kinane et al. 2008, Lockhart et al. 2012, Cullinan et al. 2013, Dietrich et al. 2013). Using a long-term follow-up should increase the possibility to explore true associations between diseases that may be overlooked in cross-sectional studies. Not many studies have this opportunity because they are time-consuming and expensive. There are also limitations in the present studies. When studying associations in older individuals over a long time, many individuals 
died, leaving fewer, possibly the healthier ones, until the end of the study period. The most important limitation is, however, the lack of information on the causes for death. The death register is held by "The Swedish cause of death register" and was not available for us to use due to restrictions. Knowing the reasons for death would have made it possible to improve the accuracy of the associations between periodontitis and death by CVDs. Both PD and BOP were registered on a tooth level. The deepest pocket per tooth and presence of bleeding on probing was registered as BOP irrespective of the number of surfaces. These measurements are broad, and the BOP index and PD could have been different if it was based on site level registrations. The diagnosis of periodontitis and the identification of carotid calcifications was based on the baseline examination in 2001, accordingly the progression of periodontitis and carotid calcifications during the follow-up was not monitored.

Panoramic radiography is commonly used in dentistry. Such images, if well exposed, provide a wealth of information that can be considered both for dental and medical diagnostics. One crucial factor is that the radiation exposure to the individual from one such panoramic overview is substantially less as from intra-oral full mouth series (Ludlow et al. 2008). Signs of carotid calcification can be detected assuming that the panoramic radiograph covers the area of interest and that the image focus is correct. The radiographic examination is sometimes hard for the aged individual with a curvature of the neck, producing technical difficulties, and sometimes the radiographic image will turn out not readable. Sometimes, it is not possible to get an optimal image to detect a possible carotid calcification and at the same time, focus on the dentition. The consequence might be that two different images must be obtained. For study purposes and the conditions of ethical approval, only one image could be taken for presence of carotid calcifications. This may explain why a rather large number of panoramic radiographs could not be analyzed for the presence of carotid calcifications. In old-old individuals and more often in older women, it may be very challenging and demanding to take a highquality panoramic radiograph. The panoramic radiographs in the 
present work were taken by trained dental hygienists and not by dental radiographic technicians. This may also, in part, explain why approximately $30 \%$ of the images could not be evaluated when studying associations between periodontitis and carotid calcifications, in study II. Worth considering is that in study II, one of the inclusion criteria was 10 teeth or more which of course also affected the lower number of readable panoramic radiographs. This was not the case in study III, studying associations between carotid calcifications and future events. The consequence of this was an unwanted reduction in the number of observations. 


\section{CONCLUSIONS}

- Just a few well-designed studies in older individuals assessing carotid calcifications on panoramic radiographs and associations to a history of stroke or associations to periodontitis existed

- The sensitivity, when identifying carotid calcifications on panoramic radiographs against Doppler sonography, varied a lot. The specificity varied but tended, in most studies, to be high

- In individuals 60-93 years, periodontitis was more common in men than in women

- Carotid calcifications identified from panoramic radiographs were found in $37.5 \%-39.1 \%$ of individuals, more often in men than in women and more often with increasing age

- Periodontitis, diagnosed with a combined clinical and radiographic definition, was associated with carotid calcifications on panoramic radiographs

- Signs of carotid calcifications identified on panoramic radiographs were associated with future incidents of stroke and/or ischemic heart diseases over 13 years follow-up

- Individuals with periodontitis had an increased risk to die and 
had an increased risk to develop ischemic heart diseases over 17 years follow-up 


\section{FUTURE RESEARCH}

Relevant further research would include a long-term intervention study, to analyse if medical interventions in patients with presence of carotid calcifications on panoramic radiographs can reduce the number of cardiovascular diseases. As cardiovascular diseases may have severe consequences with disabilities accompanied by less quality of life, and in the worst case mortality, prevention studies are essential. Many visit their dentist/dental hygienist regularly. Since an association between periodontitis and cardiovascular diseases has been found, it would be valuable to study if well designed preventive dental programs can influence the incidence of cardiovascular diseases in long term studies.

Studying different stages of periodontitis and its associations with future cardiovascular events as well as analysing if progressive periodontitis is related to the future incidence of cardiovascular diseases could also give additional information on the relationship between periodontitis and cardiovascular diseases.

To better understand the associations between periodontitis and cardiovascular diseases, studies further exploring the potential etiopathogenic mechanisms are needed. 


\section{CLINICAL IMPLICATIONS}

When a panoramic radiograph is taken, the inter-vertebral space between C3 and C4, should be assessed for carotid calcifications especially if the patient has a diagnosis of periodontitis, is in older age and male gender

If a carotid calcification on the panoramic radiograph is identified the patient should be referred for further medical evaluation to avoid an incident of stroke or ischemic heart disease

Improving periodontal health in older individuals could reduce overall mortality

A collaboration between physicians and dental professionals would be helpful to improve clinical management of periodontal and ischemic heart diseases 


\section{ACKNOWLEDGEMENTS}

I would like to express my appreciation and gratefulness to all colleagues and friends who have helped and supported me throughout my research.

I would like to thank:

Professor Stefan Renvert, my main supervisor and mentor, for your support, and constructive feedback, helping me not making issues too complicated. Thank you for helping me sort thoughts and helping me grow in my professional ability. The intellectual journey has been valuable. Thanks for giving me the opportunity to do the research

Professor Rutger Persson, my co-supervisor and co-author for your immediate guidance and huge engagement, fast thoughts and valuable criticism. Thanks for introducing me into and teaching me statistics. That was valuable

Professor Johan Sanmartin Berglund (JB), my co-supervisor and co-author for your medical knowledge and valuable input in the manuscript. Thank you for your statistical guidance

Associate Professor Rigmor Persson (REP), who assessed the radiographs 
Christina Karlsson, for collecting clinical dental data at the dental examination, and your precursors Sara Henricsson, Ingrid Jonasson and Inger Kindblad, collecting clinical dental data at the baseline

Ulrika Isaksson and Erik Resebo, for your support in collecting data, managing data files and whatsoever responsible for the logistics.

Johanna Renvert, for data management

Lisa Heitz Mayfield, for help with grammar review of the final thesis and for old friendship

Christina Stenervik, for all practical help and guidance, especially in the very end of the doctoral time

Helena Nilsson, doctoral student colleague for all kinds of support through the academic education

My colleagues, former colleagues and friends at the Dental Hygiene Program, Kristianstad University thank you for supporting and encouraging me. I am happy to work together with all of you: Ismail Abbas, Seida Ademovski Erovic, Anette Andersson, Pia Andersson, Sladjana Critén, Sara Henricsson, Pernilla Karlgren Andersson, Ann-Helene Ljunggren, Valentina Kristinsson, Randi Madsen, Carina Mårtensson, Ingrid Rejnefelt, Susanna Sättlin, Berit Vidén and Cecilia Widén.

Christel Lindahl, for supporting with all kinds of things, in the research process. Thanks Christel for your caring

Marie Jönsson, for help with creating the front cover

Andreas, for your huge understanding and support especially with practical things at home saving me time for research

Alexander, Ludwig and Victoria, my beloved children for just being in my life, and bringing me lot of happiness 
Uno, Vivi-Ann and Hans for your caring and encouragement, always believing in me

The Ministry of Health and Social Affairs in Sweden and the participating county councils, municipalities and university departments supported the Swedish National Study of Aging and Care (SNAC)

The financial support from the Research foundation at Kristianstad University, is gratefully acknowledged

Last but not the least thanks to all the study participants, if it were not for you, the studies and this thesis would not have been possible

The thesis and the included studies were accomplished within the context of the "The Swedish National Graduate School for Competitive Science on Aging and Health" (SWEAH) and funded by the Swedish Research Council 


\section{REFERENCES}

Aoyama N, Suzuki JI, Kobayashi N, Hanatani T, Ashigaki N, Yoshida A, et al. Periodontitis deteriorates peripheral arterial disease in Japanese population via enhanced systemic inflammation. Heart Vessels. 2017;32(11):13141319.

Armitage GC. Periodontal diagnoses and classification of periodontal diseases. Periodontol 2000. 2004;34:9-21. Review.

Beckström BW, Horsley SH, Scheetz JP, Khan Z, Silveira AM, Clark SJ, et al. Correlation between carotid area calcifications and periodontitis: a retrospective study of digital panoramic radiographic findings in pretreatment cancer patients. Oral Surg Oral Med Oral Pathol Oral Radiol Endod. 2007;103(3):359-66.

Bengtsson VW, Persson GR, Berglund J, Renvert S. A cross-sectional study of the associations between periodontitis and carotid arterial calcifications in an elderly population. Acta Odontol Scand. 2016;74(2):115-20.

Bengtsson VW, Persson GR, Berglund J, Renvert S. Carotid calcifications in panoramic radiographs are associated with future stroke or ischemic heart diseases: a long-term follow-up study. Clin Oral Investig. 2019;23(3):11711179 .

Borgnakke WS, Ylostalo PV, Taylor GW, Genco RJ. Effect of periodontal disease on diabetes: systematic review of epidemiologic observational evidence. J Periodontol. 2013; 84:S135-S152.

Bos D, Leening MJ, Kavousi M, Hofman A, Franco OH, van der Lugt A, et al. Comparison of atherosclerotic calcification in major vessel beds on the risk of all-cause and cause-specific mortality: the Rotterdam study. The Rotterdam Study. Circ Cardiovasc Imaging. 2015;8(12). pii: e003843.

Brott TG, Halperin JL, Abbara S, Bacharach JM, Barr JD, Bush RL; American College of Cardiology Foundation/American Heart Association Task Force on Practice Guidelines; American Stroke Association; American Association of Neuroscience Nurses; American Association of Neurological Surgeons; 
American College of Radiology; American Society of Neuroradiology; Congress of Neurological Surgeons; Society of Atherosclerosis Imaging and Prevention; Society for Cardiovascular Angiography and Interventions; Society of Interventional Radiology; Society of NeuroInterventional Surgery; Society for Vascular Medicine; Society for Vascular Surgery. 2011 ASA/ACCF/AHA/AANN/AANS/ACR/ASNR/CNS/SAIP/SCAI/SIR/SNIS/SV M/SVS guideline on the management of patients with extracranial carotid and vertebral artery disease: executive summary: a report of the American College of Cardiology Foundation/American Heart Association Task Force on Practice Guidelines, and the American Stroke Association, American Association of Neuroscience Nurses,American Association of Neurological Surgeons, American College of Radiology,American Society of Neuroradiology, Congress of Neurological Surgeons, Society of Atherosclerosis Imaging and Prevention, Society for Cardiovascular Angiography and Interventions, Society of Interventional Radiology, Society of NeuroInterventional Surgery, Society for Vascular Medicine, and Society for Vascular Surgery. Vasc Med. 2011;16(1):35-77.

Carter LC, Haller AD, Nadarajah V, Calamel AD, Aguirre A. Use of panoramic radiography among an ambulatory dental population to detect patients at risk of stroke. J Am Dent Assoc. 1997;128(7):977-84.

Castrejón-Pérez RC, Borges-Yáñez SA. Frailty from an Oral Health Point of View. J Frailty Aging. 2014; 3(3):180-6.

Chapman AR, Adamson PD, Mills NL. Assessment and classification of patients with myocardial injury and infarction in clinical practice. Heart. 2017;(1):103:10-18.

Chavarry NG, Vettore MV, Sansone C, Sheiham A. The relationship between diabetes mellitus and destructive periodontal disease: a meta-analysis. Oral Health Prev Dent. 2009;7:107-127.

Cheng C, Tempel D, van Haperen R, van der Baan A, Grosveld F, Daemen $\mathrm{MJ}$, et al. Atherosclerotic lesion size and vulnerability are determined by patterns of fluid shear stress. Circulation. 2006; 113:2744-53.

Christou P, Leemann B, Schimmel M, Kiliaridis S, Müller F. Carotid artery calcification in ischemic stroke patients detected in standard dental panoramic radiographs - a preliminary study. Adv Med Sci. 2010;55(1):26-31.

Christodoulidis G, Vittorio TJ, Fudim M, et al. Inflammation in coronary artery disease. Cardiol Rev. 2014;22:279-88.

Cohen S, Friedlander A, Jolly D, Date L. Carotid calcification on panoramic radiographs: an important marker for vascular risk. Oral Surg Oral Med Oral Pathol Oral Radiol Endod. 2002; 94:510-514.

Cullinan MP, Seymour GJ. Periodontal disease and systemic illness: will the evidence ever be enough? Periodontol 2000. 2013;62: 271-286. 
Damaskos S, Griniatsos J, Tsekouras N, Georgopoulos S, Klonaris C, Bastounis E, et al. Reliability of panoramic radiograph for carotid atheroma detection: a study in patients who fulfill the criteria for carotid endarterectomy. Oral Surg Oral Med Oral Pathol Oral Radiol Endod. 2008;106(5):736-42.

Denzel C, Lell M, Maak M, Höckl M, Balzer K, Müller KM, et al. Carotid artery calcium: accuracy of a calcium score by computed tomography-an in vitro study with comparison to sonography and histology. Eur J Vasc Endovasc Surg. 2004;28(2):214-20.

Desvarieux M, Demmer RT, Rundek T, Boden-Albala B, Jacobs DR Jr, Papapanou PN, et al. Oral Infections and Vascular Disease Epidemiology Study (INVEST). Relationship between periodontal disease, tooth loss, and carotid artery plaque: The Oral Infections and Vascular Disease Epidemiology Study (INVEST). Stroke. 2003; 34(9):2120-5.

Dietrich T, Kaye EK, Nunn ME, Van Dyke T, Garcia RI. Gingivitis susceptibility and its relation to periodontitis in men. $J$ Dent Res. 2006;85(12):1134-7.

Dietrich T, Sharma P, Walter C, Weston P, Beck J. The epidemiological. Evidence behind the association between periodontitis and incident atherosclerotic cardiovascular disease. J Clin Periodontol. 2013; 40(Suppl.14): S70S84.

Eke PI, Dye BA, Wei L, Thornton-Evans GO, Genco RJ; CDC Periodontal Disease Surveillance workgroup: James Beck (University of North Carolina, Chapel Hill, USA), Gordon Douglass (Past President, American Academy of Periodontology), Roy Page (University of Washin.). Prevalence of periodontitis in adults in the United States: 2009 and 2010. J Dent Res. 2012; 91(10):914-20.

Eke PI, Wei L, Borgnakke WS, Thornton-Evans G, Zhang X, Lu H, et al. Periodontitis prevalence in adults $\geq 65$ years of age, in the USA. Periodontol. 2000. 2016; 72(1):76-95.

Fine DH, Patil AG, Loos BG. Classification and diagnosis of aggressive periodontitis. J Periodontol. 2018;89 (Suppl 1):S103-S119.

Fisher J, Selikowitz HS, Mathur M, Varenne B. Strengthening oral health for universal health coverage. Lancet. 2018; 15;392(10151):899-901.

Friedlander AH, Baker JD. Panoramic radiography; an aid in detecting patients at risk of cerebrovascular accident. Am Dent Assoc. 1994; 125:15981603.

Friedlander AH. Identification of stroke-prone patients by panoramic and cervical spine radiography. Dentomaxillofac Radiol. 1995;24(3):160-4. 
Friedlander AH, Altman L. Carotid artery atheromas in postmenopausal women. Their prevalence on panoramic radiographs and their relationship to atherogenic risk factors. J Am Dent Assoc. 2001;132(8):1130-6.

Friedlander AH, Cohen SN. Panoramic radiographic atheromas portend adverse vascular events. Oral Surg Oral Med Oral Pathol Oral Radiol Endod. 2007;103(6):830-5.

Friedlander AH, El Saden SM, Hazboun RC, Chang TI, WongWK, Garrett NR. Detection of carotid artery calcification on the panoramic images of post-menopausal females is significantly associated with severe abdominal aortic calcification:a risk indicator of future adverse vascular events. Dentomaxillofac Radiol. 2015; 44(7):20150094.

Garoff M, Johansson E, Ahlqvist J, Jäghagen EL, Arnerlöv C, Wester P. Detection of calcifications in panoramic radiographs in patients with carotid stenoses $\geq 50 \%$. Oral Surg Oral Med Oral Pathol Oral Radiol. 2014;117(3):385-91.

Gasbarrino K, Mantzoros C, Gorgui J, Veinot JP, Lai C, Daskaopoulou SS. Circulating Chemerin Is Associated With Carotid Plaque Instability, Whereas Resistin Is Related to Cerebrovascular Symptomatology. Arterioscler Thromb Vasc Biol. 2016; 36:1670-8.

Genco RJ, Williams RC. Periodontal disease and overall health: a clinician's guide. Yardley, PA: Professional Audience Communications, 2010: 319 p.

van Gils MJ, Vukadinovic D, van Dijk AC, Dippel DW, Niessen J, van der Lugt A. Carotid atherosclerotic plaque progression and change in plaque composition over time: a 5 -year follow-up study using serial CT angiography. AJNR Am J Neuro radiol. 2012; 33(7):1267-73.

Glick M. The oral-systemic health connection: a guide to patient care. Chicago, IL: Quintessence Publishing Co, Inc. 2014: ix, 301 pp.

Glick M, Williams DM, Kleinman DV, Vujicic M, Watt RG, Weyant RJ. A new definition for oral health developed by the FDI World Dental Federation opens the door to a universal definition of oral health. J Public Health Dent. 2017; 77(1):3-5.

Goodson JM, Haffajee AD, Socransky SS. The relationship between attachment level loss and alveolar bone loss. J Clin Periodontol. 1984; 11(5): 348359.

Grau AJ, Becher H, Ziegler CM, Lichy C, Buggle F, Kaiser C, et al. Periodontal disease as a risk factor for ischemic stroke. Stroke. 2004;35(2):496-501.

Hajishengallis G, Lamont RJ. Beyond the red complex and into more complexity: the polymicrobial synergy and dysbiosis (PSD) model of periodontal disease etiology. Mol Oral Microbiol. 2012;27(6):409-19. 
Hansen GM, Egeberg A, Holmstrup P, Hansen PR. Relation of Periodontitis to Risk of Cardiovascular and All-Cause Mortality (from a Danish Nationwide Cohort Study). Am J Cardiol. 2016;15; 118(4):489-93.

Harvey JD. Periodontal Microbiology. Dent Clin North Am. 2017; 61(2):253269. Review.

Holm-Pedersen P, Russell SL, Avlund K, Viitanen M, Win blad B, Katz RV. Periodontal disease in the oldest-old living in Kungsholmen, Sweden: findings from the KEOHS project. J Clin Periodontol. 2006;33(6):376-84.

Holmlund A, Lind L. Number of teeth is related to atherosclerotic plaque in the carotid arteries in an elderly population. J Periodontol. 2012;83(3):28791.

Holmlund A, Lampa E, Lind L. Oral health and cardiovascular disease risk in a cohort of periodontitis patients. Atherosclerosis. 2017; 262:101-106.

Huibers A, de Borst GJ, Wan S, Kennedy F, Giannopoulos A, Moll FL. Noninvasive carotid artery imaging to identify the vulnerable plaque: current status and future goals. Eur J Vasc Endovasc Surg. 2015;50(5):563-572

Johansson E, Ahlqvist J, Garoff M, Levring Jäghagen E, Meimermondt A, Wester P. Carotid calcifications on panoramic radiographs: a 5-year followup study. Oral Surg Oral Med Oral Pathol Oral Radiol. 2015;120(4):51320.

Johansson EP, Ahlqvist J, Garoff M, Karp K, Jäghagen EL, Wester P. Ultrasound screening for asymptomatic carotid stenosis in subjects with calcifications in the area of the carotid arteries on panoramic radiographs: a cross-sectional study. BMC Cardiovasc Disord. 2011;11:44.

Jordan RA, Krois J, Schiffner U, Micheelis W, Schwendicke F. Trends in caries experience in the permanent dentition in Germany 1997-2014, and projection to 2030: Morbidity shifts in an aging society. Sci Rep. 2019; 2; 9(1):5534.

Kinane D, Bouchard P; Group E of European Workshop on Periodontology. Periodontal diseases and health: Consensus Report of the Sixth European Workshop on Periodontology. J Clin Periodontol. 2008;35(8 Suppl):333-7.

Kingman A, Susin C, Albandar JM. Effect of partial recording protocols on severity estimates of periodontal disease. J Clin Periodontol. 2008;35(8):659-67.

Kumagai M, Yamagishi T, Fukui N, Chiba M. Carotid artery calcifications seen on panoramic dental radiographs in the Asian population in Japan. Dentomaxillofac Radiol. 2007;36:92-96.

Kumar KR, Ranganath V, Naik R, Banu S, Nichani AS. Assessment of highsensitivity C-reactive protein and lipid levels in healthy adults and patients 
with coronary artery disease, with and without periodontitis-a crosssectional study. J Periodontal Res. 2014;49(6):836-44.

Lafon A, Pereira B, Dufour T, Rigouby V, Giroud M, Béjot Y, et al. Periodontal disease and stroke: a meta-analysis of cohort studies. Eur J Neurol. 2014;21(9):1155-61, e66-7.

Lamster IB. Geriatric periodontology: how the need to care for the aging population can influence the future of the dental profession. Periodontol 2000. 2016;72(1):7-12. Review.

Lee HJ, Choi EK, Park JB, Han KD, Oh S. Tooth Loss Predicts Myocardial Infarction, Heart Failure, Stroke, and Death. J Dent Res. 2019; 98(2):164170.

Lee JS, Kim OS, Chung HJ, Kim YJ, Kweon SS, Lee YH, et al. The correlation of carotid artery calcification on panoramic radiographs and determination of carotid artery atherosclerosis with ultrasonography. Oral Surg Oral Med Oral Pathol Oral Radiol. 2014;118(6):739-745.

Lewis DA, Brooks SL. Cartoid artery calcification in a general dental population: a retrospective study of panoramic radiographs. Gen Dent. 1999;47(1):98-103.

Libby P, Ridker PM, Hansson GK, Leducq.Transatlantic Network on A. Inflammation in atherosclerosis: from pathophysiology to practice. J Am Coll Cardiol. 2009; 54: 2129-2138.

Liljestrand JM, Havulinna AS, Paju S, Männistö S, Salomaa V, Pussinen PJ. Missing Teeth Predict Incident Cardiovascular Events, Diabetes, and Death. J Dent Res. 2015; 94(8):1055-62.

Lockhart PB, Brennan MT, Thornhill M, Michalowicz BS, Noll J, BahraniMougeot FK, et al. Poor oral hygiene as a risk factor for infective endocarditis-related bacteremia. J Am Dent Assoc. 2009; 140: 1238-1244.

Lockhart PB, Bolger AF, Papapanou PN, Osinbowale O,Trevisan M, Levison $\mathrm{ME}$, et al. Disease Committee of the Council on Cardiovascular Disease in the Young CoE, Prevention CoPVD, Council on Clinical C. Periodontal disease and atherosclerotic vascular disease: does the evidence support an independent association?: a scientific statement from the American Heart Association. Circulation. 2012;125: 2520-2544.

Ludlow IB, Davies-Ludlow LE, White SC. Patient risk related to common dental radiographic examinations: The impact of 2007 international commission on radiological protection recommendations regarding dose calculation. J Am Dent Assoc. 2008;139(9):1237-43.

Machtei EE, Hausmann E, Grossi SG, Dunford R, Genco RJ. The relationship between radiographic and clinical changes in the periodontium. J Periodontal Res. 1997; 32(8): 661-666. 
Natto ZS, Aladmawy M, Alasqah M, Papas Al. Factors contributing to tooth loss among the elderly: a cross sectional study. Singapore Dent J. 2014; $35: 17-22$.

Niinikoski H, Pahkala K, Ala-Korpela M, Viikari J, Rönnemaa T, Lagström $\mathrm{H}$, et al. Effect of repeated dietary counseling on serum lipoproteins from infancy to adulthood. Pediatrics. 2012;129:e704-13.

Norderyd O, Henriksen BM, Jansson H. Periodontal disease in Norwegian old-age pensioners. Gerodontology. 2012;29(1):4-8.

Norderyd O, Koch G, Papias A, Köhler AA, Helkimo AN, Brahm CO, et al. Oral health of individuals aged 3-80 years in Jönköping, Sweden during 40 years (1973-2013). II.Review of clinical and radiographic findings. Swed Dent J. 2015;39(2):69-86.

Ohba T, Takata Y, Ansai T, Morimoto Y, Tanaka T, Kito S, et al. Evaluation of calcified carotid artery atheromas detected by panoramic radiograph among 80-year-olds. Oral Surg Oral Med Oral Pathol Oral Radiol Endod. 2003; 96(5):647-650.

Papapanou P. Periodontal diseases: general concepts. In: Lamont RJ, Hajishengallis GN, Jenkinson HF, editors. Oral microbiology and immunology. Second edition. Washington, DC: ASM Press; 2014. p. 251-9, 261-271. 8.

Papapanou PN, Sanz M, Buduneli N, Dietrich T, Feres M, Fine DH, et al. Periodontitis: Consensus report of workgroup 2 of the 2017 World Workshop on the Classification of Periodontal and Peri-Implant Diseases and Conditions. J Periodontol. 2018 Jun;89 Suppl 1:S173-S182. doi: 10.1002/JPER.17-0721.

Persson GR, Ohlsson O, Pettersson T, Renvert S. Chronic periodontitis, a significant relationship with acute myocardial infarction. Eur Heart J 2003;24:2108-2115.

Persson GR, Pettersson T, Ohlsson O, Renvert S. High-sensitivity serum Creactive protein levels in subjects with or without myocardial infarction or periodontitis. J Clin Periodontol. 2005;32(3):219-24.

Persson RE, Hollender LG, Powell VL, MacEntee M, Wyatt CC, Kiyak HA, et al. Assessment of periodontal conditions and systemic disease in older subjects. II. focus on cardiovascular diseases. J Clin Periodontol. 2002; 29:803810.

Persson RE, Tzannetou S, Feloutzis AG, Brägger U, Persson GR, Lang NP. Comparison between panoramic and intra-oral radiographs for the assessment of alveolar bone levels in a periodontal maintenance population. J Clin Periodontol. 2003;30(9):833-9. 
Ravon NA, Hollender LG, McDonald V, Persson GR. Signs of carotid calcification from dental panoramic radiographs are in agreement with Doppler sonography results. J Clin Periodontol. 2003; 30(12):1084-1090.

Reichert S, Schulz S, Benten AC, Lutze A, Seifert T, Schlitt M, et al. Periodontal conditions and incidence of new cardiovascular events among patients with coronary vascular disease. J Clin Periodontol. 2016: 43(11):918-925.

Renvert S, Pettersson T, Ohlsson O, Persson GR. Bacterial profile and burdenof periodontal infection in subjects with a diagnosis of acute coronary syndrome. J Periodontol. 2006;77(7):1110-9.

Renvert S, Ohlsson O, Pettersson T, Persson GR. Periodontitis: a future risk of acute coronary syndrome? A follow-up study over 3 years. J Periodontol. 2010;81(7):992-1000.

Renvert S, Persson RE, Persson GR. Tooth loss and periodontitis in older individuals: results from the Swedish National Study on Aging and Care. J Periodontol. 2013;84(8):1134-44.

Renvert S, Wallin-Bengtsson V, Berglund J, Persson RG. Periodontitis in older Swedish individuals fails to predict mortality. Clin Oral Investig. 2015;19(2):193-200.

Reyes L, Herrera D, Kozarov E, Rolda S, Progulske-Fox A. Periodontal bacterial invasion and infection: contribution to atherosclerotic pathology. J Periodontol. 2013; 84: S30- S50.

Ross R. Atherosclerosis - an inflammatory disease. N Engl J Med 1999: 340: 115-126.

Rydén L, Buhlin K, Ekstrand E, de Faire U, Gustafsson A, Holmer J, et al. Periodontitis Increases the Risk of a First Myocardial Infarction: A Report From the PAROKRANK Study. Circulation. 2016;9;133(6):576-83.

Sanz M, Ceriello A, Buysschaert M, Chapple I, Demmer RT, Graziani F, et al. Scientific evidence on the links between periodontal diseases and diabetes: Consensus report and guidelines of the joint workshop on periodontal diseases and diabetes by the International Diabetes Federation and the European Federation of Periodontology. J Clin Periodontol. 2018;45(2):138149.

Scannapieco FA, Bush RB, Paju S. Associations between periodontal disease and risk for atherosclerosis, cardiovascular disease, and stroke. A systematic review. Ann Periodontol. 2003; 8: 38-53.

Scannapieco FA, Cantos A.Oral inflammation and infection, and chronic medical diseases: implications for the elderly. Periodontol. 2000. 2016; 72(1):153-75. 
Schenkein HA, Loos BG. Inflammatory mechanisms linking periodontal diseases to cardiovascular diseases. J of Clin Periodontol. 2013; 40 (Suppl 14), 51-69.

Schwendicke F, Krois J, Kocher T, Hoffmann T, Micheelis W, Jordan RA. More teeth in more elderly: Periodontal treatment needs in Germany 19972030. J Clin Periodontol. 2018;45(12):1400-1407.

Stramba-Badiale M, Fox KM, Priori SG, Collins P, Daly C, Graham I, et al. Cardiovascular diseases in women: a statement from the policy conference of the European Society of Cardiology. Eur Heart J. 2006;27(8):994-1005.

Sun HY, Jiang H, Du MQ, Wang X, Feng XP, Hu Y, et al. The Prevalence and Associated Factors of Periodontal Disease among 35 to 44-year-old Chinese Adults in the 4th NationalOral Health Survey. Chin J Dent Res. 2018;21(4):241-247.

Söder PO, Söder B, Nowak J, Jogestrand T. Early carotid atherosclerosis in subjects with periodontal diseases. Stroke. 2005; 36(6):1195-200.

Söder B, Jin LJ, Klinge B, Söder P-O. Periodontitis and premature death: a 16year longitudinal study in a Swedish urban population. J Periodont Res. 2007; 42(4):361-6.

Tamura T, Inui M, Nakase M, Nakamura S, Okumura K, Tagawa T. Clinicostatistical study of carotid calcification on panoramic radiographs. Oral Dis. 2005;11(5):314-7.

Tanaka T, Morimoto Y, Ansai T, Okabe S, Yamada K, Taguchi A, et al. Can the presence of carotid artery calcification on panoramic radiographs predict the risk of vascular diseases among 80-year-olds? Oral Surg Oral Med Oral Pathol Oral Radiol Endod. 2006;101(6):777-83.

Tiller R, Bengel W, Rinke S, Ziebolz D. Association between carotid area calcifications and periodontal risk: a cross sectional study of panoramic radiographic findings. BMC Cardiovasc Disord. 2011:9;11:67.

Tonetti MS, Van Dyke TE; working group 1 of the joint EFP/AAP workshop. Collaborators: Beck J, Bouchard P, Cutler C, D'Aiuto F, Dietrich T, Eke P, et al. Periodontitis and atherosclerotic cardiovascular disease: consensus report of the Joint EFP/AAP Workshop on Periodontitis and Systemic Diseases. J Periodontol. 2013; 84(4 Suppl):24-9.

Tonetti MS, Bottenberg P, Conrads G, Eickholz P, Heasman P, Huysmans $\mathrm{MC}$, et al. Dental caries and periodontal diseases in the ageing population: call to action to protect and enhance oral health and well-being as an essential component of healthy ageing - Consensus report of group 4 of the joint EFP/ORCA workshop on the boundaries between caries and periodontal diseases. J Clin Periodontol. 2017;(44) (Suppl 18):S135-S144. 
United Nations (2017) Ageing. Available at https://www.un.org/en/sections/issues-depth/ageing/ (accessed June 1, 2019).

Venketasubramanian N, Hennerici MG. How to handle a rejection. Teaching course presentation at the 21st European Stroke Conference, Lisboa, May 2012. Cerebrovasc Dis. 2013;35(3):209-12.

Wahlin Å, Papias A, Jansson H, Norderyd O. Secular trends over 40 years of periodontal health and disease in individuals aged 20-80 years in Jönköping, Sweden: Repeated cross-sectional studies. J Clin Periodontol. 2018;45(9):1016-1024.

Waters AM, Trinh L, Chau T, Bourchier M, Moon L. Latest statistics on cardiovascular disease in Australia. Clin Exp Pharmacol Physiol. 2013;40(6):347-56.

Williams RC, Offenbacher S. Periodontal medicine: the emergence of a newbranch of periodontology. Periodontol 2000. 2000;23:9-12.

World Health Organization. World Oral Health Report (2018). Ageing and health. Available at http://www.who.int/news-room/factsheets/detail/ageing-and-health (accessed June 1, 2019).

World Health Organization. ICD classifications (2019). Available at https://icd.who.int/browse10/2016/en (accessed June 11, 2019).

Xu J, Murphy SL, Kochanek KD, Arias E. Mortality in the United States, 2015. NCHS Data Brief. 2016; 267:1-8.

Yoon SJ, Yoon W, Kim OS, Lee JS, Kang BC. Diagnostic accuracy of panoramicradiography in the detection of calcified carotid artery. Dentomaxillofac Radiol. 2008;37(2):104-8.

Zhang W, Daly CG, Mitchell D, Curtis B. Incidence and magnitude of bacteraemia caused by flossing and by scaling and root planing. J Clin Periodontol. 2013; 40:41-52. 

PAPERS I - IV 



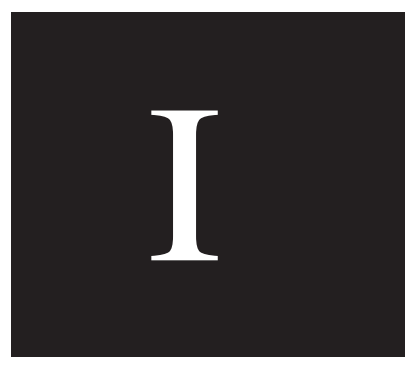





\title{
REVIEW ARTICLE
}

\section{Assessment of carotid calcifications on panoramic radiographs in relation to other used methods and relationship to periodontitis and stroke: a literature review}

\author{
VIVECA WALLIN BENGTSSON ${ }^{1}$, G. RUTGER PERSSON ${ }^{1,2,3} \&$ STEFAN RENVERT $^{1,4,5}$ \\ ${ }^{1}$ Department of Oral Sciences, Kristianstad University, Kristianstad, Sweden, ${ }^{2}$ Departments of Periodontics and Oral \\ Medicine, University of Washington, Seattle WA, USA, ${ }^{3}$ Department of Periodontology University of Bern, Switzerland, \\ ${ }^{4}$ School of Dental Scences, Trinity Collage, Dublin, Ireland, and ${ }^{5}$ Blekinge Institute of Technology, Karlskrona, Sweden
}

\begin{abstract}
Objectives. To assess the literature on carotid calcifications defined from panoramic radiographs (PMX) and concurrent diagnosis of stroke and periodontitis. Materials and methods. A literature search screening for publications using search terms such as PMX and carotid calcification, stroke and periodontitis was performed in November 2012. Results. A total of 189 articles were retrieved, among which 30 were included in the review. The sensitivity for PMX findings of carotid calcifications (CC) compared to a diagnosis by Doppler sonography varied between $31.1-100 \%$. The specificity for PMX findings of carotid calcifications compared to a diagnosis by Doppler sonography varied between $21.4-87.5 \%$. Individuals with CC findings from PMX have more periodontitis and risk for stroke. Conclusions. There is a shortage of well-designed studies in older dentate individuals assessing the associations between periodontitis and radiographic evidence of CC and in relation to stroke or other cardiovascular diseases. Statement of Clinical Relevance. Carotid calcifications are prevalent in patients with periodontitis and such individuals may have an increased risk for stroke. The absence of signs of carotid calcification on panoramic radiographs is indicative of no calcification of carotid arteries.
\end{abstract}

Key Words: panoramic radiograph, carotid calcification, periodontitis, review

\section{Introduction}

Atherosclerosis is a chronic inflammatory disease with a multifactorial nature, characterized by thickening and the loss of elasticity of the arterial walls. Arterial calcification in major vessel beds outside the brain have been associated with vascular brain disease and linked to future risk of dementia and stroke [1]. Atherosclerosis is a systemic vascular process and a major cause of cardiovascular and cerebrovascular disease. In the US, stroke is the third leading cause of death [2].

Approximately $85 \%$ of all of stroke events are ischemic in nature and are caused by atheroma in the internal carotid artery [3]. Carotid artery sclerosis accounts for $20-30 \%$ of ischemic stroke events. Data have shown that neurologically asymptomatic individuals with more than $50 \%$ stenosis of the internal carotid artery have an elevated risk of developing stroke [4]. An accumulation of low-density lipoproteins (LDL) occurs in the intimate layer of the endothelium, culminating in the formation of atheromatous plaque, with superimposition of calcium deposits. Atheromas are composed of lipids and fibrous tissue, deposited on blood vessel cell walls [5]. Many factors pre-dispose to carotid atherosclerosis including: advancing age [6,7], male gender, hypertension [7], serum levels of low-density lipoprotein (LDL) [8], smoking habits [9], diabetes mellitus $[7,10]$ and heavy alcohol intake $[11]$.

Data also suggest that chronic infections attribute to the pathogenesis of atherosclerosis [12]. Periodontitis is a destructive inflammatory process of periodontal tissues initiated by primarily gram-negative bacteria [13]. Periodontitis has been associated with coronary heart disease and stroke [14-22]. Periodontitis has also been associated with endothelial dysfunction and sub-clinical carotid atherosclerosis intima media thickness $[18,19,21,23,24]$. Thickening of the intima media has been strongly associated with risk factors for stroke and with prevalent stroke [25].

Correspondence: Stefan Renvert, Health Science, University of Kristianstad, SE 29188 Kristianstad, Sweden. Tel: +46 44204090. E-mail: stefan.renvert@hkr.se 
Data also suggest that evidence of carotid calcification may be related to periodontitis [20,26-28]. There is currently no scientific evidence explaining the association between periodontitis and vascular diseases, $i$. e. stroke and acute coronary syndrome [29].

Several methods are used to assess arterial calcification. Plain radiographs, ultrasound-based carotid intimal-media-thickness assessment, brain magnetic resonance imaging (MRI) and computer tomography (CT) are methods that are being used to assess vascular pathology including calcifications of blood vessels associated with pathophysiology of vascular brain disease. Studies have shown that, compared with ultrasound plaque imaging, quantification of CT calcification provides additional information in regard to the ability to detect complex brain vascula conditions [1]. Angiography is considered the most accurate method to diagnose atherosclerotic diseases. While this procedure is invasive, complications may occur [30-32]. In other medical diagnostics, Doppler sonography (ultrasonography) methods have been used as a surrogate gold standard while the results obtained with this non-invasive imagining method are similar to those obtained with angiography [33].

Panoramic radiography is a frequently performed diagnostic tool used in the dental practice. Atheromatous plaques, even in the case of partial calcifications, resulting from the deposition of calcium salts, can be observed on panoramic radiographs. Calcifications in the area of the carotid artery bifurcation can be detected on panoramic radiographs in the range of $2-5 \%$ of the population [34-41]. Such uni- or bilateral calcifications can present as one or more irregular radio-opacities eventually punctuated by vertical-linear radiolucent areas. The calcification is usually localized $\sim 25 \mathrm{~mm}$ posterior and inferior to the mandibular angle and adjacent to the space between vertebrae $\mathrm{C} 3$ and $\mathrm{C} 4$. Panoramic radiographs may, therefore, be suitable for the detection of such atheromatous calcifications [20,34-36,41].

The aim of the present review was to evaluate the use and value of panoramic radiographs in assessing carotid calcifications in relation to other used methods (gold standards). A second aim was to assess the literature on carotid calcifications defined from panoramic radiographs and concurrent diagnosis of stroke and periodontitis.

To identify studies included in the present review, a literature search was conducted in November 2012 The following phrases were used for screening and selection of studies: (I) (panoramic radiography and carotid calcification) OR (panoramic radiography and carotid calcifications) OR (panoramic radiography and carotid artery atheroma); (II) (carotid calcifications and stroke and panoramic radiography) OR (carotid calcification and dental) OR (carotid calcification and stroke and panoramic radiography) $O R$ (carotid calcifications and dental); and (III) (carotid calcifications and periodontitis and panoramic radiography) OR (carotid calcification and periodontiti and panoramic radiography) OR (carotid calcifications and periodontal disease and panoramic radiography) OR (carotid calcification and periodontal disease and panoramic radiography) OR (periodontitis and carotid calcification) OR (periodontitis and carotid calcifications). Additional references were found in the literature lists of selected papers.

Papers not written in the English language, case reports and animal research were excluded. The abstracts of the publications obtained from the searches were screened. Searching for articles comparing panoramic radiography to other diagnostic methods resulted in 116 potential publications, among which 16 reported on the relationship between carotid calcifications identified from panoramic radiographs and other methods of assessments. When searching for publications on the association between carotid calcification and stroke, 65 potential publications were retrieved. From these publications 10 studies reported on the associations between carotid calcifications and stroke. When searching for publications on the association between carotid calcification and periodontitis, eight potential publications were retrieved. After reading the full text of these publications, four were included in this review.

A summery of findings on the ability to assess carotid calcifications on panoramic radiographs in comparison to other standard procedures to diagnose carotid calcifications is reported in Table I. Doppler sonography is often used as the 'gold standard' for diagnosing carotid calcifications and was compared to diagnosis made on panoramic radiographs in 12 out of the 16 selected studies.

Two studies compared carotid calcifications diagnosed on panoramic radiography to anterior posterior projection radiography $[36,42]$. According to these two studies $[36,42]$, carotid calcifications and anterior posterior radiography were in concordance in all cases.

Yoon et al. [43] reported that $15 \%$ of carotid arteries were interpreted as calcified on panoramic radiography vs $41 \%$ on computer tomography. This indicates that the sensitivity to assess carotid calcification on panoramic radiographs is rather low when compared to computer tomography. Damaskos et al. [44] compared digital subtraction angiography to PMX on carotid level and showed a sensitivity of $60 \%$ and a specificity of $48 \%$

Sensitivity and specificity calculations, on a patient level, were reported in nine of the 17 studies. Thus, the sensitivity for panoramic radiography findings of carotid calcifications compared to a diagnosis by Doppler sonography varied, on a patient level from $31.1-100 \%[28,45-51,44]$. A limitation for the identification of calcifications on panoramic radiographs is that the area of interest may not be included on the radiographic image or not detectable due to a low 


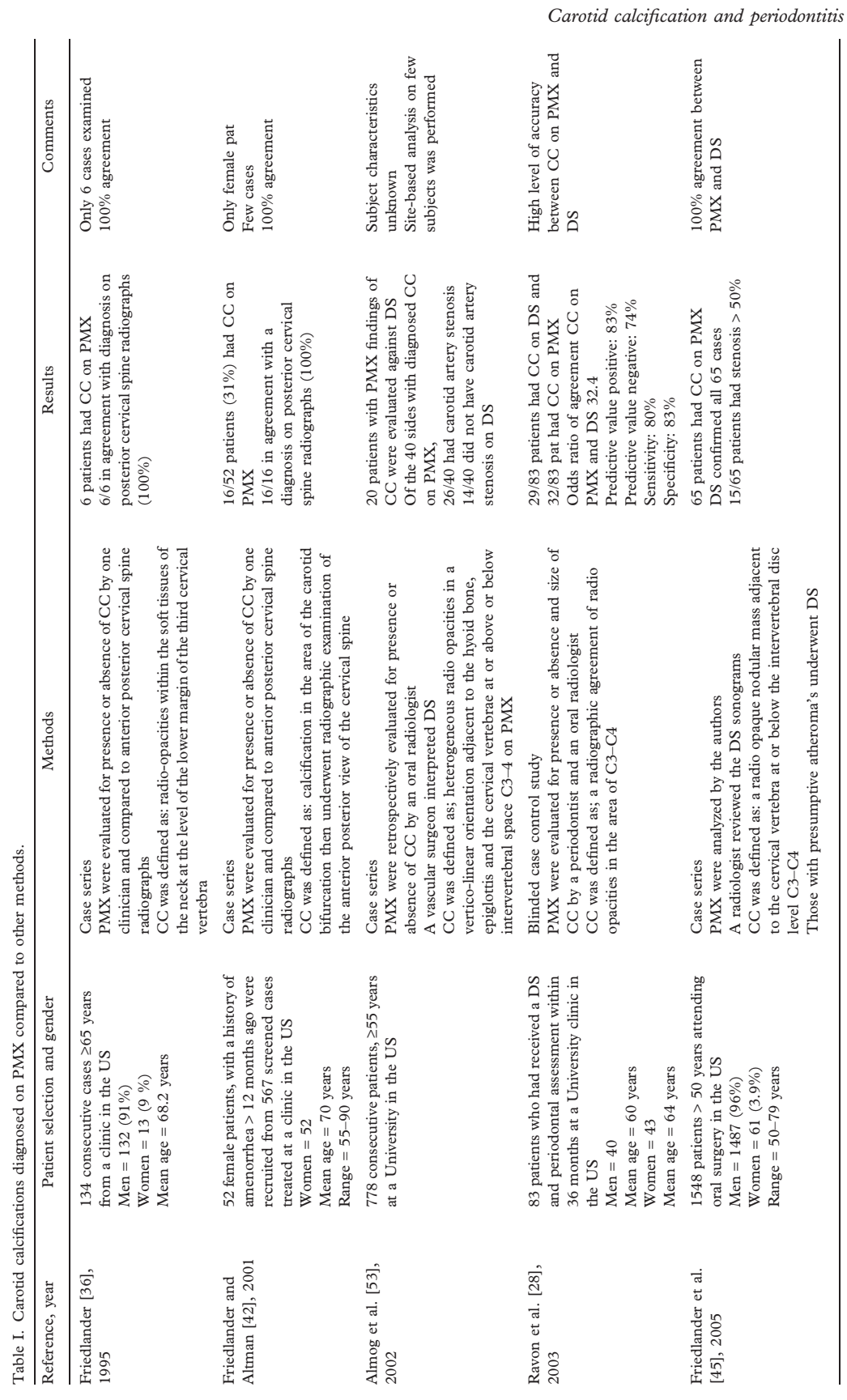

403 


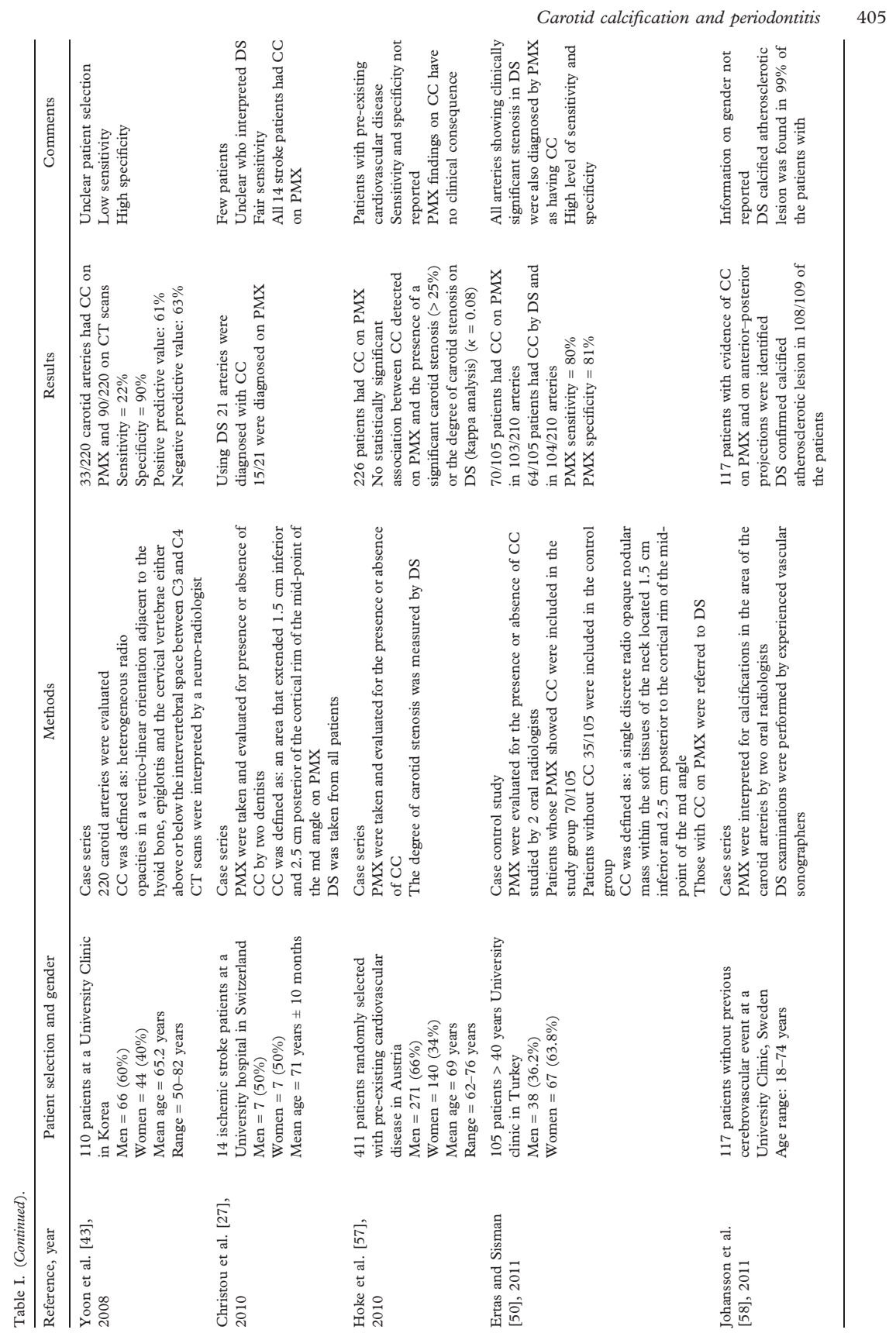


degree of calcification [52]. Thus, it is critical that the area of interest is properly projected.

The specificity for panoramic radiography findings of carotid calcifications compared to a diagnosis by Doppler sonography varied from 21.4-87.5\% $[28,47,50]$. Thus, the specificity is higher than the sensitivity, indicating that a negative diagnostic finding on a routine panoramic radiograph should be considered as an indication of no carotid stenosis, assuming the area of interest is available for analysis. A positive finding should be viewed with scrutiny to prevent false interpretations. If warranted, further medical attention is needed. It should also be pointed out that not all calcifications imply significant stenosis and not all atherosclerotic lesions are calcified [53].

The associations between carotid calcifications as defined from panoramic radiographs and stroke are reported from 10 studies (Table II). In a majority of the studies, carotid calcifications were detected in a few cases, limiting the power of the studies. For example, in the study by Kumagai et al. [54] with 2374 individuals, only 95 of these individuals had evidence of carotid calcification on PMX. Among these individuals, only eight of them had a history of stroke. Similarly, in the publication by Lewis and Brooks [55] only 9/1156 individuals had evidence of carotid calcification on PMX. None of these individuals had a history of stroke. In contrast, in the publication by Persson et al. [20], 198/ 1064 patients had evidence of carotid calcification on PMX. The study population included study individuals $\geq 60$ years and the authors reported a high level of association between carotid calcification on PMX and a history of stroke [20]. In contrast, only 15\% were $\geq 55$ years in the previously reported study [55]. In seven of the studies selected fewer than 10 individuals with stroke were identified. In two studies $[38,55]$ the mean age of the patients was lower than age 50 , limiting the possibilities of detecting carotid calcification on PMX and that the patients should have a history of stroke at that age. In the study by Christou et al. [27] based on a limited number of individuals with a history of stroke $(n=14)$ all of them demonstrated evidence of carotid calcification on PMX. Based on a limited number of studies with sufficient number of study individuals at potential risk for stroke, radiographic evidence of carotid calcification may indicate individuals at risk for stroke. Thus, studies to assess the presence of carotid calcification on panoramic radiographs and how such findings are related to cerebrovascular events should primarily be performed, including individuals at risk for such events. If studies are performed in populations with a low likelihood of carotid calcification the diagnostic specificity of panoramic radiography to detect such calcifications would approach $100 \%$ and with the reverse for test sensitivity.

Studies on the association between carotid calcifications defined from panoramic radiographs and a diagnosis of periodontitis are presented in Table III. 


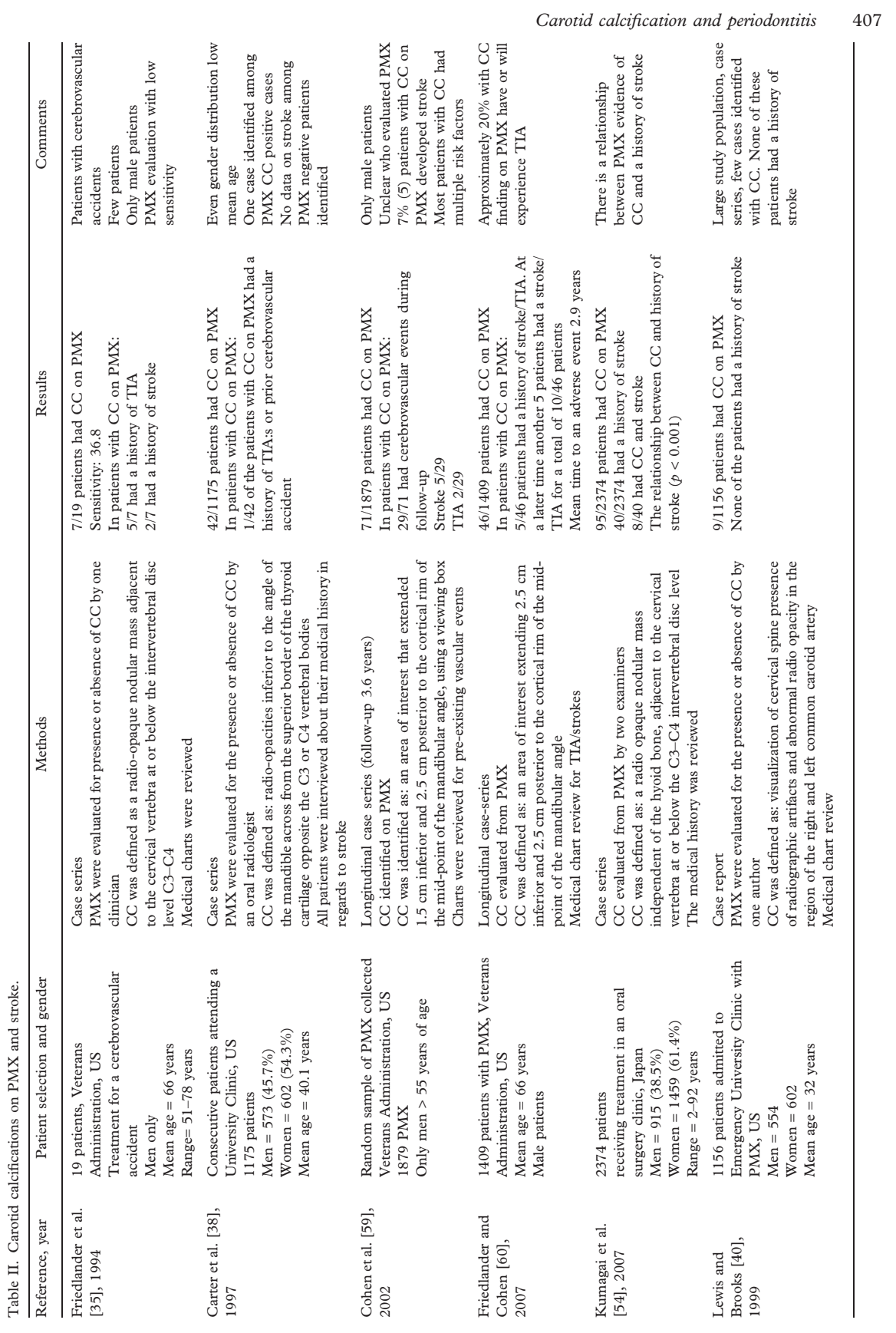




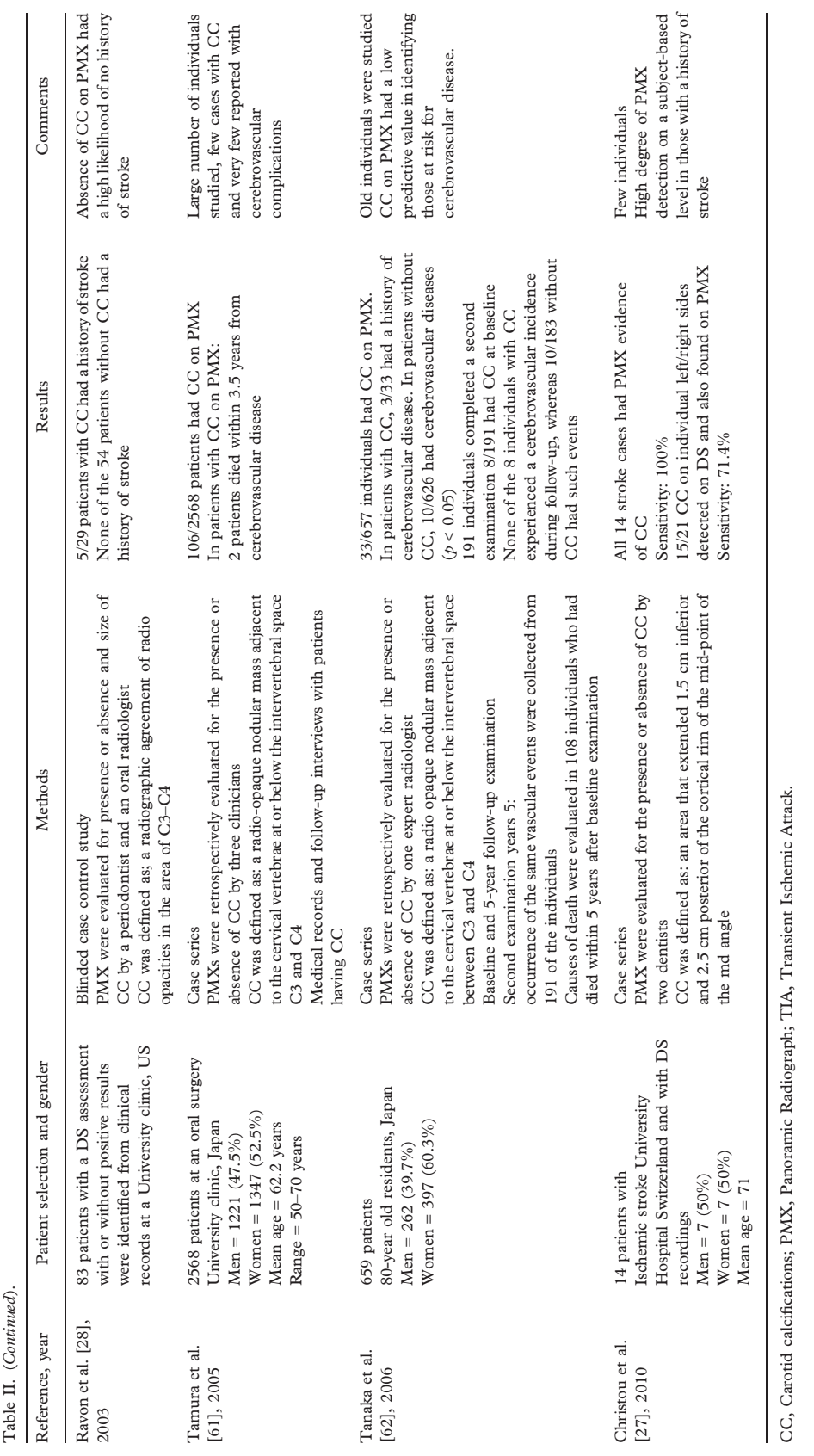




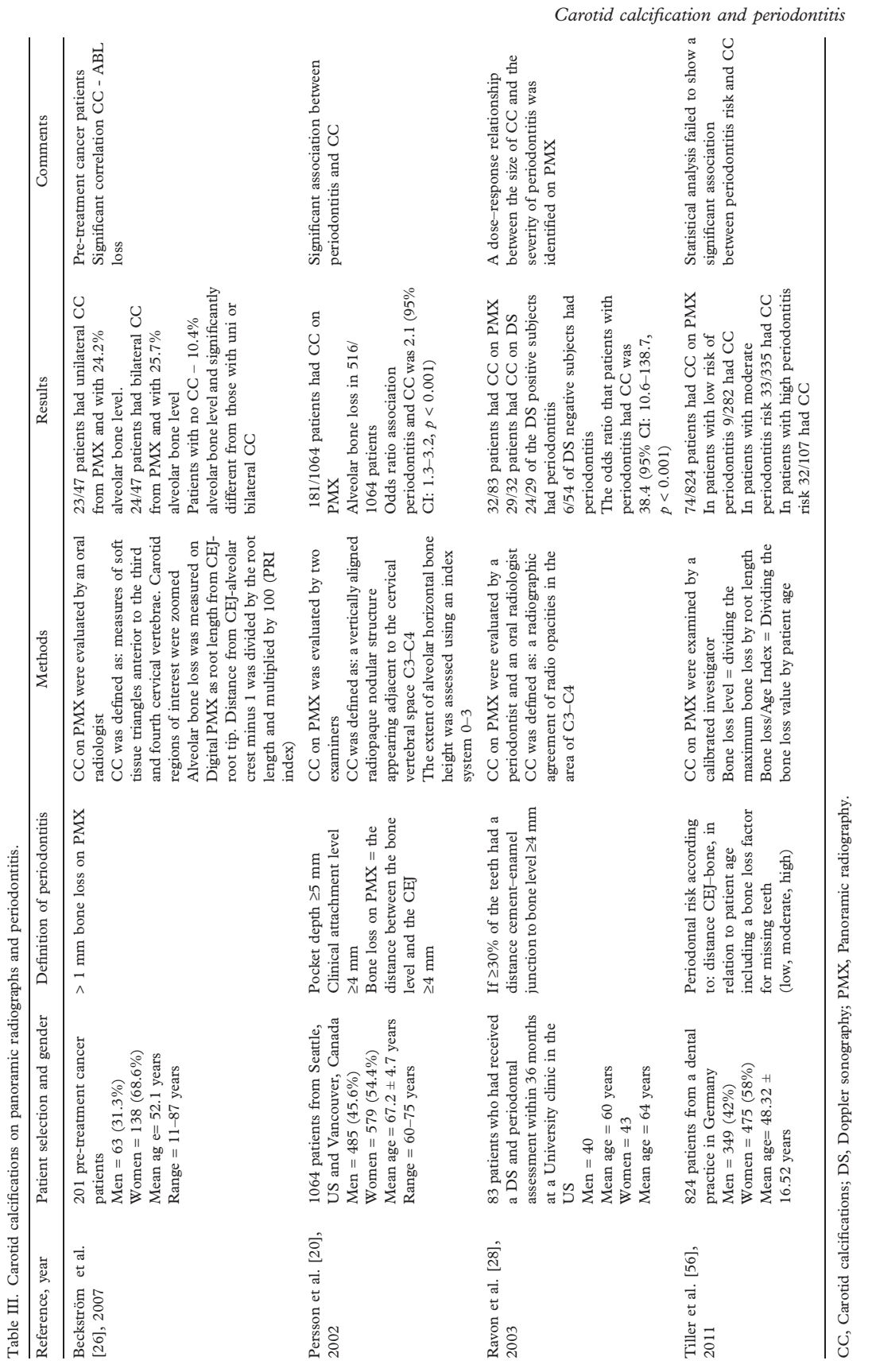


Four studies were retrieved. When periodontitis was defined as alveolar bone loss $>4 \mathrm{~mm}$ between the cement-enamel junction and bone level at $\geq 30 \%$ of sites, a dose-response relationship between the size of the carotid calcification and the severity of periodontitis on panoramic radiographs was reported [28]. Using the same definition of periodontitis, Persson et al. [20] also reported an association between carotid calcification on panoramic radiographs and periodontitis. In individuals with periodontitis, defined as $>1 \mathrm{~mm}$ bone loss on a panoramic radiograph, $25.7 \%$ of individuals with bilateral carotid calcifications had periodontitis compared to $10.4 \%$ among those without carotid calcifications [26]. In contrast, Tiller et al. [56] failed to show a significant periodontitis risk and radiographic evidence of carotid calcification on PMX when multivariate regression analysis was performed. It should also be recognized that the study by Tiller et al. [56] studied the risk of periodontitis and not a diagnosis of periodontitis.

Although it requires training to detect calcifications on panoramic radiographs, analysis of panoramic radiographs for carotid calcification made under optimal conditions with the help of view boxes and magnifying lenses could be a useful tool in assessing individuals at risk for stroke. The use of digital images could also enhance the ability to detect carotid calcifications. A shortcoming with digital panoramic images is the reduced dimensions resulting in that such images often do not include the area of interest for detection of carotid calcifications. On the other hand, digital radiographs can be adjusted for contrast. Color enhancement through computer programs may also facilitate the detection of radio-opacities, suggesting calcified carotid arteries.

\section{Conclusions}

The study designs, selection and number of study individuals and the age of the included individuals differed among the studies, making it difficult to draw any definite conclusions. The results of the present literature review indicate, though, that carotid calcifications are more frequently found in panoramic radiographs from older individuals and that periodontitis as evidence of alveolar bone loss was more often identified among individuals with radiographic evidence of carotid calcifications. The sensitivity of panoramic radiographs to identify carotid calcifications against Doppler sonography is in most studies low. The absence of radiographic evidence of carotid calcification on PMX is consistent with negative findings using Doppler sonography and, thus, the specificity is high. A positive diagnostic finding on a routine panoramic radiograph suggests further medical attention.

There is a shortage of well-designed studies in older dentate individuals assessing the associations between periodontitis and radiographic evidence of carotid calcification on panoramic radiographs and with a further relationship to a history of stroke or other cardiovascular diseases. The majority of the studies available for review can be considered as case series and there are few, if any, published longitudinal data or clinical follow-up studies beyond assessments with Doppler sonography and angiography.

Declaration of interest: The authors report no conflicts of interest. The authors alone are responsible for the content and writing of the paper.

\section{References}

[1] Bos D, Ikram MA, Elias-Smale SE, Krestin GP, Hofman A, Witteman JC, et al. Calcification in major vessel beds relates to vascular brain disease. Arterioscler Thromb Vasc Biol 2011; 31:2331-7.

[2] American Heart Association. Heart disease and stroke statistics: 2008 update. American Heart Association. Circulation 2008;117:e25-146.

[3] Hubar JS. Carotid artery calcification in the black population: a retrospective study on panoramic radiographs. Dentomaxillofac Radiol 1999;28:348-50.

[4] Nadareishvili ZG, Rothwell PM, Beletsky V, Pagniello A, Norris JW. Long term risk of stroke and other vascular events in patients with asymptomatic carotid artery stenosis. Arch Neurol 2002;59:1162-6.

[5] Zhadanov VS, Sternby NH. Monitoring of atherosclerosis. Int J Cardiol 2004;95:39-42.

[6] Madhuri V, Chandra S, Jabbar A. Age associated increase in intima media thickness in adults. Indian J Physiol Pharmaco 2010;54:371-5.

[7] Schneer S, Bachar GN, Atar E, Koronowski R, Dicker D. Evaluation of Framingham and systematic coronary risk evaluation scores by coronary computed tomographic angiography in asymptomatic adults. Am J Cardiol 2013;111:700-4.

[8] Shah S, Casas JP, Drenos F, Whittaker J, Deanfield J, Swerdlow DI, et al. Causal relevance of blood lipid fractions in the development of carotid atherosclerosis Mendelian randomization analysis. Circ Cardiovasc Genet 2013;6:63-72.

[9] Giudice R, Izzo R, Manzi MV, Pagnano G, Santoro M, Rao MA, et al. Lifestyle-related risk factors, smoking status and cardiovascular disease. High Blood Press Cardiovasc Prev 2012;19:85-92

[10] Reunanen A. Mortality in type 2 diabetes. Ann Clin Res 1983; 15:26-8.

[11] Tousoulis D, Ntarladimas I, Antoniades C, Vasiliadou C Tentolouris C, Papageorgiou N, et al. Acute effects of different alcoholic beverages on vascular endothelium, inflammatory markers and thrombosis fibrinolysis system. Clin Nutr 2008;27:594-600

[12] Lindsberg PJ, Grau AJ. Inflammation and infections as risk factors for ischemic stroke. Stroke 2003;34:2518-32.

[13] Carrion J, Scisci E, Miles B, Sabino GJ, Zeituni AE, Gu Y, et al. Microbial carriage state of peripheral blood dendritic cells (DCs) in chronic periodontitis influences DC differentiation, atherogenic potential. J Immunol 2012;189:3178-87.

[14] Beck J, Garcia R, Heiss G, Vokonas PS, Offenbacher S. Periodontal disease and cardiovascular disease. J Periodontol 1996;67:1123-37.

[15] Destefano F, Anda RF, Kahn HS, Williamson DF, Russel CM. Dental disease and risk of coronary heart disease and mortality. BMJ 1993;306:688-91. 
[16] Dörfer CE, Becher H, Ziegler CM, Kaiser C, Lutz R, Jörss $\mathrm{D}$, et al. The association of gingivitis and periodontitis with ischemic stroke. J Clin Periodontol 2004;31:396-401.

[17] Grau AJ, Buggle F, Ziegler C, Schwarz W, Meuser J, Tasman AJ, et al. Association between acute cerebrovascular ischemia and chronic and recurrent infection. Stroke 1997;28: 1724-9.

[18] Grau AJ, Becher H, Ziegler CM, Lichy C, Buggle F, Kaiser C, et al. Periodontal disease as a risk factor for ischemic stroke. Stroke 2004;35:496-501.

[19] Joshipura KJ, Hung HC, Rimm EB, Willett WC, Ascherio A. Periodontal disease, tooth loss, and incidence of ischemic stroke. Stroke 2003;34:47-52.

[20] Persson RE, Hollender LG, Powell VL, MacEntee M, Wyatt CC, Kiyak HA. Assessment of periodontal conditions and systemic disease in older subjects. II. Focus on cardiovascular diseases. J Clin Periodontol 2002;29:803-10.

[21] Kinane D, Bouchard P; Group E of European Workshop on Periodontology. Periodontal diseases and health. Consensus Report of the Sixth European Workshop on Periodontology. J Clin Periodontol 2008;35:333-7.

[22] Bouchard P, Boutouyrie P, Dáiuto F, Deanfield J, Deliargyris E, Fernandez- Avvilés F, et al. European workshop in periodontal health and cardiovascular disease-consensus report. Euro Heart J 2010;12:13-22.

[23] Desvarieux M, Demmer RT, Rundek T, Boden-Albala B, Jacobs DR Jr, Papapanou PN, et al. Relationship between periodontal disease, tooth loss, and carotid artery plaque: the Oral Infections and Vascular Disease Epidemiology Study (INVEST). Stroke 2003;34:2120-5.

[24] Söder PO, Söder B, Nowak J, Jogestrand T. Early carotic atherosclerosis in subjects with periodontal diseases. Stroke 2005;36:1195-2000.

[25] Ebrahim S, Papacosta O, Whincup P, Wannamethee G, Walker M, Nicolaides AN, et al. Carotid plaque, intima media thickness, cardiovascular risk factors, and prevalent cardiovascular disease in men and women: the British Regional Heart Study. Stroke 1999;30:841-50.

[26] Beckström BW, Horsley SH, Scheetz JP, Khan Z, Silveira AM, Clark SJ, et al. Correlation between carotic area calcifications and periodontitis: a retrospective study of digital panoramic radiographic finding in pre-treatment cancer patients. Oral Surg Oral Med Oral Pathol Oral Radiol Endod 2007;103:359-66.

[27] Christou P, Leemann B, Scimmel M, Kiliaridis S, Müller F. Carotid artery calcification in ischemic stroke patients detected in a standard dental panoramic radiographs a preliminary study. Adv Med Sci 2010;55:26-31.

[28] Ravon NA, Hollender LG, McDonald V, Persson GR. Signs of carotid calcification from dental panoramic radiographs are in agreement with Doppler sonography results. J Clin Periodontol 2003;35:277-90.

[29] Lockhart PB, Bolger AF, Papapanou PN, Osinbowale O, Trevisan M, Levison ME, et al. American Heart Association Rheumatic Fever, Endocarditis, and Kawasaki Disease Committee of the Council on Cardiovascular Disease in the Young, Council on Epidemiology and Prevention, Council on Peripheral Vascular Disease, and Council on Clinical Cardiology. Periodontal disease and atherosclerotic vascular disease: does the evidence support an independent association?: a scientific statement from the American Heart Association. Circulation 2012;125:2520-44.

[30] Cinat M, Lane CT, Pham H, Lee A, Wilson SE, Gordon I. Helical CT angiography in the preoperative evaluation of carotid artery stenosis. J Vasc Surg 1998;28:290-300.

[31] Moneta GL, Edwards JM, Chitwood RW, Taylor LM Jr, Lee RW, Cummings CA, et al. Correlation of North American Symptomatic Carotid Endarterectomy Trial (NASCET) angiographic definition of $70 \%$ to $99 \%$ internal carotid artery stenosis with duplex scanning. JVasc Surg 1993; 197:152-7

[32] Rossouw JE. Lipid-lowering interventions in angiographic trials. Am J Cardiol 1995;28:76 86C-92C.

[33] Huber P. Cerebral angiography. 2nd ed. New York: Thieme; 1982. pp 290-3; 257-82.

[34] Friedlander AH, Lande A. Panoramic radiographic identification of carotid arterial plaques. Oral Surg Oral Med Ora Pathol 1981;52:102-4.

[35] Friedlander AH, Manesh F, Waster lain CG. Prevalence of detectable carotid artery calcifications on panoramic radiographs of recent stroke victims. Oral Surg Oral Med Ora Pathol 1994;77:669-73.

[36] Friedlander AH. Identification of stroke-prone patients by panoramic and cervical spine radiography. Dentomaxillofac Radiol 1995;24:160-4.

[37] Friedlander AH, Friedlander IK. Panoramic dental radiography: an aid in detecting individuals prone to stroke. Br Dent J $1996 ; 181: 23-6$.

[38] Carter LC, Haller AD, Nadarajah V, Calamel AD, Aguirre A. Use of panoramic radiography among an ambulatory dental population to detect patients at risk of stroke. J Am Dent Assoc 1997;128:977-84.

[39] Friedlander AH, Friedlander IK, Yueh R, Littner MR. The prevalence of carotid atheromas seen on panoramic radiographs of patients with obstructive sleep apnea and their relation to risk factors for atherosclerosis. J Oral Maxillofac Surg 1999;57:516-21.

[40] Lewis DA, Brooks SL. Carotid artery calcification in a general dental population: a retrospective study of panoramic radiographs. Gen Dent 1999;47:98-103.

[41] Almog DM, Tsimidis K, Moss ME, Gottlieb RH, Carter LC. Evaluation of training program for detection of carotid artery calcifications on panoramic radiographs. Oral Surg Oral Med Oral Pathol Oral Radiol Endod 2000;90:111-17.

[42] Friedlander AH, Altman L. Carotid artery atheromas in postmenopausal women. Their prevalence on panoramic radiographs and their relationship to atherogenic risk factors. J Am Dent Assoc 2001;132:1130-6.

[43] Yoon SJ, Yoon W, Kim OS, Lee JS, Kang BC. Diagnostic accuracy of panoramic radiography in the detection of calcified carotid artery. Dentomaxillofac Radiol 2008;37:104-8.

[44] Damaskos S, Griniatsos J, Tsekouras N, Georgopoulos S, Klonaris C, Bastounis E, et al. Reliability of panoramic radiograph for carotid atheroma detection: a study in patients who fulfill the criteria for carotid endarterectomy. Ora Surg Oral Med Oral Pathol Oral Radiol Endod 2008;106: $736-42$.

[45] Friedlander AH, Garrett NR, Chin EE, Baker JD. Ultrasonographic confirmation of carotid artery atheromas diag nosed via panoramic radiography. J Am Dent Assoc 2005;136: 635-40.

[46] Bayram B, Uckan S, Acikgoz A, Müderrisoglu H, Aydinalp A. Digital panoramic radiography: a reliable method to diagnose carotid artery atheromas? Dentomaxillofac Radiol 2006;35: 266-70

[47] Madden RP, Hodges JS, Salmen CW, Rindal DB, Tunio J, Michalowicz BS, et al. Utility of panoramic radiographs in detecting cervical calcified carotid atheroma. Oral Surg Oral Med Oral Pathol Oral Radiol Endod 2007;103: 543-8.

[48] Romano-Sousa CM, Krejci L, Medeiros FM, GraciosaFilho RG, Martins MF, Guedes VN, et al. Diagnostic agreement between panoramic radiographs and color Doppler images of carotid atheroma. J Appl Oral Sci 2009; 17:45-8.

[49] Gouvea AF, Vargas PA, Jorge J, Lopes MA. Using panoramic radiographs to detect carotid artery calcifications: are they a helpful diagnostic tool? Gen Dent 2009;57:480-4. 
[50] Ertas ET, Sisman Y. Detection of incidental carotid artery calcifications during dental examinations: panoramic radiography as an important aid in dentistry. Oral Surg Oral Med Oral Pathol Oral Radiol Endod 2011;112:e11-17.

[51] Imanimoghaddam M, Rah Rooh M, Mahmoudi Hashemi E, Javadzade Blouri A. Doppler sonography confirmation in patients showing calcified carotid artery atheroma in panoramic radiography and evaluation of related risk factors. J Dent Res Dent Clin Dent Prospects 2012;6:6-11.

[52] Friedlander AH. Odd practice. Br Dent J 2009;207:464-5.

[53] Almog DM, Horev T, Illig KA, Green RM, Carter LC Correlating carotid artery stenosis detected by panoramic radiography with clinically relevant carotid artery stenosis determined by duplex ultrasound. Oral Surg Oral Med Oral Pathol Oral Radiol Endod 2002;94:768-73.

[54] Kumagai M, Yamagishi T, Fukui N, Chiba M. Carotid artery calcification seen on panoramic dental radiographs in the Asian population in Japan. Dentomaxillofac Radiol 2007;36:92-6.

[55] Lewis DA, Brooks SL. Carotid artery calcification in a general dental population: a retrospective study of panoramic radiographs. Gen Dent 1999;47:98-103.

[56] Tiller R, Bengel W, Rinke S, Ziebolz D. Association between carotid area calcifications and periodontal risk: a cross sectional study of panoramic radiographic findings. BMC Cardiovasc Disord 2011;11:67.
[57] Hoke M, Schmidt B, Schillinger T, Kluger W, Wiesbauer F, Mlekusch W, et al. Evidence of carotid atherosclerosis in orthopantomograms and the risk for future cardiovascular events. Vasa 2010;39:298-304.

[58] Johansson EP, Ahlqvist J, Garof MM, Karp K, Jäghagen EL, Wester P. Ultrasound screening for asymptomatic carotic stenosis in subjects with calcifications in the area of the carotid arteries on panoramic radiographs: a cross-sectional study. BMC Cardiovasc Disord 2011;11:44.

[59] Cohen SN, Friedlander AH, Jolly DA, Date L. Carotid calcification on panoramic radiographs: an important marker for vascular risk. Oral Surg Oral Med Oral Pathol Oral Radiol Endod 2002;94:510-14.

[60] Friedlander AH, Cohen SN. Panoramic radiographic atheromas portend adverse vascular events. Oral Surg Oral Med Oral Pathol Oral Radiol Endod 2007;103:830-5.

[61] Tamura T, Inui $M$, Nakase $M$, Nakamura $S$, Okumura $K$, Tagawa T. Clinico-statistical study of carotid calcification on panoramic radiographs. Oral Dis 2005;11:314-17.

[62] Tanaka T, Morimoto $\mathrm{Y}$, Ansai T, Okabe S, Yamada K, Taguchi A, et al. Can the presence of carotid artery calcification on panoramic radiographs predict the risk of vascular diseases among 80-year-olds? Oral Surg Oral Med Oral Pathol Oral Radiol Endod 2006;101: $777-83$. 
II 



\title{
A cross-sectional study of the associations between periodontitis and carotid arterial calcifications in an elderly population
}

\author{
VIVECA WALLIN BENGTSSON ${ }^{1}$, G. RUTGER PERSSON ${ }^{1,2,3}$, JOHAN BERGLUND $^{4}$ \& \\ STEFAN RENVERT ${ }^{1,4,5}$
}

${ }^{1}$ University of Kristianstad, Kristianstad, Sweden, ${ }^{2}$ Department of Periodontics, University of Washington, Seattle, WA, USA, ${ }^{3}$ Department of Oral Medicine, University of Washington, Seattle, WA, USA, ${ }^{4}$ Institute of Technology, Karlskrona, Sweden, and ${ }^{5}$ Dublin Dental Hospital Trinity College, Dublin, Ireland

\begin{abstract}
Objective. To evaluate if the presence of periodontitis is associated with carotid arterial calcifications diagnosed on panoramic radiographs in an elderly population. Materials and methods. Study individuals were randomly selected from the Swedish civil registration database representing the aging population (60-96 years) in Karlskrona, Sweden. Bleeding on probing (BOP) and the deepest probing measurement at each tooth were registered. The proportions of teeth with a probing depth $\geq 5 \mathrm{~mm}$ and the proportion of teeth with bleeding on probing were calculated. Analog panoramic radiographs were taken and the proportion of sites with a distance $\geq 5 \mathrm{~mm}$ between the alveolar bone level and the cement-enamel junction (CED) were assessed. A diagnosis of periodontitis was declared if a distance between the alveolar bone level and the CEJ $\geq 5 \mathrm{~mm}$ could be identified from the panoramic radiographs at $>10 \%$ of sites, probing depth of $\geq 5 \mathrm{~mm}$ at one tooth or more and with BOP at $>20 \%$ of teeth. Results. Readable radiographs were obtained from 499 individuals. Carotid calcification was identified in $39.1 \%$. Individuals were diagnosed with periodontitis in $18.4 \%$. Data analysis demonstrated that individuals with periodontitis had a higher prevalence of carotid calcifications (Pearson $\left.\chi^{2}=4.05 p<0.05\right)$ and with a likelihood of $1.5(95 \% \mathrm{CI}=1.0,2.3$, $p<0.05)$. Conclusions. Data analysis demonstrated a significant association between periodontitis and carotid calcification.
\end{abstract}

Key Words: Carotid arterial calcifications, panoramic radiographs, periodontitis

\section{Introduction}

Over the past decades, the lifespan in Western societies has steadily increased. The main cause of serious illness or death has shifted from acute infections to chronic diseases $[1,2]$. In developed countries cardiovascular diseases (CVD) comprise a variety of heart and vascular conditions and are responsible for $\sim 30 \%$ of all cases of mortality [1]. Atherosclerosis is the primary reason for myocardial infarction, stroke and thromboembolic events. Development of atherosclerosis is a lifelong process, starting in early childhood, with clinical manifestations many years after [3]. Atherosclerotic disease is common in the area where the carotid artery bifurcates into the internal and external carotid arteries [4]. It is widely accepted that age, gender, high blood pressure, smoking, dyslipidaemia and diabetes are major risk factors for the development of cardiovascular disease [5]. Chronic inflammation may also result in atherosclerosis and is considered a risk factor for cardiovascular disease $[6,7]$.

Over the last 10 years, epidemiological studies have focused on potential associations between chronic oral infections and cardiovascular disease. In a systematic review assessing the incidence of cardiovascular events a statistically significant increased risk for atherosclerotic cardiovascular disease was reported in individuals with periodontitis [8]. Periodontitis is a bacterially-induced, chronic inflammatory disease that destroys connective tissues and alveolar bone, resulting in tooth loss [9].

Periodontitis may result in bacteraemia. The bacteria may invade the endothelial layer and further spread into deeper tissue and activate the host inflammatory response by multiple mechanisms $[10,11]$. Atheromas can grow due to macrophage-secreted

Correspondence: Viveca Wallin Bengtsson, DDS, Senior Periodontist, Health Science, University of Kristianstad, SE 29188 Kristianstad, Sweden. Tel: +46 44208594. Fax: +46 723093606. E-mail: viveca.wallin_bengtsson@hkr.se

(Received 14 fanuary 2015; accepted 6 May 2015) 


\section{$116 V . W$. Bengtsson et al.}

growth factors mediating smooth muscle cell proliferation [7]. Data have shown that patients with periodontitis have higher C-reactive protein values (hs-CRP) in serum indicating a generalized inflammatory effect of the disease [12-14]. Periodontitis has been associated with endothelial dysfunction and subclinical carotid atherosclerosis (intima media thickness) correlating with future cardiovascular disease events including stroke [15-21] and it has also been demonstrated that an infection with major periodontal pathogens is associated with a future stroke [22].

Carotid artery calcification can be identified on panoramic dental radiographs [23-27]. Data suggest that periodontitis may be related to evidence of carotid calcification [28-32]. A recent literature review reporting on the associations between periodontitis and carotid calcification on panoramic dental radiographs concluded that periodontitis was more often identified among individuals with radiographic evidence of carotid calcification. This literature review also indicated that carotid calcification is more frequently found in panoramic dental radiographs from older adults [33].

The objective of the present study was to evaluate if periodontitis is associated with the presence of carotid arterial calcifications diagnosed on panoramic radiographs in an elderly population.

\section{Materials and methods}

\section{Individuals}

The Regional Ethics Committee Lund, Sweden, approved the study (LU 605-00, LU 744-00). All enrolled participants signed an informed consent form. Details of the study population have been presented elsewhere [34-36]. Study individuals were randomly selected from the Swedish civil registration database representing the aging population (60-96 years) in Karlskrona community, Sweden. The enrolment of study individuals occurred between 2001-2004. Study individuals were invited by mail. The study samples were selected randomly in age cohorts of $60,66,72$ and 78 years. In the age cohorts of $81,84,87,90,93$ and 96 years, all inhabitants were included. Study individuals were divided into sub-groups in the age cohorts between 60-72 years (young-old) and individuals between ages 78-96 years (old-old).

In the present report, dentate individuals with $>10$ teeth and with panoramic radiographs allowing for analysis of the area of interest for detection of carotid calcification were included.

\section{Dental examinations}

Two experienced dental hygienists performed routine clinical dental examinations. Periodontal probes (CP-12 probes, Hu-Friedy Inc. Chicago, IL) were used to measure probing depths (PD) at four sites of all existing teeth including fully erupted third molars. Within each individual, the presence of bleeding or not, and the PD value using the value at the site of each tooth with the deepest PD was used to calculate the proportions of teeth with a probing depth $\geq 5 \mathrm{~mm}$ and the proportion of teeth with bleeding on probing.

Analog panoramic radiographs (Orthopantomograph OP 100, Instrumentarium, Tuusala, Finland) were taken with a standard exposure of $75 \mathrm{kV} /$ $10 \mathrm{~mA}$. The extent of alveolar bone loss was measured at the mesial and distal aspects of existing teeth (third molars not included). The number of inter-proximal sites that could be assessed from the panoramic radiographs was used to calculate the proportion of sites with a distance $\geq 5 \mathrm{~mm}$ between the alveolar bone level and the cement-enamel junction (CEJ). A millimeter graded transparent plastic ruler, a $2 \times$ magnification viewer and a light view box source provided the conditions by which the distances between the alveolar bone level and CEJ were measured. An independent experienced examiner (REP) masked to the information about medical and dental information, gender, age and survival status performed all the radiographic measurements.

Reliability measurements were made for double reading of X-rays. The ICC correlation coefficient between the two observer measurements for the distance between the apex and CEJ was $0.93(95 \%$ $\mathrm{CI}=0.91-0.96, p<0.01)$ and was based on a total of 91 observations, with a mean difference of $0.94 \mathrm{~mm}$ $(\mathrm{SD}= \pm 1.3)$.

The periodontal diagnosis was defined by the extent of bone level loss, probing depth (PD) and bleeding on probing (BOP). Thus, a diagnosis of periodontitis was declared if a distance between the alveolar bone level and the CEJ $\geq 5 \mathrm{~mm}$ could be identified from the panoramic radiographs presented at $>10 \%$ of sites, PD of $\geq 5 \mathrm{~mm}$ at one tooth or more and with bleeding on probing at $>20 \%$ of teeth.

\section{Statistical methods}

The data were analyzed using descriptive statistics. Independent $t$-tests (equal variance not assumed) and non-parametric tests (Mann-Whitney U-test) were performed to assess group differences. The data were also analyzed using Pearson's $\chi^{2}$ test and Mantel-Haenszel common odds ratio. Statistical significance was declared at $p<0.05$. The SPSS PASW 22.0 statistical software (SPSS Inc., Chicago, IL) for an Apple computer was used in the analysis. 
Table I. Comparisons between the young-old and the old-old age cohorts with $>10$ teeth.

\begin{tabular}{|c|c|c|c|c|c|c|c|}
\hline Variable & \multicolumn{3}{|c|}{ Young-Old $(n=433)$} & \multicolumn{3}{|c|}{ Old-Old $(n=281)$} & Significance \\
\hline Remaining teeth, $n$ & \multicolumn{3}{|c|}{$23.0 \pm 4.4$} & \multicolumn{3}{|c|}{$18.7 \pm 5.0$} & $p<0.001$ \\
\hline BoP (\%) & \multicolumn{3}{|c|}{$24.1 \pm 21.4$} & \multicolumn{3}{|c|}{$27.1 \pm 24.2$} & $p=0.10$ \\
\hline \multirow{2}{*}{$\begin{array}{l}\text { Periodontitis } \\
\text { Composite definition (\%) }\end{array}$} & Positive & \multicolumn{2}{|l|}{ Negative } & Positive & \multicolumn{2}{|l|}{ Negative } & \multirow{2}{*}{$\begin{array}{l}\chi^{2}=10.1 \\
p<0.001 \\
\mathrm{OR}=1.8,95 \% \\
\mathrm{CI}=1.3,2.6, \\
p<0.001\end{array}$} \\
\hline & 16.2 & 83.8 & & 26.0 & 74.0 & & \\
\hline \multirow[t]{2}{*}{ Carotid calcification (\%) } & Positive & Negative & $\mathrm{NR}^{\star}$ & Positive & Negative & $\mathrm{NR}^{\star}$ & \multirow{2}{*}{$\begin{array}{l}\chi^{2}=7.3 \\
p<0.01 \\
\mathrm{OR}=1.7,95 \% \\
\mathrm{CI}=1.2,2.4 \\
p<0.01\end{array}$} \\
\hline & 23.1 & 44.6 & 32.3 & 33.7 & 39.5 & 26.7 & \\
\hline
\end{tabular}

* Non Readable (NR) radiographs were not included in the $\chi^{2}$ analysis.

\section{Results}

The present study included 714 individuals with $\geq 10$ teeth as assessed from the panoramic radiographs. The area of interest for detecting carotid calcifications was not readable on 215 radiographs $(30.1 \%)$, leaving a total of 499 individuals (313 women; $62.7 \%$ ) in the study. Thus, the study included $293(58.7 \%)$ in the age cohort between 60-72 years (young-old) and $206(41.3 \%)$ individuals between ages 78-93 (oldold). On average, study individuals had 21.3 remaining teeth $(\mathrm{SD}= \pm 5.1)$. The average proportion of teeth with BOP was $25.3 \%(S D= \pm 22.6 \%)$. A positive finding suggesting carotid calcification was identified in 195/ 499 individuals (39.1\%). Using the composite definition of periodontitis, 91 out of the 499 individuals had a diagnosis of periodontitis (18.4\%).

\section{Differences in relation to age and gender}

Results from the data analysis for the comparisons between the young-old and old-old cohorts are presented in Table I. Statistical analysis failed to demonstrate differences in BOP by age category. The prevalence of periodontitis as defined above was higher in the older cohort (Pearson $\chi^{2}=10.1$, $p<0.001)$ with a likelihood of $1.8(95 \% \mathrm{CI}=1.3$, 2.6, $p<0.001)$. A diagnosis of periodontitis was higher among men (Pearson $\chi^{2}=12.9, p<0.001$ ) with a likelihood of $2.0(95 \% \mathrm{CI}=1.4,2.9, p<0.001)$. Based on panoramic readings, the older cohort had significantly more signs of carotid calcification with a likelihood of $1.7(95 \% \mathrm{CI}=1.1,2.4, p<0.01)$. In the younger age cohort, signs of carotid calcification were significantly higher among men (Pearson $\chi^{2}=5.2$, $p<0.05)$ with a likelihood of $1.8(95 \% \mathrm{CI}=1.1,2.9$, $p<0.05)$. Males had more evidence of carotid calcifications than women (Pearson $\chi^{2}=4.6, p<0.05$ ), with a likelihood of $1.5(95 \% \mathrm{CI}=1.0,2.2, p<0.05)$.
Relationship between periodontitis and the evidence of carotid calcification

Data analysis demonstrated that individuals with periodontitis had a higher prevalence of carotid calcifications (Pearson $\chi^{2}=4.05 p<0.05$ ) and with a likelihood of 1.5 (95\% CI $=1.0,2.3, p<0.05)$.

\section{Discussion}

The present study has shown that there was a significant association between periodontitis and carotid arterial calcifications as measured on panoramic radiographs in this aging population (60-96). The prevalence of periodontitis as well as signs of carotid calcification was higher in the older cohort. Using the composite definition of periodontitis, $18.4 \%$ had a diagnosis of periodontitis and with higher likelihood among men. This observation is consistent with other studies demonstrating worse periodontal conditions among men $[37,38]$. In a recent publication by Kassebaum et al. [39] severe periodontitis was reported to be the sixth most prevalent condition in the world and the prevalence of periodontitis was reported to increase with age. Depending on the criteria used to define periodontitis, the prevalence of periodontitis in the US varies between $12-76 \%$ $[38,40]$. A past experience of periodontitis can be assessed by attachment loss and/or loss of alveolar bone, whereas assessment of present disease requires additional measurement such as BOP and PD. A high agreement between panoramic radiographs, periapical radiographs and posterior bite-wing radiographs with regards to periodontal bone height measurements has been demonstrated $[41,42]$.

Data from 'The National Health and Nutrition Examination Survey (NHANES) 2009-2010' reported the prevalence of moderate and severe periodontitis in the adult American population to be 
$38.5 \%$. Periodontitis was based on clinical parameters into (1) severe periodontitis, as the presence of two or more interproximal sites with $\geq 6 \mathrm{~mm}$ attachment level (AL) and one or more interproximal site with $\geq 5 \mathrm{~mm}$ PD; (2) moderate periodontitis, as two or more interproximal sites with $\geq 4 \mathrm{~mm} \mathrm{AL}$ or two or more interproximal sites with $\mathrm{PD} \geq 5 \mathrm{~mm}$; or (3) mild periodontitis, defined as two or more interproximal sites with $\geq 3 \mathrm{~mm}$ AL and two or more interproximal sites with $\geq 4 \mathrm{~mm}$ PD or one site with $\geq 5 \mathrm{~mm}$ [40]. The definition of periodontitis used in the present study combined clinical parameters $\mathrm{PD}>5 \mathrm{~mm}$ at one or more teeth, radiographic parameters as a distance between bone level and the CEJ $\geq 5 \mathrm{~mm}$ at $>10 \%$ of sites and with BOP at $>20 \%$ of teeth. In spite of these more strict criteria for periodontitis, $18.4 \%$ of the individuals were identified in the present study as having periodontitis. Severe periodontitis was found in $8.5 \%$ among individuals $\geq 65$ years in the NHANES National Health and Nutritional Examination Survey) study by Eke et al. [40]. Most likely, the diagnosis of periodontitis in our study is more comparable to the severe form according to the definitions used by Eke et al. [40].

To be included, the study individuals had to have a minimum of $>10$ teeth and in the dental examination all teeth were measured at four sites including fully erupted third molars. The presence of bleeding or not and the PDvalue using the value at the site of each tooth with the deepest PD were registered. Kingman et al. [43] showed that half-mouth protocol correctly identified $60 \%$ of patients with attachment loss $\geq 3 \mathrm{~mm}$, whereas full-mouth examination of the same sites identified $74 \%$. According to Kingman et al. [43], our study with full mouth examination should correctly identify more patients with periodontitis compared to a half-mouth examination.

In the present study alveolar bone loss was assessed from panoramic radiographs. It has been demonstrated that findings of carotid calcifications on panoramic radiographs are in agreement with ultrasonography assessments [28]. Associations between periodontitis and the evidence of carotid calcifications on panoramic radiographs (PMX) have previously been reported using both small populations $[28,30]$ and larger populations $[25,44]$. The present study included 499 individuals and the results are in agreement to what has previously been reported from four studies. Ravon et al. [28] demonstrated a dose-response relationship between absence and presence and the size of carotid calcification and severity of periodontitis. In a recent review the authors concluded that periodontitis was more often identified among individuals with radiographic evidence of carotid calcifications on panoramic radiographs and is consistent with the result in the present study [33].

Carotid artery calcification in the area of the carotid artery bifurcation can be detected on panoramic radiographs in the range of $2-5 \%$ of the population [33]. In the present study, a positive finding suggesting carotid calcification was identified in 195/499 individuals (39.1\%). The frequency of carotid calcification is high in the present study. One explanation could be the high age of the individuals. Previous studies and literature reviews have shown that carotid calcifications are more frequent in older individuals $[44,45]$. In the present study, carotid calcifications were frequently detected among men in the younger age cohort. This could, to some degree, explain why life expectancy is shorter for men. There is a general agreement that men in the Western world have a shorter life expectancy than women and that men on average are younger than women at stroke onset [46].

In our study we never met the frailest individuals as they were unable to come to the research clinic and, accordingly, could not undergo dental examination or panoramic radiographic examination. This is of course a limitation of the present study, but is also inevitable when working with a group of elderly individuals. The results reported in the present study, however, reflect the situation among elderly individuals healthy enough to be able to attend a dental examination.

Only 10 individuals $(2 \%)$ reported a current smoking habit, therefore data were not corrected for smoking habits.

In summary the results of the present study suggest that if a panoramic radiograph is taken the clinician should assess the inter-vertebral space between C3 and C4, especially if the patient has a diagnosis of periodontitis, is of older age and male gender. In cases where carotid calcifications are found the patient should be referred to medical evaluation.

\section{Acknowledgements}

We acknowledge the contribution of Rigmor Persson (REP), University of Washington, in assessing the radiographs. We also want to acknowledge Ingrid Jonasson, Blekinge Institute of Technology, for clinical data collection and Johanna Renvert, University of Kristianstad, for data management.

Declaration of interest: The authors report no conflicts of interest. The authors alone are responsible for the content and writing of the paper.

\section{References}

[1] Minino AM, Murphy SL, Xu J, Kochanek KD. Deaths: Final data for 2008. Natl Vital Stat Rep 2011;59:1-126.

[2] Go AS, Mozaffarian D, Roger VL, Benjamin EJ, Berry JD, Borden WB, et al. Heart disease and stroke statistics 2013 update: A report from the American Heart Association. Circulation 2013;127:e6-e245. 
[3] Niinikoski H, Pahkala K, Ala-Korpela M, Viikari J, Rönnemaa T, Lagström H, et al. Effect of repeated dietary counseling on serum lipoproteins from infancy to adulthood. Pediatrics 2012;129:e704-13.

[4] Cheng C, Tempel D, van Haperen R, van der Baan A, Grosveld F, Daemen MJ, et al. Atherosclerotic lesion size and vulnerability are determined by patterns of fluid shear stress. Circulation 2006;113:2744-53.

[5] Kannel WB. Sixty years of preventive cardiology: A Framingham perspective. Clin Cardiol 2011;34:342-3.

[6] Ross R. Atherosclerosis is an inflammatory disease. Am Heart J 1999;138:419-20.

[7] Reyes L, Herrera D, Kozarov E, Roldán S, Progulske-Fox AJ Periodontal bacterial invasion and infection: Contribution to atherosclerotic pathology. Clin Periodontol 2013;40:30-50.

[8] Tonetti MS, Van Dyke TE. Periodontitis and atherosclerotic cardiovascular disease: Consensus report of the joint EFP/ AAP workshop on periodontitis and systemic diseases. In proceedings of the Working group 1 of the joint EFP/AAP workshop. J Clin Periodontol 2013;40:S24-9.

[9] Laine ML, Crielaard W, Loos BG. Genetic susceptibility to periodontitis. Periodontol 2000;58:37-68.

[10] Roberts GJ. Dentists are innocent! "Everyday" bacteraemia is the real culprit: A review and assessment of the evidence that dental surgical procedures are a principal cause of bacterial endocarditis in children. Pediatr Cardiol 1999;20:317-25.

[11] Lockhart PB, Brennan MT, Thornhill M, Michalowicz BS, Noll J, Bahrani-Mougeot FK, et al. Poor oral hygiene as a risk factor for infective endocarditis-related bacteremia. J Am Dent Assoc 2009;140:1238-44

[12] Loos BG, Craandijk J, Hoek FJ, Wertheim-van Dillen PM, van der Velden U. Elevation of systemic markers related to cardiovascular diseases in the peripheral blood of periodontitis patients. J Periodontol 2000;71:1528-34.

[13] Noack B, Genco RJ, Trevisan M, Grossi S, Zambon J, De Nardin E. Periodontal infections contribute to elevated systemic C-reactive protein level. J Periodontol 2001;72: 1221-7.

[14] Kanaparthy A, Kanaparthy R, Niranjan N. Evaluation of serum C-reactive protein levels in subjects with aggressive and chronic periodontitis and comparison with healthy controls. Dent Res J 2012;9:261-5.

[15] Desvarieux M, Demmer R, Rundek T, Boden-Albala B, David JR, Papapanou PN, et al. Relationship between periodontal disease, tooth loss, and carotid artery plaque. The oral infections and vascular disease epidemiol Study (INVEST). Stroke 2003;34:2120-5.

[16] Joshipura JK, Hung HH, Rimm EB, Wilett WC, Ascherio A. Periodontal disease, tooth loss, and incidence of ischemic stroke. Stroke 2003;34:47-52.

[17] Grau AJ, Becher H, Ziegler M, Lichy C, Buggle F, Kaiser C, et al. Periodontal disease as a risk factor for ischemic stroke. Stroke 2004;35:496-501.

[18] Kinane D, Bouchard P. Periodontal disease and health: Consensus Report of the Sixth European Workshop on Periodontology. J Clin Periodontol 2008;35:333-7.

[19] Jimenez M, Krall EA, Garcia RI, Vokonas PS, Dietrich T. Periodontitis and incidence of cerebrovascular disease in men. Ann Neurol 2009;66:505-12

[20] Kim HD, Sim SJ, Moon JY, Hong YC, Han DH. Associations between periodontitis and haemorrhagic stroke among Koreans: A case control study. J Periodontol 2010;81:658-65.

[21] Pradeep AR, Hadge P, Arjun Raju P, Shetty SR, Shareef K, Guruprasad CN. Periodontitis as a risk factor for cerebrovascular accident: A case control study in the Indian population. J Periodontal Res 2010;45:223-8.

[22] Pussinen PJ, Jauhiainen $M$, Vilkuna-Rautiainen $T$, Sundvall J, Vesanen M, Mattila $\mathrm{K}$, et al. Periodontitis decreases the antiatherogenic potency of high density lipoprotein. J Lipid Res 2004;45:139-47.

[23] Friedlander AH, Baker JD. Panoramic radiography; an aid in detecting patients at risk of cerebrovascular accident. Am Dent Assoc 1994;125:1598-603.

[24] Cohen S, Friedlander A, Jolly D, Date L. Carotid calcification on panoramic radiographs: An important marker for vascular risk. Oral Surg Oral Med Oral Pathol Oral Radiol Endo 2002; 94:510-14.

[25] Persson RE, Hollender LG, Powell VL, MacEntee $M$ Wyatt CC, Kiyak HA. Assessment of periodontal conditions and systemic disease in older subjects II focus on cardiovascular diseases. J Clin Periodontol 2002;29:803-10.

[26] Kumagai M, Yamagishi T, Fukui N, Chiba M. Carotid artery calcifications seen on panoramic dental radiographs in the Asian population in Japan. Dentomaxillofac Radiol 2007;36: 92-6.

[27] Tanaka T, Morimoto Y, Ansai T, Okabe S, Yamada K, Taguchi A, et al. Can the presence of carotid artery calcification on panoramic radiographs predict the risk of vascular diseases among 80-year olds? Oral Surg Oral Med Oral Pathol Oral Radiol Endod 2006;101:777-83.

[28] Ravon NA, Hollender LG, McDonald V, Persson GR. Signs of carotid calcification from dental panoramic radiographs are in agreement with Doppler sonography results. J Clin Periodontol 2003;35:277-90.

[29] Persson RE, Kiyak AH, Wyatt CC, MacEntee M, Persson GR. Smoking a weak predictor of periodontitis in older adults. J ClinPeriodontol 2005;32:512-17.

[30] Beckström BW, Horsley SH, Scheetz JP, Khan Z, Silveira AM, Clark SJ, et al. Correlation between carotid area calcifications and periodontitis: A retrospective study of digital panoramic radiographic finding in pre-treatment cancer patients. Surg Oral Med Oral Pathol Oral Radiol Endod 2007;103:359-66.

[31] Christou P, Leemann B, Scimmel M, Kiliaridis S, Müller F. Carotid artery calcification in ischemic stroke patients detected in a standard dental panoramic radiographs a preliminary study. Adv Med Sci 2010;55:26-31.

[32] Friedlander AH, Sung EC, Chung EM, Garrett NR. Radiographic quantification of chronic dental infection and its relationship to the atherosclerotic process in the carotid arteries. Oral Surg Oral Med Oral Pathol Oral Radiol Endod 2010; 109:615-21.

[33] Wallin Bengtsson V, Persson RG, Renvert S. Assessment of carotid calcifications on panoramic radiographs in relation to other used methods and relationship to periodontitis and stroke: A literature review. Acta Odontol Scand 2014;72: 401-12.

[34] Fagerström C, Palmqvist R, Carlsson J, Hellström Y. Malnutrition and cognitive impairment among people 60 years of age and above living in regular housing and in special housing in Sweden: A population-based cohort study. Int J Nurs 2011; 48:863-71.

[35] Persson GR, Berglund J, Persson RE, Renvert S. Prediction of hip and hand fractures in older persons with or without a diagnosis of periodontitis. Bone 2011;48:552-6.

[36] Lindström V, Andersson K, Lintrup M, Holst G, Berglund J. Prevalence of sleep problems and pain among the elderly in Sweden. J Nutr Health and Aging 2012;16:180-3.

[37] Hugoson A, Laurell L, Lundgren D. Frequency distribution of individuals aged 20-70 years according to severity of periodontal disease experience in 1973 and 1983. J Clin Periodontol 1992;19:227-32.

[38] Albandar JM. Periodontal diseases in North America. Periodontol 2000 29:31-69.

[39] Kassebaum NJ, Bernabé E, Dahiya M, Bhandari B, Murray CJL, Marcenes W. Global burden of severe 
120 V. W. Bengtsson et al.

periodontitis in 1990-2010: A systematic review and metaregression. J Dent Res 2014;93:1045-53.

[40] Eke PI, Dye BA, Wei L, Thornton-Evans GO, Genco RJ Prevalence of periodontitis in adults in the United States: 2009 and 2010. J Dent Res 2012;91:914-20.

[41] Åkesson L, Rohlin M, Håkansson J, Håkansson $\mathrm{H}$, Näsström K. Comparison between panoramic and posterior bitewing radiography in the diagnosis of periodontal bone loss. J Dent 1989;17:266-71.

[42] Persson RE, Tzannetou S, Feloutzis AG, Brägger U, Persson GR, Lang NP. Comparison between panoramic and intra-oral radiographs for the assessment of alveolar bone levels in a periodontal maintenance population. J Clin Periodontol 2003;30:833-9.
[43] Kingman A, Susin C, Albandar JM. Effect of partial recording protocols on severity estimates of periodontal disease. J Clin Periodontol 2008;35:659-67.

[44] Tiller R, Bengel W, Rinke S, Ziebolz D. Association between carotid area calcifications and periodontal risk: A cross sectional study of panoramic radiographic findings. BMC Cardiovasc Disord 2011;11:67.

[45] Kumagai M, Yamagishi T, Fukui N, Chiba M. Long-term cigarette smoking increases the prevalence of carotid artery calcification seen on panoramic dental radiographs in male patients. Tohoku J Exp Med 2007;212:21-5.

[46] Luker JA, Bernhardt J, Grimmer-Somers KA. Age and gender as predictors of allied health quality stroke care. J Multidiscip Healthc 2011;4:239-45. 
III 



\section{Carotid calcifications in panoramic radiographs are associated with future stroke or ischemic heart diseases: a long-term follow-up study}

Viveca Wallin Bengtsson ${ }^{1}$ (D) - G. Rutger Persson ${ }^{1,2,3} \cdot$ Johan Berglund $^{4} \cdot$ Stefan Renvert ${ }^{1,4,5}$

Received: 16 April 2018 / Accepted: 19 June 2018 / Published online: 2 July 2018

C) The Author(s) 2018

\section{Abstract}

Objective To assess if carotid calcifications detected in panoramic radiographs are associated with future events of stroke, and/or ischemic heart diseases over 10-13 years in individuals between 60 and 96 years.

Materials and methods Baseline (2001-2004) panoramic radiographs were assessed for evidence of carotid calcifications from individuals with no previous history of stroke and/or ischemic heart diseases. A radiopaque nodular mass adjacent to the cervical vertebrae, at or below the intervertebral space $\mathrm{C} 3-\mathrm{C} 4$, was interpreted as carotid calcification. Annual medical records were searched for ICD 10 codes through 2014.

Results Signs of carotid calcification was demonstrated in 238/635 (37.5\%) of the study individuals. Signs of carotid calcification was associated with future stroke and/or ischemic heart diseases $\left(\chi^{2}=9.1\right.$, OR 1.6, 95\% CI 1.2, 2.2, $\left.p<0.002\right)$. In individuals 60 72 years, a significant association between radiographic signs of carotid calcification and stroke and/or ischemic heart diseases $\left(\chi^{2}=12.4\right.$, OR 2.4, 95\% CI 1.5, 4.0, $p<0.000$ ) (adjusted for high blood pressure, diabetes type 2, BMI; OR 1.9, 95\% CI 1.1, 3.5, $p=0.03$ ). Individuals (60-72 years) with radiographic evidence of carotid calcifications had a mean cumulative stroke and/or ischemic heart diseases survival time of 12.1 years compared to those without such evidence (13.0 years) (log rank Mantel-Cox $\left.\chi^{2}=10.7, p=0.001\right)$.

Conclusions Evidence of carotid calcifications in panoramic radiographs is associated with an event of stroke and/or ischemic heart diseases in 60-96-year-old individuals.

Clinical relevance Radiographic evidence of carotid calcifications is associated with stroke and/or ischemic heart diseases. Patients with signs of carotid calcifications should therefore be referred for medical examination.

Keywords Carotid calcification $\cdot$ Panoramic radiographs $\cdot$ Stroke $\cdot$ Ischemic heart diseases

\section{Introduction}

Cardiovascular and/or cerebro-vascular diseases have been associated with atherosclerosis which is a consequence of progressive chronic inflammatory conditions [1]. Such diseases cause approximately $30 \%$ of human mortality [2]

Data suggest that over a 5-year period, plaque in the arterial vessels changes with decreasing fibrous and lipid tissue

Viveca Wallin Bengtsson
viveca.wallin_bengtsson@hkr.se
G. Rutger Persson
rutger.persson@hkr.se
Johan Berglund
johan.sanmartin.berglund@bth.se
Stefan Renvert

\footnotetext{
University of Kristianstad, Elmetorpsvägen 15, 291 88 Kristianstad, Sweden

2 Department of Periodontics, University of Washington, Seattle, WA, USA

Department of Oral Medicine, University of Washington, Seattle, WA, USA

4 Institute of Technology, Karlskrona, Sweden

Dublin Dental Hospital Trinity College, Dublin, Ireland
} 
composition, and with increasing calcifications through a heterogeneous but slow process [3]. Over time, an increase of carotid intima-media thickness, aortic calcifications, and carotid plaques has been identified as predictors of stroke [4-6].

Both invasive and noninvasive methods are currently used to assess the presence and extent of arterial calcifications [7]. Intravascular ultrasound and optical coherence tomography are examples of invasive diagnostic methods that may be the most predictable method in identifying an elevated risk for a stroke/cardiovascular event [8]. Doppler sonography (DS), computed tomography (CT), magnetic resonance imaging (MRI), and digital subtraction angiography are examples of noninvasive diagnostic methods to identify carotid calcifications $[9,10]$.

In dental practice, panoramic radiography is a frequently performed radiographic diagnostic method that can also be utilized to identify carotid artery calcifications when the area of the carotid artery bifurcates is visible [11-18]. Calcifications in the area of the carotid bifurcation are usually localized posterior and inferior to the mandibular angle adjacent to the space between the third or fourth cervical vertebrae (C3 and C4). Data suggest that calcification identified in panoramic radiographs can be identified in $3-15 \%$ of the adult population [11,19-21]. A high level of accuracy between signs of carotid calcifications diagnosed in panoramic radiographs and DS findings has been reported [18]. In a recent literature review, we concluded that signs of carotid calcifications are more frequently found in panoramic dental radiographs from older individuals [22].

Few studies have assessed the relationship between radiographic signs of carotid calcifications and future medical events, or studies especially assessing if signs of carotid calcifications are associated with future stroke or ischemic heart disease events $[12,13,23]$.

The aim of the present study was to assess if carotid calcifications detected in panoramic radiographs are associated with future events of stroke, and/or ischemic heart diseases over 10-13 years in individuals between 60 and 96 years.

\section{Material and methods}

\section{Description of study individuals}

The Ethics Committee Lund, Sweden, approved the study (file numbers 604/00 and 744/00). The study was conducted consistent with the principles of the Helsinki declarations. All study participants signed informed consent. The authors had access to the Swedish National Study of Ageingg and Care (SNAC) Blekinge database and take responsibility for the data integrity, and analysis. The data manager ensured the completeness of the research dataset.
The enrollment of study individuals occurred between 2001 and 2004 (baseline). The study participants were randomly selected from the Swedish population database from the metropolitan Karlskrona area (The Swedish Tax Agency electronic database). In order to represent the elderly population, individuals between ages 60 and 96 were enrolled. A randomized selection was made from the Swedish civil registration database in the age groups $60,66,72$, and 78 . In the age groups of 81,84 , and 87 (and older), all individuals in the community were invited. Study participants were invited by regular mail. The overall response rate was $62 \%$ representing approximately $10 \%$ of the entire population $\geq 60$ years of age. More individuals in the older age group declined participation compared to individuals in the younger age groups. All study participants were examined by medical and dental research teams at the research center in Karlskrona.

Baseline inclusion criteria were as follows: age between 60 and 96 years and living in the county of Karlskrona, Sweden, and with the completion of a comprehensive baseline medical/ dental examination. The study protocol required that, at baseline all study participants had a panoramic radiograph taken at the research clinic. Only those individuals with a panoramic radiograph from which the area of interest (the bifurcation area; intervertebral space at or below the $\mathrm{C} 3$ and $\mathrm{C} 4$ vertebrae) could be assessed. On an annual basis, the medical electronic database through 2014 or until the study individual either was lost to follow-up or had died was used for the collection of medical events. The data collection was focused on information about events of stroke or ischemic heart diseases for the respective year. The medical records of the 726 enrolled study participants were searched for conditions defined by the International Statistical Classification of Diseases and Related Health Problems, 10th revision (ICD-10).

\section{Examination of analogue panoramic radiographs}

At baseline (2001-2004), analogue panoramic radiographs using a standard exposure of $75 \mathrm{kV} / 10 \mathrm{~mA}$ were taken with an Orthopantomograph (OP 100, Instrumentarium, Tuusala, Finland). An example of a panoramic radiograph with the intervertebral space at or below the vertebrae C3-C4 visible and suitable for the assessment of the presence, or absence of a radiopaque nodular mass is presented (Fig. 1). An independent, experienced examiner [24] from the Department of Oral Medicine, School of Dentistry, University of Washington, Seattle, WA, USA, performed the radiographic measurements, with no information on medical conditions, age, or gender of the study participants. Reliability measurements in assessing evidence of carotid calcifications were performed. Reliability assessments of carotid calcifications were made from two different occasions through intraexaminer assessments of carotid calcification signs from 100 randomly selected 
Fig. 1 Panoramic radiograph using a standard exposure of $75 \mathrm{kV} / 10 \mathrm{~mA}$ and taken with an Orthopantomograph (OP 100, Instrumentarium, Tuusala,

Finland) with carotid calcification on the right side

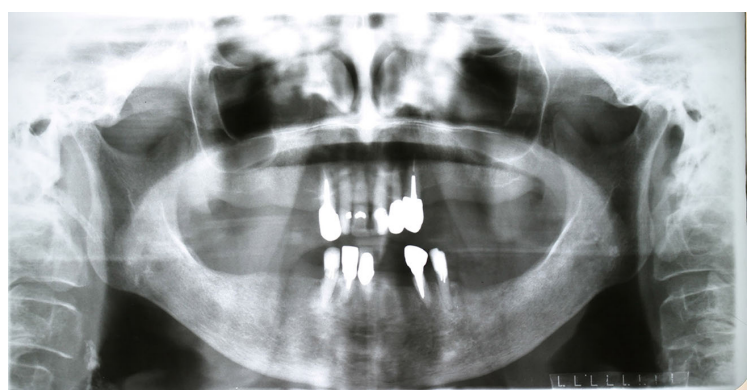

panoramic radiographs resulting in a Cronbach's alpha of 0.91 . The interval between the two sets of readings was approximately 1 year.

\section{Medical examinations}

Events of stroke (cerebrovascular diseases) or ischemic heart diseases (cardiovascular diseases) were registered according to the ICD 10 codes: ICD 60-69 for stroke and ICD 20-25 for ischemic heart diseases. This information was collected from the electronic medical database at the research center of the general hospital in Karlskrona, Sweden. Between 2001 and 2014, a physician (JB) reviewed the medical records annually for all individuals in the study.

\section{Statistical methods}

The data were analyzed using descriptive and inferential statistics. Because the data were assumed not to follow a normal distribution pattern, both independent $t$ tests (equal variance not assumed) and nonparametric tests (Mann-Whitney $U$ test) were also performed to assess group differences. Dichotomous data were analyzed using Pearson $\chi^{2}$ test, Mantel-Haenszel odds ratios. The data were also studied by binominal logistic regression. The Kaplan-Meier estimator (log rank Mantel-Cox) was used to study events of stroke and ischemic heart diseases in study individuals with or without radiographic evidence of carotid calcifications during the study period. Statistical significance was set with $\alpha$ at $p<$ 0.05 . The IBM SPSS version 23.0 statistical software package (SPSS Inc., Armonk, NY, USA) for Macintosh computer was used in the analyses.

\section{Results}

Demographic and medical data in $60,66,72$, and 78 years and older study participants are presented (Table 1 ). The younger age groups $(60,66$, and 72 years $)$ included 350 study participants. The older age groups $(78,81,84,87,90,93$, and 96 years) included 376 study participants. All study participants were Caucasians. During the study period (2001-2014), $66 / 350(18.9 \%)$ in the younger age group and $285 / 376$ $(75.8 \%)$ participants in the 78 age group had died.

The data on all study participants identified a significant association between carotid calcifications and a future event of stroke and/or ischemic heart diseases $\left(\chi^{2}=9.1\right.$, OR 1.6, $95 \%$ CI $1.2,2.2, p<0.002)$. In the younger age group, this association was more pronounced $\left(\chi^{2}=12.4\right.$, OR $2.4,95 \% \mathrm{CI}$ $1.5,4.0, p<0.000)$. In the younger age group, there was also a significant association between carotid calcifications and an event of stroke ( $\chi^{2}=4.5$, OR $2.3,95 \%$ CI $\left.0.9,6.2, p=0.03\right)$.

At the baseline examination, 91 individuals $(14.3 \%)$ of the total 726 individuals reported a history of stroke and/or ischemic heart diseases. Radiographic signs of carotid calcifications in panoramic radiographs were found in 45/91 (49.5\%) of the individuals with a known previous history of stroke and/ or ischemic heart disease. The gender distribution of such signs was $13 / 45(28.9 \%)$ in women and $32 / 45(71.1 \%)$ in men. The mean age of these 91 individuals at the time of examination was 68 years among $60-72$ years and the corresponding figure among 78-96 years was 81.8 years. Data reporting on future events of stroke or separately ischemic heart diseases or a combination of both on the remaining 635 individuals that reported no previous event of stroke and/or ischemic heart diseases are reported in subanalysis. The subanalysis are described in Tables 2, 3, and 4. Medical records between 2001 and 2014 identified events of stroke and/or ischemic heart diseases in 195/635 (30.7\%) of these study individuals (Table 1).

Men in the 60-72 years age group had a higher odds ratio (OR) for a stroke event than women (OR 3.1, 95\% CI 1.0, 8.3, $p=0.02)$. Statistical analysis, however, failed to demonstrate a gender difference for ischemic heart diseases (OR 1.3, 95\% CI $0.7,2.4, p=0.4)$. Data analysis also failed to demonstrate gender differences in the 78 and older age group for the 
Table 1 Summary of key characteristics for the study participants at baseline, distributed in two study groups

\begin{tabular}{|c|c|c|c|}
\hline & $\begin{array}{l}\text { Study individuals } \\
60-96 \text { years }\end{array}$ & $\begin{array}{l}\text { Study individuals } \\
60-72 \text { years }\end{array}$ & $\begin{array}{l}\text { Study individuals } \\
78-96 \text { years }\end{array}$ \\
\hline Number of study participants & 726 & 350 & 376 \\
\hline $\begin{array}{l}\text { Gender distribution } \\
\text { identifying \% women }\end{array}$ & $350 / 726(48.4 \%)$ & $230 / 350(65.7 \%)$ & $120 / 376(40.0 \%)$ \\
\hline $\begin{array}{l}\text { BMI (mean and SD, at } \\
\text { baseline) }\end{array}$ & $27.1 \pm 4.1$ & $27.5 \pm 4.4$ & $26.7 \pm 3.7$ \\
\hline $\begin{array}{l}\text { Hypertension (self-reported at } \\
\text { baseline) }\end{array}$ & $31.8 \%$ & $30.5 \%$ & $33.5 \%$ \\
\hline $\begin{array}{l}\text { Type } 2 \text { diabetes mellitus } \\
\text { (self-reported at baseline }\end{array}$ & $7.9 \%$ & $6.9 \%$ & $8.8 \%$ \\
\hline $\begin{array}{l}\text { An event of stroke and/or is- } \\
\text { chemic heart diseases dur- } \\
\text { ing the study period }\end{array}$ & $34.4 \%$ & $25.1 \%$ & $43.1 \%$ \\
\hline $\begin{array}{l}\text { An event of stroke during the } \\
\text { study period }\end{array}$ & $13.1 \%$ & $6.9 \%$ & $18.9 \%$ \\
\hline $\begin{array}{l}\text { An event of ischemic heart } \\
\text { diseases during the study } \\
\text { period }\end{array}$ & $23.4 \%$ & $18.9 \%$ & $27.7 \%$ \\
\hline $\begin{array}{l}\text { A first event of stroke and/or } \\
\text { ischemic heart diseases } \\
\text { during the study period in } \\
\text { individuals with no history } \\
\text { of stroke and/or ischemic } \\
\text { heart diseases (self-reported } \\
\text { at baseline) }\end{array}$ & $195 / 635(30.7 \%)$ & $66 / 316(20.9 \%)$ & $129 / 319(40.4 \%)$ \\
\hline $\begin{array}{l}\text { A first event of stroke during } \\
\text { the study period in } \\
\text { individuals with no history } \\
\text { of stroke (self-reported at } \\
\text { baseline) }\end{array}$ & $81 / 687(11.8 \%)$ & $17 / 331(5.1 \%)$ & $64 / 356(18 \%)$ \\
\hline $\begin{array}{l}\text { A first event of ischemic heart } \\
\text { diseases during the study } \\
\text { period in individuals with } \\
\text { no history of ischemic heart } \\
\text { diseases (self-reported at } \\
\text { baseline) }\end{array}$ & $145 / 666(21.8 \%)$ & $59 / 331(17.8 \%)$ & $86 / 335(25.7 \%)$ \\
\hline
\end{tabular}

$B M I$ body mass index

incidence of stroke (OR 1.0, 95\% CI 0.6, 1.8, $p=0.9$ ) or for the incidence of ischemic heart diseases (OR $1.4,95 \%$ CI 0.9 , $2.4, p=0.12$ ).

A positive finding of carotid calcification was demonstrated in 238/635 (37.5\%) of the study individuals. Carotid calcifications were more frequent in the older age group 135/319 $(42.3 \%)$ as compared to the $60-72$ age group $103 / 316(32.6 \%)$ ( $\chi^{2}=6.4$, OR $1.5,95 \%$ CI $\left.1.1,2.1, p=0.01\right)$. Independent of age, radiographic signs of carotid calcifications were more frequently identified in men $\left(\chi^{2}=11.1\right.$, OR $1.8,95 \%$ CI 1.3 , $2.5, p=0.001)$

In Table 2, data on the associations between signs of carotid calcifications in panoramic radiographs, gender, self-reported high blood pressure at baseline, type 2 diabetes, body mass index (BMI), smoking reported at baseline, and future events of stroke and ischemic heart diseases are presented for individuals without a previous history of the respectively event (stroke, ischemic heart diseases or stroke and/or ischemic heart diseases). The same information but in the 60-72 years is presented in Table 3. Logistic regression analysis of the results identified, in individuals 60-72 years, a significant association between carotid calcifications in panoramic radiographs and stroke and/or ischemic heart diseases, both crude and adjusted for confounders (high blood pressure, type 2 diabetes, BMI) (crude OR 2.4, 95\% CI 1.4, 4.1, $p=0.002$, and adjusted OR $1.9,95 \%$ CI 1.1, 3.5, $p=0.03$ ). A statistically significant crude association between radiographic evidence of carotid calcifications and a recorded diagnosis of ischemic heart diseases was also found in the younger age group (6072) (crude OR 2.1, 95\% CI 1.2, 3.7, $p=0.01$ ). This association was, however, not statistically significant when adjusted for confounders (high blood pressure, type 2 diabetes, BMI) (adjusted OR 1:7, 95\% CI $p=0.07$ ). When individuals 78 96 years were included in the analysis, only a history of high blood pressure was significantly associated with future stroke and/or ischemic heart diseases (Table 4).

We did not have data on cause of death available for analysis. It should, however, be highlighted that when analyzing 
Table 2 Associations between carotid calcifications, gender, high blood pressure, type 2 diabetes mellitus, BMI, smoking, and future events of stroke or ischemic heart diseases

\begin{tabular}{|c|c|c|c|}
\hline & $\begin{array}{l}\text { An event of stroke and/or ischemic } \\
\text { heart diseases }(N=635)\end{array}$ & Stroke $(N=687)$ & Ischemic heart diseases $(N=666)$ \\
\hline Carotid calcifications & $\begin{aligned} \chi^{2} & =7.0, \text { OR } 1.6,95 \% \text { CI } 1.2-2.2 \\
p & <0.008^{*}\end{aligned}$ & $\begin{aligned} \chi^{2} & =1.5, \text { OR } 1.3,95 \% \text { CI } 0.8-2.1 \\
p & =0.2\end{aligned}$ & $\begin{aligned} \chi^{2} & =4.6, \text { OR } 1.5,95 \% \text { CI } 1.0-2.2 \\
p & =0.03 *\end{aligned}$ \\
\hline Gender & $\begin{aligned} \chi^{2} & =4.8, \text { OR } 1.5,95 \% \text { CI } 1.0,2.1 \\
p & =0.03^{*}\end{aligned}$ & $\begin{aligned} \chi^{2} & =2.4, \text { OR } 1.4,95 \% \text { CI } 0.9-2.3 \\
p & =0.1\end{aligned}$ & $\begin{aligned} \chi^{2} & =3.1, \text { OR } 1.4,95 \% \text { CI } 1.0-2.1 \\
p & =0.08\end{aligned}$ \\
\hline High blood pressure & $\begin{array}{l}\chi^{2}=15.4, \text { OR } 2.0,95 \% \text { CI } 1.4-2.9, \\
\quad p=0.000^{*}\end{array}$ & $\begin{aligned} \chi^{2} & =2.7, \text { OR } 1.5,95 \% \text { CI } 0.9-2.5 \\
p & =0.1\end{aligned}$ & $\begin{array}{c}\chi^{2}=10.7, \text { OR } 1.9,95 \% \text { CI } 1.3-2.8, \\
p=0.001 *\end{array}$ \\
\hline Type 2 diabetes mellitus & $\begin{aligned} \chi^{2} & =2.7, \text { OR } 1.7,95 \% \text { CI } 0.9-3.2 \\
p & =0.1\end{aligned}$ & $\begin{array}{l}\chi^{2}=0.3, \text { OR } 1.3,95 \% \text { CI } 0.6-2.9 \\
\quad p=0.6\end{array}$ & $\begin{aligned} \chi^{2} & =1.6, \text { OR } 1.5,95 \% \text { CI } 0.8-2.9 \\
p & =0.2\end{aligned}$ \\
\hline BMI & Correlation coefficient $0.06, p=0.1$ & Correlation coefficient $-0.47, p \leq 0.2$ & Correlation coefficient $0.1, p=0.1$ \\
\hline Smoking & $\begin{aligned} \chi^{2} & =2.5, \text { OR } 0.6,95 \% \text { CI } 0.4-1.1 \\
p & =0.1\end{aligned}$ & $\begin{aligned} \chi^{2} & =0.9, \text { OR } 0.7,95 \% \text { CI } 0.3-1.5 \\
p & =0.3\end{aligned}$ & $\begin{aligned} \chi^{2} & =1.1, \text { OR } 0.7,95 \% \text { CI } 0.4-1.3 \\
\quad p & =0.3\end{aligned}$ \\
\hline
\end{tabular}

Self-reported at baseline: high blood pressure, Type 2 diabetes mellitus, smoking (yes = current and sometimes, no = never and former). BMI (body mass index) examined at baseline

radiographic signs of carotid calcifications among those who had died during the course of the study, $47.0 \%$ had positive signs of carotid calcifications compared to $31.2 \%$ in the material that were survivors. The OR of death before the endpoint of the study presenting with signs of carotid calcifications at baseline was 2.0 (95\% CI 1.4, 2.7, $p<0.001)$.

\section{Kaplan-Meier survival analysis}

Relationships between a positive/negative sign of carotid calcification and cumulative events of a first event of stroke and or a first event of ischemic heart diseases were illustrated by Kaplan-Meier survival analysis (Figs. 2 and 3). Study participants (60-72 years) with baseline radiographic evidence of carotid calcification and no previous history of an event had a mean cumulative stroke and/or ischemic heart diseases survival time of 12.1 years compared to those without such evidence (mean cumulative survival time 13.0 years) (log rank Mantel-Cox $\left.\chi^{2}=10.7, p=0.001\right)$. Individuals (60-72 years) with baseline radiographic evidence of carotid calcifications, and no history of an ischemic event, had a mean cumulative ischemic heart diseases survival time 12.5 years compared to those without such evidence (mean survival time was 13.2 years) (log rank Mantel-Cox $\chi^{2}=9.5, p=0.002$ ).

\section{Discussion}

The present long-term follow-up study demonstrated that in individuals between 60 and 72 years, radiographic signs of carotid calcifications were found in panoramic radiographs and associated with future events of stroke and/or ischemic

Table 3 Associations between carotid calcifications, gender, high blood pressure, type 2 diabetes mellitus, BMI, smoking, and future events of stroke or ischemic heart diseases in individuals $60-72$ years

\begin{tabular}{|c|c|c|c|}
\hline & $\begin{array}{l}\text { An event of stroke and/or ischemic } \\
\text { heart diseases }(N=316)\end{array}$ & Stroke $(N=331)$ & Ischemic heart diseases $(N=331)$ \\
\hline Carotid calcifications & $\begin{array}{l}\chi^{2}=9.6, \text { OR } 2.4,95 \% \text { CI } 1.44 .1 \\
\quad p<0.002 *\end{array}$ & $\begin{aligned} \chi^{2} & =3.0, \text { OR } 2.3,95 \% \text { CI } 0.9-6.2 \\
p & =0.08\end{aligned}$ & $\begin{aligned} \chi^{2} & =6.5, \text { OR } 2.1,95 \% \text { CI } 1.2-3.7 \\
p & =0.01^{*}\end{aligned}$ \\
\hline Gender & $\begin{aligned} \chi^{2} & =2.3, \text { OR } 1.5,95 \% \text { CI } 0.9-2.7, \\
p & =0.1\end{aligned}$ & $\begin{array}{c}\chi^{2}=5.3, \text { OR } 3.1,95 \% \text { CI } 1.1-8.3 \\
\quad p=0.02 *\end{array}$ & $\begin{aligned} \chi^{2}=0.8, \text { OR } 1.3,95 \% \text { CI } 0.7-2.4 \\
p<0.4^{*}\end{aligned}$ \\
\hline High blood pressure & $\begin{array}{c}\chi^{2}=7.8 \text { OR } 2.2,95 \% \text { CI } 1.3-4.0 \\
\quad p=0.005 \%\end{array}$ & $\begin{aligned} \chi^{2} & =1.4, \text { OR } 1.8,95 \% \text { CI } 0.7-4.9 \\
p & =0.2\end{aligned}$ & $\begin{array}{l}\chi^{2}=8.7, \text { OR } 2.4,95 \% \text { CI } 1.3-4.3 \\
\quad p=0.003^{*}\end{array}$ \\
\hline Type 2 diabetes mellitus & $\begin{aligned} \chi 2 & =6.4, \text { OR } 3.3,95 \% \text { CI } 2.6-8.8 \\
p & =0.01 *\end{aligned}$ & $\begin{aligned} \chi^{2} & =1.0, \text { OR } 2.2,95 \% \text { CI } 0.5-10.3 \\
p & =0.3\end{aligned}$ & $\begin{aligned} \chi^{2} & =4.3, \text { OR } 2.7,95 \% \text { CI } 1.0-7.0 \\
p & <0.04^{*}\end{aligned}$ \\
\hline BMI & Correlation coefficient $0.16, p=0.004^{*}$ & Correlation coefficient $-0.03, p=0.5$ & Correlation coefficient $0.17, p=0.002 *$ \\
\hline Smoking & $\begin{aligned} \chi^{2} & =0.7, \text { OR } 0.7,95 \% \text { CI } 0.3-1.6 \\
p & =0.4\end{aligned}$ & $\begin{aligned} \chi^{2} & =0.7, \text { OR } 1.6,95 \% \text { CI } 0.5-5.2 \\
p & =0.4\end{aligned}$ & $\begin{aligned} \chi^{2} & =0.6, \text { OR } 0.7,95 \% \text { CI } 0.3-1.6 \\
p & =0.4\end{aligned}$ \\
\hline
\end{tabular}

Self-reported at baseline: high blood pressure, type 2 diabetes mellitus, smoking (yes = current and sometimes, no = never and former). BMI (body mass index) examined at baseline 
Table 4 Associations between carotid calcifications, gender, high blood pressure, type 2 diabetes mellitus, BMI, smoking, and future events of stroke or ischemic heart diseases in individuals $78-96$ years

\begin{tabular}{|c|c|c|c|}
\hline & $\begin{array}{l}\text { An event of stroke and/or ischemic } \\
\text { heart diseases }(N=319)\end{array}$ & Stroke $(N=356)$ & Ischemic heart diseases $(N=335)$ \\
\hline Carotid calcifications & $\begin{aligned} \chi^{2} & =0.1, \text { OR } 1.1,95 \% \text { CI } 0.7-1.7 \\
p & =0.7\end{aligned}$ & $\begin{aligned} \chi^{2} & =0.008, \text { OR } 1.0,95 \% \text { CI } 0.6-1.7 \\
p & =0.9\end{aligned}$ & $\begin{aligned} \chi^{2} & =0.2, \text { OR } 1.1,95 \% \text { CI } 0.7-1.8 \\
p & =0.7\end{aligned}$ \\
\hline Gender & $\begin{aligned} \chi^{2} & =1.6, \text { OR } 1.3,95 \% \text { CI } 0.8-2.1 \\
p & =0.2\end{aligned}$ & $\begin{aligned} \chi^{2} & =0.02, \text { OR } 1.0,95 \% \text { CI } 0.6-1.8 \\
p & =0.9\end{aligned}$ & $\begin{aligned} \chi^{2} & =2.0, \text { OR } 1.4,95 \% \text { CI } 0.9-2.4 \\
p & =0.2\end{aligned}$ \\
\hline High blood pressure & $\begin{aligned} \chi 2 & =6.9, \text { OR } 1.9,95 \% \text { CI } 1.2-3.1 \\
p & =0.009 *\end{aligned}$ & $\begin{aligned} \chi^{2} & =1.1, \text { OR } 1.4,95 \% \text { CI } 0.8-2.6 \\
p & =0.9\end{aligned}$ & $\begin{aligned} \chi^{2} & =2.8, \text { OR, } 95 \% \text { CI } 0.9-2.6 \\
p & <0.1\end{aligned}$ \\
\hline Type 2 diabetes mellitus & $\begin{aligned} \chi^{2} & =0.004, \text { OR } 1.0,95 \% \text { CI } 0.4-2.2 \\
p & =1.0\end{aligned}$ & $\begin{aligned} \chi^{2} & =0.01, \text { OR } 0.9,95 \% \text { CI } 0.6-1.7 \\
p & =0.9\end{aligned}$ & $\begin{aligned} \chi^{2} & =0.009, \text { OR } 1.0,95 \% \text { CI } 0.4-2.3, \\
p & =0.9\end{aligned}$ \\
\hline BMI & Correlation coefficient $0.02, p=0.8$ & Correlation coefficient $-0.73, p<0.2$ & Correlation coefficient $0.06, p=0.3$ \\
\hline Smoking & $\begin{aligned} \chi^{2} & =0.005, \text { OR } 0.9,95 \% \text { CI } 0.4-2.3 \\
p & =0.8\end{aligned}$ & $\begin{aligned} \chi^{2} & =0.5, \text { OR } 0.6,95 \% \text { CI } 0.2-2.2 \\
p & <0.5\end{aligned}$ & $\begin{aligned} \chi^{2} & =0.02, \text { OR } 0.9,95 \% \text { CI } 0.3-2.6 \\
p & =0.9\end{aligned}$ \\
\hline
\end{tabular}

Self-reported at baseline: high blood pressure, type 2 diabetes mellitus, BMI, smoking (yes = current and sometimes no = never and former). BMI (body mass index) examined at baseline

heart diseases. The frequency of stroke and ischemic heart diseases also increased with age. The associations between carotid calcifications stroke and/or ischemic heart diseases or ischemic heart diseases alone were, however, not significant in the old age group (78-96 years). It is possible that several of the individuals in the older age group died from events of stroke and/or ischemic heart diseases. The number of stroke and/or ischemic heart diseases may therefore be underestimated especially in the older age group with the highest mortality rate.

Characteristics of the study participants (i.e., age, gender, BMI, hypertension, type 2 diabetes mellitus) in the present study (Table 1) suggested that many of the study participants presented with conditions partly explanatory to future risks of stroke and/or ischemic heart diseases. In the 60-72-year age group, a significant association between radiographic evidence of carotid calcifications and an event of stroke, and/or ischemic heart diseases also remained when adjusted for confounders (high blood pressure, type 2 diabetes, and BMI).

Several studies have previously demonstrated an association between carotid calcifications observed in panoramic radiographs and a history of stroke $[11,15,18,20,25$, 26]. There are few prospective studies that have examined if carotid calcifications detected in panoramic radiographs
Fig. 2 Kaplan-Meier curves of 316 individuals $60-72$ years old with no history of stroke and/or ischemic heart diseases, comparing individuals with and without carotid calcification Cumulative stroke and/or ischemic heart diseases survival in relation to the number of year before an event of stroke and/or ischemic heart diseases is estimating. $X$-axis: time to stroke in years. $Y$-axis: first event describing the percentage of the population with stroke at a certain time (year) from baseline

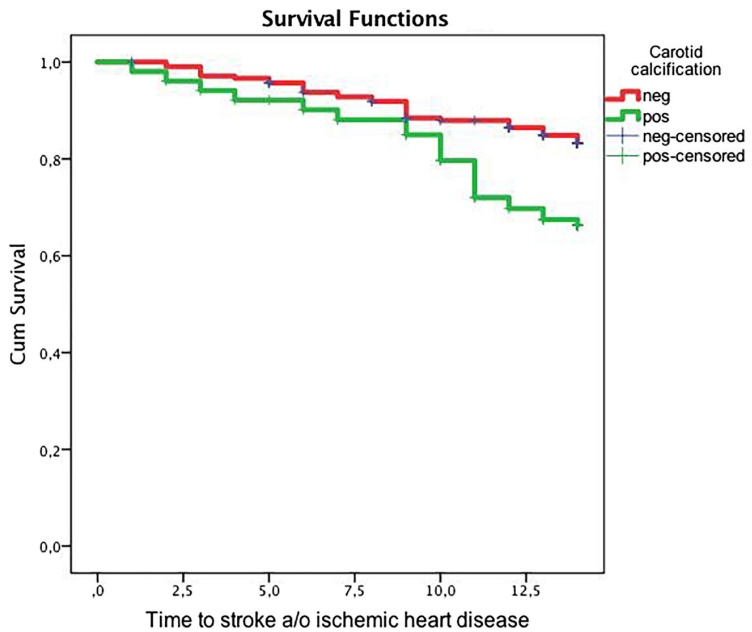


Fig. 3 Kaplan-Meier curves of 331 individuals $60-72$ years old with no history of ischemic hear diseases, comparing individuals with and without carotid

ischemic heart diseases survival

in relation to the number of years before an event of ischemic heart diseases is estimating. $X$-axis: time to ischemic heart diseases in years. $Y$-axis: first event

describing the percentage of the population with ischemic heart diseases at a certain time (year) from baseline

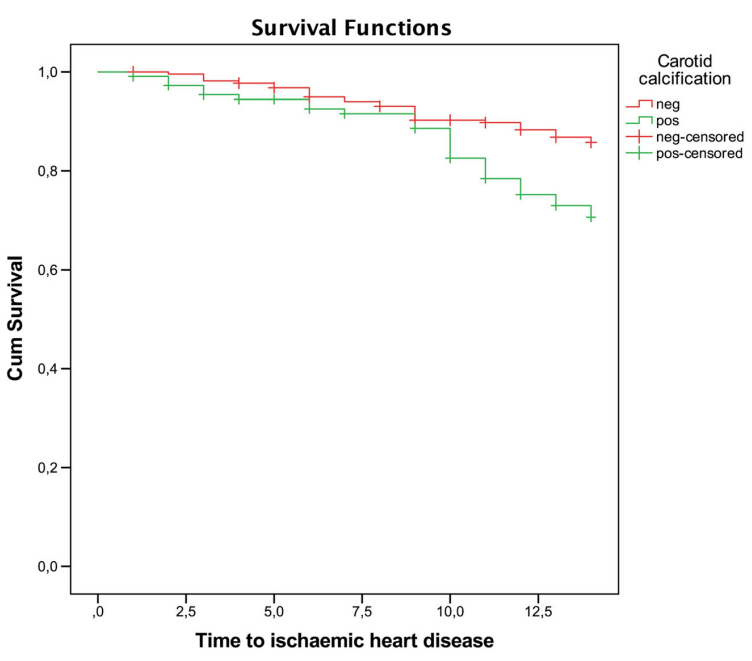

are associated with future diagnostic events of stroke and/or ischemic heart diseases $[6,13,23]$. To our best knowledge, the present study is the first study that has a long-time (> 10 years) follow-up period of cases $\geq 60$ years of age with/ without radiographic signs of carotid calcifications investigating medically diagnosed future stroke and/or ischemic heart diseases.

In two reports with a follow-up period of approximately 3 years, it was demonstrated that male veterans $>55$ years with signs of carotid calcifications identified in panoramic radiographs had a higher OR of events of myocardial infarction, stroke, TIA, revascularization, and angina than those without such signs $[13,23]$. Our data are also in accordance with a recent study over 5 years demonstrating that individuals with carotid calcifications in panoramic radiographs had a higher risk of future vascular events compared to controls [6].

The frequency of carotid calcifications in the present study is high. This is in agreement with previous reports and literature reviews demonstrating frequent findings of radiographic signs of carotid calcifications in older individuals [14, 15, 20, 21].

The present study identified a lower mean cumulative stroke and/or ischemic heart disease survival time, and a lower mean cumulative ischemic heart disease survival time, among individuals with a positive radiographic finding of carotid calcification. The survival time difference in comparison to those without such evidence of carotid calcifications in panoramic radiography was approximately 1 year, which must be considered clinically significant.
One shortcoming in the present study was that we were unable to search the records for the reasons of death among our study participants. The observation that the mortality rate for individuals with radiographic evidence of carotid calcifications was much higher than among individuals alive at the study endpoint is important. Information about cause of mortality could have contributed to a better understanding of the relationships between positive findings of carotid calcifications in panoramic radiographs and future events of stroke and/or ischemic heart diseases. However, among the 351 individuals that died during the course of the study, a diagnosis of stroke and/or ischemic heart diseases occurred in 155 individuals. In the remaining 196 individuals, carotid calcification was detected in $46.4 \%$.

To obtain panoramic radiographs suitable for the detection of carotid calcifications, it is important that the patient is placed in a correct position when the radiograph is taken. Otherwise, many cases may not be identified. Furthermore, atherosclerotic plaques can be either calcified or noncalcified [18], which is a limitation with a radiographic method of detection. Thus, the present study results are only based on radiographic findings suggesting the presence of calcified plaque. It is also possible that both positive and negative findings in panoramic radiographs may be misinterpreted by the examiner resulting in either a false positive or negative score. There is a risk for misinterpreting images similar to carotid calcifications representing, i.e., the hyoid bone, the epiglottis, calcified ligaments (stylomandibular and stylohoid), sialoliths, phleboliths, and calcified lymph nodes) [27-29]. 
To minimize this risk, it is important that the examiner of the radiographs has good knowledge of the anatomical structures and pathological conditions. In the present study, the examiner had a high degree of agreement between repeated readings of panoramic radiographs.

In the present study, only radiographs exposed at baseline were analyzed. Therefore, any new development of carotid calcifications during the course of study prior to a possible event would not have been recorded resulting in an underestimation of the association between carotid calcifications and recorded events of stroke and/or other ischemic heart diseases.

In dentistry, panoramic radiography is a common procedure performed to detect signs of oral diseases. Several studies have identified that it is possible to detect signs of carotid calcifications from such radiographs given that the region of interest is exposed. Radiographs, exposed for dental reasons, can be assessed for carotid calcifications. In order to evaluate panoramic radiographs for possible signs of carotid calcification, the dentist should be familiar with the anatomy of the region. It is also advisable to receive training by a radiologist to avoid potential misinterpretations. If a radiographic sign of carotid calcification is identified in a panoramic radiograph, the dentist should first consider other risk factors associated with stroke and ischemic heart diseases. It may also be advantageous to discuss the situation with a physician before a referral for further medical evaluation. Dental students should be given training in identifying radiographic signs in the area of interest.

In conclusion, data from the present study demonstrated that signs of carotid calcifications in panoramic radiographs are associated with future events of stroke and/or ischemic heart diseases, or ischemic heart diseases alone in older individuals and especially among individuals 60-72 years.

Acknowledgements The Ministry of Health and Social Affairs in Sweden and the participating county councils, municipalities and university departments supported the Swedish National study on Aging and Care (SNAC) (www. snac.org). We are grateful to the participants, and the participating counties and municipalities. We also acknowledge the contribution by Research Associate Professor Rigmor Persson (REP), University of Washington who assessed the radiographs. We also want to acknowledge Ms. Ingrid Jonasson, Blekinge Institute of Technology, Karlskrona, Sweden, who collected the clinical dental data, and Ms. Johanna Renvert, University of Kristianstad, for data management. This study was accomplished within the context of the "Swedish National Graduate School for Competitive Science on Aging and Health" (SWEAH) and funded by the Swedish Research Council.

Funding The Swedish National Study on Ageing and Care, SNAC (www.snac.org), is financially supported by the ministry of Health and Social Affairs, Sweden, and the participating county councils, municipalities, and university departments.

\section{Compliance with ethical standards}

Conflict of interest The authors declare that they have no conflict of interest.

Ethical approval All procedures performed in the study, involving human participants, were in accordance with the ethical standards of the regional research ethics committee and with the 1964 Helsinki declaration and its later amendments.

Informed consent Informed consent was obtained from all individual participants included in the study. Open Access This article is distributed under the terms of the Creative
Commons Attribution 4.0 International License (http:// creativecommons.org/licenses/by/4.0/), which permits unrestricted use, distribution, and reproduction in any medium, provided you give appropriate credit to the original author(s) and the source, provide a link to the Creative Commons license, and indicate if changes were made.

\section{References}

1. Cheng C, Tempel D, van Haperen R, van der Baan A, Grosveld F, Daemen MJ, Krams R, de Crom R (2006) Atherosclerotic lesion size and vulnerability are determined by patters of fluid shear stress. Circulation 113:2744-2753

2. Minino AM, Murphy SL, Xu J, Kochanek KD (2011) Deaths: final data for 2008. Natl Vital Stat Rep 59:1-126

3. van Gils MJ, Vukadinovic D, van Dijk AC, Dippel DW, Niessen WJ, van der Lugt A (2012) Carotid atherosclerotic plaque progression and change in plaque composition over time: a 5-year followup study using serial CT angiography. AJNR Am J Neuroradiol 33(7):1267-1273

4. Esposito-Bauer L, Saam T, Ghodrati I, Pelisek J, Heider P, Bauer M, Wolf P, Bockelbrink A, Feurer R, Sepp D, Winkler C, Zepper P, Boeckh-Behrens T, Riemenschneider M, Hemmer B, Poppert H (2013) MRI plaque imaging detects carotid plaques with a high risk for future cerebrovascular events in asymptomatic patients. PLoS One 24(8):7, 67927

5. Hollander M, Hak AE, Koudstaal PJ, Bots ML, Grobbee DE, Hofman A, Witteman JC, Breteler MM (2003) Comparison between measures of atherosclerosis and risk of stroke: the Rotterdam study. Stroke 34:2367-2373

6. Johansson E, Ahlqvist J, Garoff M, Levring Jäghagen E, Meimermondt A, Wester P (2015) Carotid calcifications on panoramic radiographs: a 5-year follow-up study. Oral Surg Oral Med Oral Pathol Oral Radiol 120(4):513-520

7. Bos D, Leening MJ, Kavousi M, Hofman A, Franco OH, van der Lugt A, Vernooij MW, Ikram MA (2015) Comparison of atherosclerotic calcification in major vessel beds on the risk of all-cause and cause-specific mortality: the Rotterdam study. Circ Cardiovasc Imaging 8(12):e003843

8. Denzel C, Lell M, Maak M, Höckl M, Balzer K, Müller KM, Fellner C, Fellner FA, Lang W (2004) Carotid artery calcium: accuracy of a calcium score by computed tomography-an in vitro study with comparison to sonography and histology. Eur J Vasc Endovasc Surg 28(2):214-220

9. Huibers A, de Borst GJ, Wan S, Kennedy F, Giannopoulos A, Moll FL, Richards T (2015) Non-invasive carotid artery imaging to identify the vulnerable plaque: current status and future goals. Eur $\mathrm{J}$ Vasc Endovasc Surg 50(5):563-572 
10. Langlois Y, Roederer GO, Chan A, Phillips DJ, Beach KW, Martin D, Chikos PM, Strandness DE Jr.(1983) Evaluating carotid artery disease. The concordance between pulsed Doppler/spectrum analysis and angiography. Ultrasound Med Biol 9(1):51-63

11. Friedlander AH, Baker JD (1994) Panoramic radiography; an aid in detecting patients at risk of cerebrovascular accident. Am Dent Assoc 125:1598-1603

12. Friedlander AH, El Saden SM, Hazboun RC, Chang TI, Wong WK, Garrett NR (2015) Detection of carotid artery calcification on the panoramic images of post-menopausal females is significantly associated with severe abdominal aortic calcification: a risk indicator of future adverse vascular events. Dentomaxillofac Radiol 44(7):20150094

13. Cohen S, Friedlander A, Jolly D, Date L (2002) Carotid calcification on panoramic radiographs: an important marker for vascular risk. Oral Surg Oral Med Oral Pathol Oral Radiol Endod 94:510-514

14. Persson RE, Hollender LG, Powell VL, MacEntee M, Wyatt CC Kiyak HA, Persson GR (2002) Assessment of periodontal conditions and systemic disease in older subjects II focus on cardiovascular diseases. J Clin Periodontol 29:803-810

15. Kumagai M, Yamagishi T, Fukui N, Chiba M (2007) Carotid artery calcifications seen on panoramic dental radiographs in the Asian population in Japan. Dentomaxillofacial Radiology 36:92-96

16. Tanaka T, Morimoto Y, Ansai T, Okabe S, Yamada K, Taguch A, Awano S, Kito S, Takata Y, Takehara T, Ohba T (2006) Can the presence of carotid artery calcification on panoramic radiographs predict the risk of vascular diseases among 80-year olds? Oral Surg Oral Med Oral Pathol Oral Radiol Endod 101(6):777-783

17. Lee JS, Kim OS, Chung HJ, Kim YJ, Kweon SS, Lee YH, Shin MH, Yoon SJ (2014) The correlation of carotid artery calcification on panoramic radiographs and determination of carotid artery atherosclerosis with ultrasonography. Oral Surg Oral Med Oral Pathol Oral Radiol 118(6):739-745

18. Ravon NA, Hollender LG, McDonald V, Persson GR (2003) Signs of carotid calcification from dental panoramic radiographs are in agreement with Doppler sonography results. J Clin Periodontol 30(12):1084-1090

19. Johansson EP, Ahlqvist J, Garoff M, Karp K, Jäghagen EL, Wester P $(2011,2011)$ Ultrasound screening for asymptomatic carotid stenosis in subjects with calcifications in the area of the carotid arteries on panoramic radiographs: a cross-sectional study. BMC Cardiovasc Disord 11:44

20. Carter LC, Haller AD, Nadarajah V, Calamel AD, Aguirre A (1997, 1997) Use of panoramic radiography among an ambulatory dental population to detect patients at risk of stroke. J Am Dent Assoc 128(7):977-984

21. Ohba T, Takata Y, Ansai T, Morimoto Y, Tanaka T, Kito S, Awano S, Akifusa S, Takehara T (2003) Evaluation of calcified carotid artery atheromas detected by panoramic radiograph among 80 year-olds. Oral Surg Oral Med Oral Pathol Oral Radiol Endod 96(5):647-650

22. Bengtsson VW, Persson GR, Renvert S (2014) Assessment of carotid calcifications on panoramic radiographs in relation to other used methods and relationship to periodontitis and stroke: a literature review. Acta OdontScand 72(6):401-412

23. Friedlander AH, Cohen SN (2007) Panoramic radiographic atheromas portend adverse vascular events. Oral Surg Oral Med Oral Pathol Oral Radiol Endod 103(6):830-835

24. Persson RE, Hollender LG, Powell VL, MacEntee M, Wyatt CC, Kiyak HA, Persson GR (2002) Assessment of periodontal conditions and systemic disease in older subjects. II. Focus on cardiovascular diseases. J Clin Periodontol 29(9):803-810

25. Lewis DA, Brooks SL (1999) Cartoid artery calcification in a general dental population: a retrospective study of panoramic radiographs. Gen Dent 47(1):98-103

26. Christou P, Leemann B, Scimmel M, Kiliaridis S, Müller F (2010) Carotid artery calcification in ischemic stroke patients detected in a standard dental panoramic radiographs a preliminary study. Adv Med Sci 55:26-31

27. Almog DM, Tsimidis K, Moss ME, Gottilieb RH, Carter LC (2000) Evaluation of a training program for detection of carotid artery calcifications on panoramic radiographs. Oral Surg Oral Med Oral Pathol Oral Radiol Endod 90:111-117

28. Carter LC (2000) Discrimination between calcified triticeous cartilage and calcified carotid atheroma on panoramic radiography. Oral Surg Oral Med Oral Pathol Oral Radiol Endod 90:108-110

29. Kamikawa RS, Fenyo-Pereira M, Fernandes A, Meurer MT (2006) Study of the localization of radiopacities similar to calcified carotid atheroma by means of panoramic radiography. Oral Surg Oral Med Oral Pathol Oral Radiol Endod 101:374-378 



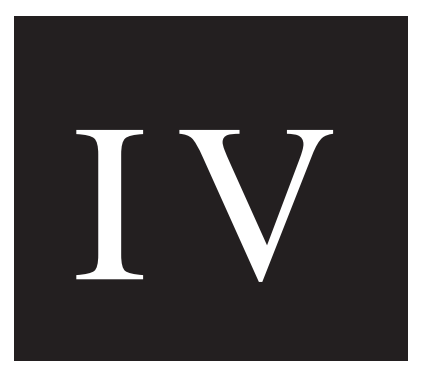



DR. VIVECA WALLIN BENGTSSON (Orcid ID : 0000-0002-8092-665X)

PROF. RUTGER PERSSON (Orcid ID : 0000-0002-3620-5978)

PROF. JOHAN SANMARTIN BERGLUNDH (Orcid ID : 0000-0003-4312-2246)

PROF. STEFAN RENVERT (Orcid ID : 0000-0003-0992-2362)

Article type : Original Article Clinical Periodontology

\section{Periodontitis related to cardiovascular events and mortality, a} long-time longitudinal study

Viveca Wallin Bengtsson DDS, Senior Periodontist ${ }^{1}$, G. Rutger Persson DDS, PhD,

Professor ${ }^{123}$, Johan Sanmartin Berglund MD, PhD, Professor 4,5, Stefan Renvert 4,1,6,7 DDS, PhD, Professor

${ }^{1}$ University of Kristianstad, Kristianstad, Sweden

${ }^{2}$ Department of Periodontics, University of Washington, Seattle, WA, USA

${ }^{3}$ Departments of Periodontics and Oral Medicine, University of Washington, Seattle, WA, USA

${ }^{4}$ Department of Health, Blekinge Institute of Technology, Karlskrona, Sweden

${ }^{5}$ Department of Clinical Sciences, Lund University, Lund, Sweden

${ }^{6}$ Dublin Dental Hospital Trinity College, Dublin, Ireland

${ }^{7}$ Faculty of Dentistry, The University of Hong Kong, Hong Kong SAR, China

Correspondence to Dr Viveca Wallin Bengtsson University of Kristianstad Elmetorpsvägen 15, 29188 Kristianstad, Sweden. Phone: 0046723093606. 
Mail to: viveca.wallin_bengtsson@hkr.se

Running title: Periodontitis related to cardiovascular events and mortality, a long time longitudinal study

Keyword: Periodontitis, cardiovascular events, mortality, longitudinal study

Acknowledgement The Ministry of Health and Social Affairs, Sweden, the participating county councils, municipalities and university departments, the Swedish National study on Aging and Care (SNAC) (www. snac.org) supported the study. The study was also supported by the Research Foundation at Kristianstad University, Sweden. The sponsors had no role in any aspect of the study design or reporting of findings.

We also acknowledge the contribution by Associate Professor Rigmor Persson (REP), University of Washington who analyzed the radiographs. We also want to acknowledge Ms. Ingrid Jonasson, Blekinge Institute of Technology, Karlskrona, Sweden, who collected the clinical dental data, and Ms. Johanna Renvert, University of Kristianstad, for data management. We are specifically grateful to the study participants. The study was accomplished within the context of the Swedish National Graduate School for Competitive Science on Aging and Health (SWEAH) and funded by the Swedish Research Council. 
Conflict of interest: none.

\begin{abstract}
Aims: The present study aimed to assess if individuals $\geq 60$ years of age with periodontitis are more likely to develop stroke, or ischemic heart diseases, or at higher risk of death over a period of 17 years.
\end{abstract}

Material and methods: At baseline, individuals $\geq 60$ received a dental examination including a panoramic radiograph. Periodontitis was defined as having $\geq 30 \%$ sites with $\geq 5 \mathrm{~mm}$ distance from cemento-enamel junction to the marginal bone level. Medical records were annually reviewed from 2001-2018. Findings from the medical records identifying an ICD10 code (stroke and ischemic heart diseases), or death was registered.

Results: Associations between periodontitis and incidence of ischemic heart disease was found in this 17-years follow-up study in all individuals 60-93 years (HR:1.5, CI:1.1-2.1, $\mathrm{p}=0.017$ ), in women (HR:2.1, CI:1.3-3.4, p=0.002), and in individuals 78-96 years (HR:1.7, CI:1.0-2.6, $\mathrm{p}=0.033$ ). Periodontitis was associated with mortality in all individuals (HR:1.4, CI:1.2-1.8, $\mathrm{p}=0.002)$, specifically in men (HR:1.5, CI:1.1-1.9, p=0.006) or in ages 60-72 years (HR:2.2, CI:1.5-3.2, $\mathrm{p}=0.000)$. Periodontitis was more prevalent among men (OR: 1.8, CI:1.3-2.4, $\mathrm{p}=0.000$ ).

Conclusions: Individuals with periodontitis have an increased risk for future events of ischemic heart diseases and to die. 


\section{Clinical relevance}

Scientific rationale for the study: Cross sectionally associations between periodontitis and cardiovascular diseases are well known. Understanding of the impact of periodontal disease, on the incidence of cardiovascular diseases over time, among older adults, is limited.

Principal findings: This study demonstrated that in a group of older adults in Sweden, periodontitis was a statistical risk indicator for ischemic heart diseases. Over the time studied, periodontitis was significantly associated with mortality.

Practical implications: Improving periodontal health in older individuals may reduce overall mortality and ischemic heart diseases. Both dental and medical professionals should be aware of the associations, and in best case cooperate, as periodontitis increase the risk for ischemic heart diseases and mortality. 


\section{Introduction}

Periodontitis is a chronic disease with an infectious etiology, and with an inflammatory response resulting in breakdown of soft and hard tissues around teeth (Bartold \& van Dyke, 2013). Severe periodontitis has been identified as the sixth most prevalent disease in the world (Kassebaum et al., 2014). In the US, the prevalence of periodontitis is reported to be $47 \%$ (Eke, Dye, Wei, Thornton-Evans, \& Genco, 2012). In older individuals, it is even more prevalent (Eke et al., 2016).

Periodontal infections may cause bacteremia triggering host systemic inflammatory responses and chronic inflammation and related to the pathogenesis of atherosclerosis (Aoyama et al., 2017). Data suggest that periodontitis is associated with subclinical atherosclerosis (Desvarieux et al., 2003; Lockhart et al., 2012; Söder, Söder, Nowak, \& Jogestrand, 2005). Atherosclerosis is considered the leading cause of cardiovascular diseases (CVDs) (Desvarieux et al., 2003; Lockhart et al., 2012). CVDs are the most common causes of death in the US (Roth et al., 2018). Periodontitis shares many risk indicators with CVDs, including age, male gender, hypertension, diabetes, high body mass index (BMI). Having the same risk indicators may constitute confounding factors for both periodontitis and CVDs (Lockhart et al., 2012).

CVDs include all diseases associated with the heart and blood vessels, such as stroke, coronary heart disease, and heart failure (Waters, Trinh, Chau, Bourchier, \& Moon, 2013). Overall, there is consistent and relatively stable epidemiologic evidence linking periodontitis to CVDs and periodontitis is generally accepted as a CVD risk indicator. The majority of 
studies assessing associations between periodontitis and CVDs are cross-sectional cohort or case-control studies (Desvarieux et al., 2003; Lockhart et al., 2012, Tonetti, \& Van Dyke, 2013). Few studies with a prospective longitudinal study design have been reported.

The present study aimed to assess if individuals $\geq 60$ years of age with periodontitis are more likely to develop stroke, or ischemic heart diseases, or at higher risk of death over a period of 17 years.

\section{Material and Methods}

\section{Study individuals}

The study individuals were selected by inclusion criteria from the Swedish National Study of Aging and Care (SNAC). SNAC is a population based, prospective longitudinal study in which SNAC-Blekinge is one participating research center. At the baseline in 2001-2003, an equal number of study individuals in age cohorts of $60,66,72$, and 78 were randomly selected from the Swedish population database for Karlskrona city (The Swedish Tax Agency electronic database) and were invited by regular mail. All individuals in the community at age $81,84,87,90,93$ and 96 years were also invited to participate, representing the older population in Karlskrona, Sweden. In total, 1402 individuals agreed to participate. All participants signed informed consent. The principles of the Helsinki declarations were followed. The Ethics Committee Lund, Sweden approved the study (LU 604-00, LU 744-00). Baseline inclusion criteria were; (I) age between 60-96 years and living in the community of Karlskrona, Sweden, (II) dentate, with one or more teeth. Exclusion criteria were; (I) nonreadable panoramic radiographs. 
Medical and dental research teams at a research center in Karlskrona, Sweden examined the study participants. The overall response rate was $62 \%$, representing approximately $10 \%$ of the entire population $\geq 60$ years of age in the community.

\section{Radiographic measurement}

An analogue panoramic radiograph using a standard exposure of $75 \mathrm{kV} / 10 \mathrm{~mA}$ was obtained using an Orthopantomograph (OP 100, Instrumentarium, Tuusala, Finland, film Kodak T-Mat G/RA, intensifying screen Kodak Lanex Regular, film processor Durr XR 24). The radiographic measurements were made from the panoramic radiographs exposed at baseline between 2001 and 2003. Thus, 858 readable panoramic radiographs were identified with a minimum of 1 tooth and were included in the study.

An independent, experienced examiner (REP) performed the radiographic measurements. The examiner was masked to medical conditions, gender, age, and survival status of the study individuals. Bone loss was measured, based on the number of readable interproximal sites, as percent loss of bone from the enamel cement junction (CEJ) to the highest marginal bone level on the mesial and distal surface of each tooth. Alveolar bone-loss $\geq 5 \mathrm{~mm}$ distance from CEJ to marginal bone level on $\geq 30 \%$ of sites was used as definition of periodontitis. Intraclass coefficient (ICC) analysis between randomly selected cases for double assessments regarding the reproducibility of the distance between CEJ to the apex was 0.93 (95\% CI: 0.91$0.96, \mathrm{p}<0.01$ ) between the first and second reading. 


\section{Medical examination}

Cerebrovascular diseases (stroke) and ischemic heart diseases were registered from an electronic medical database at the research center of the general hospital in Karlskrona, and in accordance with the International Statistical Classification of Diseases and Related Health Problems $10^{\text {th }}$ revision ICD 10 codes (ICD-10): ICD I60-69 for stroke and ICD I20-25 for ischemic heart diseases. A physician (JB) annually reviewed the medical database, including all medical records between 2001-2018, assessing medical records of the participating individuals in the 17 years period following the baseline examination. Any findings from the medical records identifying an ICD10 code were identified as a positive finding. Death or the first event of a stroke or ischemic heart disease was recorded as an event. Information on hypertension, body mass index (BMI), diabetes type 2 or smoking was identified from selfreported questionnaire on medical history at baseline, with focus on a history of stroke or a history of acute myocardial infarction (AMI). Smoking included both current and former smoking versus non-smoking included only those individuals with no current nor former history of smoking.

\section{Statistics}

The Statistical Package for the Social Sciences (SPSS) Predictive Analytics Software (PASW) 25.0 statistical software package (SPSS Inc., Armonk, NY, USA) for Personal Computer (PC) was used in the analyses. The data were analyzed using descriptive and inferential statistics. Dichotomous data were analyzed using the Pearson $\chi 2$ test, and by Mantel-Haenszel common odds ratio. Survival statistics with Cox regression analysis, method enter, was used to study adjusted associations. Multivariable adjustment was done for age, body mass index (BMI) $>30$, diagnosis of diabetes mellitus type 2 , gender, hypertension, history of acute myocardial 
infarction (AMI), history of stroke, periodontitis and smoking. Proportional hazards assumption was evaluated graphically with "log-log" plots. Time was defined as months from inclusion (dental examination) to either stroke, respectively ischemic heart diseases or death outcome or censoring due to emigration, death or end of follow-up. Statistical significance was declared at $\mathrm{p}<0.05$.

\section{Results}

\section{Demographic data}

Data derived from 858 individuals (women 53.5\%). During the 17 year follow-up period 492/858 (57.3\%) died, and 51/858 (5.9\%) moved away. The ages at baseline varied between 60-93 years with a median age 72.0 years (SD: \pm 9.3 ) years. On average, the individuals had 18.6 remaining teeth (SD: \pm 7.5 ). Approximately half of the individuals $428 / 838(51.1 \%)$ reported that they did not, or had never smoked. At the baseline examination, periodontitis was declared in 212/858 (24.7\%) (Table 1). Men had a higher prevalence of periodontitis than women, 121/212 (57.1\%) (OR: 1.8, CI:1.3-2.4, p=0.000). Dividing the individuals into a young- old (YO) 60-72 years age group, and an old- old (OO) 78-96 years age group, included 471/858 (54.9\%) respectively 387/858 (45.1\%) individuals.

\section{Periodontitis and incidence of ischemic heart diseases or stroke during the follow-up period}

The cumulative incidence of ischemic heart diseases between 2001-2018, was 203/858 (23.7

\%), with men 102/203 (50.2\%) and women 101/203 (49.8\%) (OR:1.2, CI:0.9-1.7, p=0.221). 
The incidence of ischemic heart diseases was 57.2 incidences per year and 6668 per 100000 and year. The cumulative incidence of stroke, was 118/858 (13.8\%), almost equal men respectively women developed stroke 60/118 (50.8\%) respectively 58/118 (49.2\%) (OR:1.2, CI:0.8-1.8, p=0.308). Stroke incidence was 24.86 per year, which corresponds to 2898 strokes per 100000 persons and year.

Cox regression analysis with periodontitis as an independent variable and incidence of a first event of stroke or ischemic heart diseases as the dependent variable and with adjustment for the following variables: age group, $\mathrm{BMI} \geq 30$, diabetes type 2 , gender, hypertension, history of acute myocardial infarction, history of stroke, and smoking was used. Periodontitis increased the risk for ischemic heart diseases in all individuals (HR:1.5, CI:1.1-2.1, p=0.017) (Figure 1), in women (HR:2.1, CI:1.3-3.4, p=0.002) and in the OO group (HR:1.7, CI:1.0-2.6, $\mathrm{p}=0.033$ ) (Table 2). Concerning associations between periodontitis and stroke, no significant association was identified in neither all individuals, women, men, YO nor OO (Table 3).

\section{Associations to mortality during the follow up period}

Data on the cause of death was not available, but during the 17-year follow up period 492/858 (57.3\%) had died. Among those who had died, 160/492 (32.5\%) had periodontitis whereas among those who were alive 52/366 (14.2\%) had periodontitis (OR:2.9, CI:2.1-41.1, $\mathrm{p}=0.000$ ). Cox regression analysis with periodontitis as the independent variable and mortality as the dependent variable and with adjustment for the following variables: age group, BMI $\geq$ 30, diabetes type 2, gender, hypertension, history of acute myocardial infarction (AMI), history of stroke and smoking was used. Periodontitis increased the risk for all cause mortality 
in all individuals (HR:1.4, CI:1.2-1.8, p=0.002)(Figure 2), in men (HR:1.5, CI:1.1-1.9, $\mathrm{p}=0.006)$ and in the $\mathrm{YO}$ group (HR:2.2, CI:1.5-3.2, $\mathrm{p}=0.000)$. No associations in women or in the $\mathrm{OO}$ individuals between periodontitis and mortality were identified (HR:1.4, CI: 1.0-1.9, $\mathrm{p}=0.055)$ respectively $(\mathrm{HR}: 1.2, \mathrm{CI}: 1.0-1.6, \mathrm{p}=0.102)($ Table 4$)$.

\section{Discussion}

The present study identified that over the 17-year follow- up period, periodontitis increased the risk of a future incidence of ischemic heart diseases in all individuals, in women and in the $\mathrm{OO}$ age group. The incidence of CVDs increased with age, and the incidence for ischemic heart diseases was higher in men. Another study has reported that after menopause, women have a higher incidence of AMI compared to agematched men (Stramba et al. 2006). In the present study, the incidence of a first ischemic heart disease was not significantly higher in women than men. There are few other longitudinal studies concerning periodontitis and incidences of CVDs. In a Danish national registerbased cohort study with a follow-up period of 15-years, patients with periodontitis were reported to have an increased risk of CVDs (Hansen, Egeberg, Holmstrup, \& Hansen, 2016). In this study the individuals were consecutively included with a hospital diagnosis of chronic or acute periodontitis based on ICD 10 codes. The classifications of periodontitis was different from our classification which have a more definitive definition with the severity and distribution specified. The age of the study population was $>18$ years, and gender differences were never reported which make comparisons impossible. A Korean nationwide cohort follow-up study of 7.6 years, showed a dose-dependent association with tooth loss and incident myocardial infarction, heart failure and ischemic stroke, especially in individuals with periodontitis (Lee, Choi, Park, Han, \& Oh, 2019). The circumstances between 
the study above and our study are not the same. The classification of periodontitis was in the study by Lee et al (2019) not defined and the study individuals included were from 20 years, mean age not mentioned. Also the included individuals had a history of a CVD event meaning that they were at an increased risk for a subsequent CVD (Park et al. 2013).

Another main finding in this study was that individuals with periodontitis were at higher risk to die during the 17- years follow up compared to individuals without a diagnosis of periodontitis. Recently published data have shown that periodontitis increased the risk for allcause mortality within 15 years (Hansen, Egeberg, Holmstrup, \& Hansen, 2016). In a 3 year follow-up study, individuals with severe periodontitis and with a diagnosis of coronary vascular disease more often, but not significant, developed the combined endpoint (myocardial infarction, stroke/transient ischemic attack, cardio-vascular death and death caused by stroke), compared to individuals without periodontitis (18.9\% versus $14.2 \%)$ (Reichert et al., 2016). As we didn't know the reasons for death such a combined endpoint was not possible to include. In our study it was also shown that in men and in the YO (60-72 years) there was an association between periodontitis and mortality. Young individuals (30-40 years) with periodontitis and missing molars have been reported to have an increased risk for early death over 16 years (Söder, Jin, Klinge, \& Söder, 2007). A consequence of an inflammatory burden from periodontitis, may be missing teeth which could explain the identified association between periodontitis, and CVDs as being stronger in younger individuals (Lee et al. 2019). In another recent study, $\geq 9$ missing teeth was also associated with mortality (Liljestrand et al. 2015).

Deaths by CVDs have decreased during the latest 60 years, as a result of preventive care and advances in medicine (GBD Risk factor Collaborators, 2018). Many older individuals are 
using preventive medications that may delay or even prevent a CVD event to occur (van der Vorst et al., 2019).

Recent data reported that the numbers of missing teeth were related to heart failure and myocardial infarction, whereas the number of teeth missing was not significantly related to stroke in a longitudinal study with a median follow up time of 15.8 years (Holmlund, Lampa, \& Lind, 2017). In another study the same tendency was reported, missing teeth ( $\geq 5$ missing teeth) was statistically associated with an event of coronary heart disease and acute myocardial infarction, whereas tooth loss was not associated with stroke in a 13-year prospective longitudinal study (Liljestrand et al., 2015). Unfortunately, associations between periodontitis and CVDs were not reported making comparisons to the present studies impossible.

In the literature, different classifications and parameters for periodontitis have been used. Missing teeth have also been proposed as proxi for current or past periodontitis as it is considered to reflect an accumulation of oral inflammation to which an individual has been experienced throughout life (Holmlund, \& Lind, 2012). Correctly, if untreated, periodontitis may result in tooth loss and is one of the major reasons for tooth loss in adulthood (Natto, Aladmawy, Alasqah, \& Papas, 2014). In a recent study by Lee et al. (2019) edentulous individuals demonstrated the highest cardiovascular risk. It is, however, difficult to to be sure of the reason for missing teeth unless it is clearly reported in the dental records. On the other hand, bone loss as used in the present study to define periodontal disease is a very strong indicator of that the patient have had periodontal inflammation. Accordingly using 
periodontal bone loss instead of missing teeth may be a more certain way to define inflammatory burden over time.

The prevalence of periodontitis in the present study was rather low (24.7\%). In the US, the reported prevalence of periodontitis in individuals 65 years and older has been reported to be $70 \%$, and with increasing prevalence by increasing age (Eke, Dye, Wei, Thornton-Evans, \& Genco, 2012). Possible reasons to these differences may be related to the use of different classifications of periodontitis and also the difference between CAL measurements and radiographic evidence of bone loss. Eke et al. (2012), when defining "total periodontitis" used CAL measurements and included both mild, moderat and severe stages of periodontitis. Among individuals defined as periodontits patients in the present study, individuals with bone loss corresponding to mild periodontitis were not included. The definition of periodontitis used in the present study is based on bone loss of $\geq 5 \mathrm{~mm}$ from the CEJ to the alveolar bone level on $\geq 30 \%$ of sites. The use of the $5 \mathrm{~mm}$ level is chosen to account for possible measurement errors. Individuals affected with periodontitis in older ages reflects a long history of periodontitis.

The new accepted classification of periodontitis includes clinical variables (clinical attachment level (CAL) and probing pocket depth) as well as bone loss in radiographs (Papapanou et al., 2018). The bone loss reflects the accumulated progressive effect of periodontitis over long time (Needleman et al. 2018; Reddy, Geurs, Jeffcoat, Proskin, \& Jeffcoat, 2000). Clinical parameters partly reflecting the inflammatory activity, could be more transient giving the information of the periodontal status at that specific moment. Studies have reported that mean proportion of bone loss increased with age but proportion of teeth with 
periodontal pockets remained unmodified (Billings et al., 2018). In another study the alveolar bone loss progressed with age but was limited after the age of 50 (Persson, Hollender, \& Persson, 1998). In older individuals gingival recession is the main reason for attachment loss (Billings et al., 2018). Crestal bone height and CAL have shown good correlation (Machtei, Hausmann, Grossi, Dunford, \& Genco 1997). It has been proven that attachment loss precedes radiographic evidence of crestal alveolar bone loss during periods of periodontal disease activity (Goodson, Haffajee, \& Socransky, 1984) whereas over time these differences seem to level off (Machtei, Hausmann, Grossi, Dunford, \& Genco, 1997). In our study the limit of alveolar bone-loss $\geq 5 \mathrm{~mm}$ distance from CEJ to marginal bone level reflects a definitive bone loss and such a bone loss being present on $\geq 30 \%$ of sites corresponds to a general disease distribution.

One limitation with the present study was that the most fragile and medically compromised individuals were not able to participate. This may have affected the results possibly lowering the associations between periodontitis and CVDs. The individuals in the preset study were 60 years or older. While the follow-up period was long obviously many died during the course of the study. The causes of death were not known but the main reasons for death are still CVDs (GBD Causes of Death Collaborators, 2018). The consequence of not knowing the reasons for death makes it impossible to include mortality by CVDs in a combined endpoint among others, which should have strengthen the associations between periodontitis and CVDs.

A strength with the study is that it is a long time follow-up and the CVD events are easy to follow and control. Because associations between periodontitis and future CVDs have been 
shown it would be interesting to study if well designed preventive dental programs can influence the incidence of CVDs in long term studies.

In conclusion, a diagnosis of periodontitis in individuals 60-93 years was associated with an increased risk for death over time. Further a diagnosis of periodontitis was associated with an increased risk to develop ischemic heart diseases. 


\section{References}

Aoyama, N., Suzuki, J.I., Kobayashi, N., Hanatani, T., Ashigaki, N., Yoshida, A., ... Isobe, M. (2017). Periodontitis deteriorates peripheral arterial disease in Japanese population via enhanced systemic inflammation. Heart Vessels, 32, 1314-1319. doi:10.1007/s00380-0171003-6.

Bartold, P. M., \& van Dyke, T. E. (2013). Periodontitis: a host-mediated disrupture of microbial homeostasis unlearning learned concepts. Periodontology 2000, 62, 203-217. doi: 10.1111/j.1600-0757.2012.00450.x.

Billings, M., Holtfreter, B., Papapanou, P. N., Mitnik, G. L., Kocher, T., \& Dye, B. A. (2018). Age-dependent distribution of periodontitis in two countries: Findings from NHANES 2009 to 2014 and SHIP-TREND 2008 to 2012. Journal of Periodontology, 89( Suppl. 1), 140-158. doi: 10.1002/JPER.17-0670.

van der Vorst, E. P. C., Peters, L. J. F., Müller, M., Gencer, S., Yan, Y., Weber, C., \& Döring, Y. (2019). G-Protein Coupled Receptor Targeting on Myeloid Cells in Atherosclerosis. Front Pharmacology, 22( 10), 531. doi: 10.3389/fphar.2019.00531.

Desvarieux, M., Demmer, R. T., Rundek, T., Boden-Albala, B., Jacobs, D. R. Jr., Papapanou, P. N., \& Sacco, R.L. (2003). Oral Infections and Vascular Disease Epidemiology Study (INVEST). Relationship between periodontal disease, tooth loss, and carotid artery plaque: The Oral Infections and Vascular Disease Epidemiology Study (INVEST). Stroke; 34( 9), 2120-2125. 
Eke, P. I., Dye, B. A., Wei, L., Thornton-Evans, G. O., \& Genco, R. J. (2012). CDC Periodontal Disease Surveillance workgroup: James Beck, Gordon Douglass Roy Page. Prevalence of Periodontitis in Adults in the United States: 2009 and 2010. Journal of Dental Research, 91, 914-920.

Eke, P. I., Wei, L., Borgnakke, W. S., Thornton-Evans, G., Zhang, X., Lu, H... Genco, R. J. (2016). Periodontitis prevalence in adults, $\geq 65$ years of age, in the USA. Periodontology 2000, 72, 76-95. doi: 10.1111/prd.12145.

GBD 2017 Causes of Death Collaborators. (2018). Global, regional, and national age-sex-specific mortality for 282 causes of death in 195 countries and territories, 1980-2017: a systematic analysis for the Global Burden of Disease Study 2017. Lancet, 10, 392( 10159), 1736-1788. doi: 10.1016/S0140-6736(18)32203-7.

GBD 2017 Risk Factor Collaborators. (2018). Global, regional, and national comparative risk assessment of 84 behavioural, environmental and occupational, and metabolic risks or clusters of risks for 195 countries and territories, 1990-2017: a systematic analysis for the Global Burden of Disease Study 2017. Lancet, 10, 392( 10159), 1923-1994. doi: 10.1016/S0140-6736(18)32225-6.

Goodson, J. M., Haffajee, A. D., \& Socransky, S. S. (1984).The relationship between attachment level loss and alveolar bone loss. Journal of Clinal Periodontology, 11( 5), 348359. 
Hansen, G. M., Egeberg, A., Holmstrup, P., \& Hansen, P. R. (2016). Relation of Periodontitis to Risk of Cardiovascular and All-Cause Mortality (from a Danish Nationwide Cohort Study). American Journal of Cardiology, 15, 118( 4), 489-493. doi:10.1016/j.amjcard.2016.05.036.

Holmlund, A., \& Lind, L. (2012). Number of teeth is related to atherosclerotic plaque in the carotid arteries in an elderly population. Journal of Periodontology, 83( 3), 287-291. doi: 10.1902/jop.2011.110100.

Holmlund, A., Lampa, E., \& Lind, L. (2017). Oral health and cardiovascular disease risk in a cohort of periodontitis patients. Atherosclerosis, 262, 101-106. doi:10.1016/j.atherosclerosis.2017.05.009.

Kassebaum, N. J, Bernabé, E., Dahiya, M., Bhandari, B., Murray, C. J. L., \& Marcenes W. (2014). Global burden of severe periodontitis in 1990-2010: a systematic review and metaregression. Journal of Dental Research, 93, 1045-1053. doi: 10.1177/0022034514552491.

Lee, H. J., Choi, E. K., Park, J. B., Han, K. D., \& Oh, S. (2019). Tooth Loss Predicts Myocardial Infarction, Heart Failure, Stroke, and Death. Journal of Dental Research, 98( 2), 164-170. doi: 10.1177/0022034518814829.

Liljestrand, J. M., Havulinna, A. S., Paju, S., Männistö, S., Salomaa, V., \& Pussinen, P. J. (2015). Missing Teeth Predict Incident Cardiovascular Events, Diabetes, and Death. Jornal of Dental Research, 94( 8), 1055-1062. doi: 10.1177/0022034515586352. 
Lockhart, P. B., Bolger, A. F., Papapanou, P. N., Osinbowale, O., Trevisan, M., Levison, M. E., \& Baddour, L. M. (2012). American Heart Association Rheumatic Fever, Endocarditis, and Kawasaki Disease Committee of the Council on Cardiovascular Disease in the Young, Council on Epidemiology and Prevention, Council on Peripheral Vascular Disease, and Council on Clinical Cardiology. Periodontal disease and atherosclerotic vascular disease: does the evidence support an independent association? A scientific statement from the American Heart Association. Circulation, 22, 125, 2520-2544. doi: 10.1161/CIR.0b013e31825719f3.

Machtei, E. E., Hausmann, E., Grossi, S. G., Dunford, R., \& Genco, R.J. (1997). The relationship between radiographic and clinical changes in the periodontium. Journal of Periodontal Research, 32( 8), 661-666.

Natto. Z. S., Aladmawy, M., Alasqah, M., \& Papas, A. (2014). Factors contributing to tooth loss among the elderly: A cross sectional study. Singapore Dental Journal, 35, 17-22. doi: 10.1016/j.sdj.2014.11.002.

Needleman, I., Garcia, R., Gkranias, N., Kirkwood, K. L., Kocher, T., Iorio, A. D., ... Petrie, A. (2018). Mean annual attachment, bone level, and tooth loss: A systematic review. Journal of Periodontology, 89( Suppl 1), 120-139. doi:10.1002/JPER.17-0062.

Papapanou, P. N., Sanz, M., Buduneli, N., Dietrich, T., Feres, M., Fine, D. H., ... Tonetti, M. S. (2018). Periodontitis: Consensus report of workgroup 2 of the 2017 World Workshop on the Classification of Periodontal and Peri-Implant Diseases and Conditions. Journal of Periodontology, 89( Suppl 1), 173-182. doi: 10.1002/JPER.17-0721. 
Park, H. W., Yoon, C. H., Kang, S. H., Choi, D. J., Kim, H. S., Cho, M. C., ... Kim, Y. J. (2013). Early- and late-term clinical outcome and their predictors in patients with ST-segment elevation myocardial infarction and non-ST segment elevation myocardial infarction. International Journal of Cardiology, 169( 4), 254-261.

Persson, R. E., Hollender, L. G., Persson, G. R. (1998). Assessment of alveolar bone levels from intraoral radiographs in subjects between ages 15 and 94 years seeking dental care. Journal of Clinical Periodontology; 25( 8):647-54. PubMed PMID: 9722269.

Reddy, M. S., Geurs, N. C., Jeffcoat, R. L., Proskin, H., \& Jeffcoat, M. K. (2000). Periodontal disease progression. Journal of Periodontology, 71( 10), 1583-1590.

Reichert, S., Schulz, S., Benten, A. C., Lutze, A., Seifert, T., Schlitt, M., ... Schlitt, A. (2016). Periodontal conditions and incidence of new cardiovascular events among patients with coronary vascular disease. Journal of Clinical Periodontology, 43( 11), 918-925. doi: 10.1111/jcpe.12611.

Roth, G. A., Johnson, C. O., Abate, K. H., Abd-Allah, F., Ahmed, M., Alam, K., .. Murray, C. J. L. (2018). Global Burden of Cardiovascular Diseases Collaboration, The Burden of Cardiovascular Diseases Among US States, 1990-2016. JAMA Cardiology, 3( 5), 375-389. doi:10.1001/jamacardio.2018.0385. 
Stramba-Badiale, M., Fox, K. M., Priori, S. G., Collins, P., Daly, C., Graham, ... Tendera, M. (2006). Cardiovascular diseases in women: a statement from the policy conference of the European Society of Cardiology. European Heart Journal; 27( 8):994-1005.

Söder, P. O., Söder, B., Nowak, J., \& Jogestrand, T. (2005). Early carotid atherosclerosis in subjects with periodontal diseases. Stroke, 36( 6), 1195-2000.

Söder, B., Jin, L. J., Klinge, B., \& Söder, P-O. (2007). Periodontitis and premature death: a 16-year longitudinal study in a Swedish urban population. Journal of Periodontal Research, 42( 4), 361-366.

Tonetti, M. S., \& Van Dyke, T. E. (2013). Working group 1 of the joint EFP/AAP workshop. Periodontitis and atherosclerotic cardiovascular disease: consensus report of the Joint EFP/AAP Workshop on Periodontitis and Systemic Diseases. Journal of Periodontology, $\mathbf{8 4}$ ( 4 Suppl), 24-29. doi: 10.1902/jop.2013.1340019.

Waters, A. M., Trinh, L., Chau, T., Bourchier, M., \& Moon, L. (2013). Latest statistics on cardiovascular disease in Australia. Clinical and Experimental Pharmacology and Physiology, 40( 6), 347-356. doi: 10.111/1440-1681.12079. 
Table 1. Baseline 2001-2003, characteristics of the study individuals

\begin{tabular}{l|l}
\hline & $\begin{array}{l}\geq \mathbf{1} \text { remaining tooth, dental } \\
\text { examination, panoramic radiograph } \\
\mathbf{n}=\mathbf{8 5 8}\end{array}$ \\
\hline Variables & \\
\hline Median age, years & $72.0(\mathrm{SD}: \pm 9.3)$ \\
\hline Gender (women) & $53.5 \%$ \\
\hline Remaining teeth & $18.6(\mathrm{SD}: \pm 7.5)$. \\
\hline Periodontitis & $212858(24.7 \%)$ \\
\hline No current nor former & $428 / 838(49.9 \%)$ \\
smoker & $192 / 853(22.4 \%)$ \\
\hline BMI $\geq 30$ & $260 / 847(30.3 \%)$ \\
\hline Hypertension & $35 / 853(4.1 \%)$ \\
\hline History of stroke & $66 / 850(7.7 \%)$ \\
\hline History of AMI & $66 / 856(7.7 \%)$ \\
\hline Diabetes type 2 & \\
\hline
\end{tabular}

$\mathrm{AMI}=$ Acute myocardial infarction, $\mathrm{BMI}=$ Body mass index Periodontitis= Alveolar bone-loss $\geq 5 \mathrm{~mm}$ distance from CEJ to marginal bone level on $\geq 30 \%$ of sites. Selfreported at baseline: No current nor former smoker, hypertension, history of stroke, history of AMI and diabetes type 2 
Table 2. Associations between ischemic heart diseases and different independent variables by Cox regression analysis

\begin{tabular}{|c|c|c|c|c|c|}
\hline $\begin{array}{l}\text { Independent } \\
\text { variables at } \\
\text { baseline }\end{array}$ & $\begin{array}{l}\text { All individuals } \\
\text { ( } n=858) \\
\text { HR Cl } \\
\text { p-value }\end{array}$ & $\begin{array}{l}\text { Women } \\
(n=459) \\
\text { HR Cl } \\
\text { p-value }\end{array}$ & $\begin{array}{l}\text { Men } \\
\text { (n=399) } \\
\text { HR Cl } \\
\text { p-value }\end{array}$ & $\begin{array}{l}\text { YO } \\
(n=471) \\
\text { HR Cl } \\
\text { p-value }\end{array}$ & $\begin{array}{l}\text { OO } \\
(n=387) \\
\text { HR Cl } \\
p \text {-value }\end{array}$ \\
\hline Age category & $\begin{array}{l}\text { HR:1.9 Cl:1.4-2.5 } \\
\mathbf{p}=\mathbf{0 . 0 0 0 * *}\end{array}$ & $\begin{array}{l}\text { HR:2.5 Cl:1.6-3.8 } \\
\mathbf{p}=\mathbf{0 . 0 0 0 * *}\end{array}$ & $\begin{array}{l}H R: 1.4 \quad C l: 0.9-2.2 \\
p=0.098\end{array}$ & & \\
\hline $\mathrm{BMI} \geq 30$ & $\begin{array}{l}\text { HR:1.2 Cl:0.9-1.7 } \\
p=0.246\end{array}$ & $\begin{array}{ll}\text { HR:1.2 } & \text { Cl:0.8-2.0 } \\
p=0.417 & \end{array}$ & $\begin{array}{l}\text { HR:1.3 Cl:0.8-2.2 } \\
p=0.304\end{array}$ & $\begin{array}{ll}\text { HR:1.3 Cl:0.8-2.0 } \\
p=0.284\end{array}$ & $\begin{array}{ll}\mathrm{HR}: 1.2 & \mathrm{Cl}: 0.7-2.1 \\
\mathrm{p}=0.479\end{array}$ \\
\hline Diabetes type 2 & $\begin{array}{l}\text { HR:1.5 Cl:1.0-2.4 } \\
p=0.079\end{array}$ & $\begin{array}{l}\text { HR:1.5 Cl:0.8-3.0 } \\
p=0.243\end{array}$ & $\begin{array}{l}\text { HR:1.4 Cl:0.7-2.6 } \\
p=0.310\end{array}$ & $\begin{array}{l}\text { HR:1.6 Cl:0.8-2.9 } \\
p=0.153\end{array}$ & $\begin{array}{l}\text { HR:1.4 Cl:0.7-3.0 } \\
p=0.311\end{array}$ \\
\hline Gender & $\begin{array}{l}\begin{array}{l}\text { HR:1.2 Cl:0.9-1.6 } \\
p=0.349\end{array}\end{array}$ & & & $\begin{array}{ll}\text { HR:1.4 Cl:1.0-2.2 } \\
p=0.079\end{array}$ & $\begin{array}{ll}\text { HR:0.9 Cl:0.6-1.5 } \\
p=0.768\end{array}$ \\
\hline Hypertension & $\begin{array}{l}\text { HR:1.5 Cl:1.1-2.0 } \\
\mathbf{p}=0.009 * *\end{array}$ & $\begin{array}{l}\text { HR:1.8 Cl:1.2-2.8 } \\
\mathbf{p}=\mathbf{0 . 0 0 6 * *}\end{array}$ & $\begin{array}{l}\text { HR:1.2 Cl:0.7-1.8 } \\
p=0.498\end{array}$ & $\begin{array}{l}\text { HR:1.5 Cl:1.0-2.3 } \\
\mathbf{p}=\mathbf{0 . 0 4 9 *}\end{array}$ & $\begin{array}{l}\text { HR:1.5 Cl:1.0-2.3 } \\
p=0.079\end{array}$ \\
\hline History of AMI & $\begin{array}{l}\text { HR:2.3 Cl:1.5-3.5 } \\
\mathbf{p}=0.000^{* *}\end{array}$ & $\begin{array}{l}\text { HR:2.5 Cl:1.1-5.8 } \\
\mathbf{p}=0.033^{*}\end{array}$ & $\begin{array}{l}\text { HR:2.4 Cl:1.4-4.1 } \\
\mathbf{p}=\mathbf{0 . 0 0 1} * *\end{array}$ & $\begin{array}{l}\mathrm{HR}: 2.5 \quad \mathrm{Cl}: 1.2-5.0 \\
\mathrm{p}=\mathbf{0 . 0 1 0}\end{array}$ & $\begin{array}{l}\text { HR:2.2 Cl:1.2-4.0 } \\
\mathbf{p}=\mathbf{0 . 0 0 6 * *}\end{array}$ \\
\hline Periodontitis & $\begin{array}{l}\text { HR:1.5 Cl:1.1-2.1 } \\
\mathrm{p}=\mathbf{0 . 0 1 7 *}\end{array}$ & $\begin{array}{l}\text { HR:2.1 Cl:1.3-3.4 } \\
\mathrm{p}=\mathbf{0 . 0 0 2} * *\end{array}$ & $\begin{array}{l}\text { HR:1.1 Cl:0.7-1.7 } \\
p=0.749\end{array}$ & $\begin{array}{ll}\text { HR:1.3 } & \text { Cl:0.8-2.2 } \\
p=0.229\end{array}$ & $\begin{array}{l}\text { HR:1.7 Cl:1.0-2.6 } \\
\mathbf{p}=\mathbf{0 . 0 3 3} *\end{array}$ \\
\hline Smoking & $\begin{array}{l}\text { HR:1.1 Cl:0.8-1.5 } \\
p=0.634\end{array}$ & $\begin{array}{l}\text { HR:1.0 Cl:0.7-1.6 } \\
p=0.900\end{array}$ & $\begin{array}{l}\text { HR:1.2 Cl:0.8-1.8 } \\
p=0.475\end{array}$ & $\begin{array}{l}\text { HR:1.3 Cl:0.9-2.0 } \\
p=0.181\end{array}$ & $\begin{array}{ll}\mathrm{HR}: 0.9 & \mathrm{Cl}: 0.5-1.4 \\
\mathrm{p}=0.579\end{array}$ \\
\hline
\end{tabular}

AMI $=$ Acute myocardial infarction, $\mathrm{BMI}=$ Body mass index,

Periodontitis $=$ Alveolar bone-loss $\geq 5 \mathrm{~mm}$ distance from CEJ to marginal bone level on $\geq 30 \%$ of

sites

$*=\mathrm{p}<0.0 .5, * *=\mathrm{p}<0.01$ 
Table 3 Associations between stroke and different independent variables by Cox regression analysis

\begin{tabular}{|c|c|c|c|c|c|}
\hline $\begin{array}{l}\text { Independent } \\
\text { variabels at } \\
\text { baseline }\end{array}$ & $\begin{array}{l}\text { All individuals } \\
\text { (n=858) } \\
\text { HR Cl } \\
\text { p-value }\end{array}$ & $\begin{array}{l}\text { Women } \\
(n=459) \\
\text { HR Cl } \\
\text { p-value }\end{array}$ & $\begin{array}{l}\text { Men } \\
(n=399) \\
\text { HR Cl } \\
\text { p-value }\end{array}$ & $\begin{array}{l}\text { YO } \\
(n=471) \\
\text { HR Cl } \\
\text { p-value }\end{array}$ & $\begin{array}{l}\text { OO } \\
(n=387) \\
\text { HR Cl } \\
\text { p-value }\end{array}$ \\
\hline Age cut & $\begin{array}{l}\mathrm{HR}: 3.4 \mathrm{Cl}: 2.3-5.1 \\
\mathbf{p}=0.000 * *\end{array}$ & $\begin{array}{l}\mathrm{HR}: 3.6 \mathrm{Cl}: 2.0-6.4 \\
\mathbf{p}=0.000 * *\end{array}$ & $\begin{array}{l}\mathrm{HR}: 3.2 \quad \mathrm{Cl}: 1.8-5.7 \\
\mathbf{p}=0.000 * *\end{array}$ & & \\
\hline $\mathrm{BMI} \geq 30$ & $\begin{array}{l}\text { HR:0.7 Cl:0.4-1.1 } \\
p=0.157\end{array}$ & $\begin{array}{ll}\text { HR:0.7 } & \mathrm{Cl}: 0.3-1.4 \\
p=0.282 & \end{array}$ & $\begin{array}{l}\text { HR:0.8 Cl:0.4-1.6 } \\
p=0.479\end{array}$ & $\begin{array}{ll}H R: 1.0 & C l: 0.5-2.0 \\
p=0.953 & \end{array}$ & $\begin{array}{ll}\text { HR:0.5 Cl:0.3-1.1 } \\
p=0.098\end{array}$ \\
\hline Diabetes type 2 & $\begin{array}{ll}H R: 0.8 \quad C l: 0.4-1.7 \\
p=0.613\end{array}$ & $\begin{array}{l}\text { HR:0.6 Cl:0.2-2.2 } \\
p=0.474\end{array}$ & $\begin{array}{l}H R: 1.0 \quad C l: 0.4-2.7 \\
p=0.924\end{array}$ & $\begin{array}{ll}\mathrm{HR}: 0.4 \quad \mathrm{Cl}: 0.1-1.8 \\
p=0.245\end{array}$ & $\begin{array}{ll}H R: 1.2 & C l: 0.5-2.8 \\
p=0.704 & \end{array}$ \\
\hline Gender & $\begin{array}{l}\text { HR:1.3 Cl:0.9-1.9 } \\
p=0.188\end{array}$ & & & $\begin{array}{l}\text { HR:1.2 Cl:0.6-2.2 } \\
p=0.587\end{array}$ & $\begin{array}{l}\text { HR:1.3 Cl:0.8-2.2 } \\
p=0.294\end{array}$ \\
\hline Hypertension & $\begin{array}{l}\mathrm{HR}: 1.8 \quad \mathrm{Cl}: 1.2-2.6 \\
\mathbf{p}=0.006^{* *}\end{array}$ & $\begin{array}{l}\mathrm{HR}: 2.1 \quad \mathrm{Cl}: 1.2-3.6 \\
\mathbf{p}=\mathbf{0 . 0 1 3} *\end{array}$ & $\begin{array}{l}\mathrm{HR}: 1.6 \quad \mathrm{Cl}: 0.9-2.8 \\
p=0.118\end{array}$ & $\begin{array}{l}\text { HR:1.7 Cl:0.9-3.1 } \\
p=0.128\end{array}$ & $\begin{array}{l}\mathrm{HR}: 1.8 \quad \mathrm{Cl}: 1.1-3.1 \\
\mathbf{p}=0.019 *\end{array}$ \\
\hline History of Stroke & $\begin{array}{l}\mathrm{HR}: 3.7 \quad \mathrm{Cl}: 2.0-6.9 \\
\mathbf{p}=0.000 * *\end{array}$ & $\begin{array}{ll}\mathrm{HR}: 2.7 & \mathrm{Cl}: 1.0-7.5 \\
p=0.052 & \end{array}$ & $\begin{array}{l}\mathrm{HR}: 4.6 \quad \mathrm{Cl}: 2.1-10.2 \\
\mathrm{p}=\mathbf{0 . 0 0 0} * *\end{array}$ & $\begin{array}{l}\mathrm{HR}: 6.2 \quad \mathrm{Cl}: 2.7-14.4 \\
\mathbf{p}=0.000 * *\end{array}$ & $\begin{array}{ll}\mathrm{HR}: 2.3 & \mathrm{Cl}: 0.9-6.1 \\
p=0.088 & \end{array}$ \\
\hline Periodontitis & $\begin{array}{ll}\mathrm{HR}: 1.2 \quad \mathrm{Cl}: 0.8-1.8 \\
\mathrm{p}=0.442\end{array}$ & $\begin{array}{l}\mathrm{HR}: 1.3 \quad \mathrm{Cl}: 0.7-2.4 \\
\mathrm{p}=0.485\end{array}$ & $\begin{array}{l}\mathrm{HR}: 1.2 \quad \mathrm{Cl}: 0.6-2.1 \\
p=0.627\end{array}$ & $\begin{array}{l}\mathrm{HR}: 1.1 \quad \mathrm{Cl}: 0.5-2.3 \\
\mathrm{p}=0.865\end{array}$ & $\begin{array}{ll}\mathrm{HR}: 1.2 & \mathrm{Cl}: 0.7-2.0 \\
p=0.535 & \end{array}$ \\
\hline Smoking & $\begin{array}{l}\mathrm{HR}: 1.0 \quad \mathrm{Cl}: 0.7-1.5 \\
p=0.915\end{array}$ & $\begin{array}{ll}\mathrm{HR}: 0.8 \quad \mathrm{Cl}: 0.4-1.4 \\
p=0.381\end{array}$ & $\begin{array}{l}\mathrm{HR}: 1.2 \quad \mathrm{Cl}: 0.7-2.1 \\
\mathrm{p}=0.544\end{array}$ & $\begin{array}{l}\mathrm{HR}: 1.2 \quad \mathrm{Cl}: 0.7-2.3 \\
p=0.496\end{array}$ & $\begin{array}{ll}\mathrm{HR}: 0.9 \quad \mathrm{Cl}: 0.6-1.6 \\
p=0.834\end{array}$ \\
\hline
\end{tabular}

AMI= Acute myocardial infarction, BMI=Body mass index,

Periodontitis $=$ Alveolar bone-loss $\geq 5 \mathrm{~mm}$ distance from CEJ to marginal bone level on $\geq 30 \%$ of

sites

$*=\mathrm{p}<0.0 .5, * *=\mathrm{p}<0.01$ 
Table 4 Associations between mortality and different independent variables by Cox regression analysis

\begin{tabular}{|c|c|c|c|c|c|}
\hline $\begin{array}{l}\text { Independent } \\
\text { variabels at } \\
\text { baseline }\end{array}$ & $\begin{array}{l}\text { All individuals } \\
\text { (n=858) } \\
\text { HR Cl } \\
\text { p-value }\end{array}$ & $\begin{array}{l}\text { Women } \\
\text { (n=459) } \\
\text { HR Cl } \\
\text { p-value }\end{array}$ & $\begin{array}{l}\text { Men } \\
(n=399) \\
\text { HR Cl } \\
\text { p-value }\end{array}$ & $\begin{array}{l}\text { YO } \\
\text { (n=471) } \\
\text { HR Cl } \\
\text { p-value }\end{array}$ & $\begin{array}{l}\text { OO } \\
(n=387) \\
\text { HR Cl } \\
\text { p-value }\end{array}$ \\
\hline Age cut & $\begin{array}{l}\mathrm{HR}: 5.7 \quad \mathrm{Cl}: 4.6-7.0 \\
\mathbf{p}=\mathbf{0 . 0 0 0} * *\end{array}$ & $\begin{array}{l}\mathrm{HR}: 5.9 \quad \mathrm{Cl}: 4.3-7.9 \\
\mathbf{p}=\mathbf{0 . 0 0 0} * *\end{array}$ & $\begin{array}{l}\mathrm{HR}: 5.6 \quad \mathrm{Cl}: 4.2-7.5 \\
\mathbf{p}=\mathbf{0 . 0 0 0} * *\end{array}$ & & \\
\hline $\mathrm{BMI} \geq 30$ & $\begin{array}{l}\text { HR:1.0 Cl:0.8-1.3 } \\
p=0.863\end{array}$ & $\begin{array}{l}\text { HR:1.0 Cl:0.8-1.5 } \\
p=0.675\end{array}$ & $\begin{array}{l}\text { HR:1.0 Cl:0.7-1.3 } \\
p=0.808\end{array}$ & $\begin{array}{ll}\text { HR:1.4 Cl:0.9-2.0 } \\
p=0.117\end{array}$ & $\begin{array}{ll}\text { HR:0.9 Cl:0.7-1.2 } \\
p=0.422\end{array}$ \\
\hline Diabetes type 2 & $\begin{array}{ll}H R: 1.1 & C l: 0.8-1.5 \\
p=0.591 & \end{array}$ & $\begin{array}{l}\text { HR:1.2 Cl:0.7-2.0 } \\
p=0.554\end{array}$ & $\begin{array}{ll}H R: 1.1 & C l: 0.7-1.7 \\
p=0.835 & \end{array}$ & $\begin{array}{l}\text { HR:1.0 Cl:0.6-1.9 } \\
p=0.887\end{array}$ & $\begin{array}{ll}\text { HR:1.1 Cl:0.7-1.6 } \\
p=0.671\end{array}$ \\
\hline Gender & $\begin{array}{l}\mathrm{HR}: 1.3 \quad \mathrm{Cl}: 1.1-1.6 \\
\mathbf{p}=\mathbf{0 . 0 0 9} * *\end{array}$ & & & $\begin{array}{l}\text { HR:1.3 Cl:0.9-1.9 } \\
p=0.112\end{array}$ & $\begin{array}{l}\text { HR:1.3 Cl:1.0-1.7 } \\
\mathbf{p}=\mathbf{0 . 0 2 5 *}\end{array}$ \\
\hline Hypertension & $\begin{array}{l}\mathrm{HR}: 1.2 \quad \mathrm{Cl}: 1.0-1.5 \\
\mathbf{p}=\mathbf{0 . 0 3 3} *\end{array}$ & $\begin{array}{l}\text { HR:1.4 Cl:1.1-1.9 } \\
\mathbf{p}=\mathbf{0 . 0 1 2} *\end{array}$ & $\begin{array}{ll}\mathrm{HR}: 1.1 & \mathrm{Cl}: 0.9-1.5 \\
p=0.371\end{array}$ & $\begin{array}{l}\mathrm{HR}: 1.2 \quad \mathrm{Cl}: 0.8-1.7 \\
p=0.444\end{array}$ & $\begin{array}{l}\text { HR:1.3 Cl:1.0-1.6 } \\
p=0.057\end{array}$ \\
\hline History of AMI & $\begin{array}{l}\mathrm{HR}: 1.1 \quad \mathrm{Cl}: 0.8-1.5 \\
\mathrm{p}=0.540\end{array}$ & $\begin{array}{l}\text { HR:1.4 Cl:0.7-2.7 } \\
p=0.287\end{array}$ & $\begin{array}{ll}\mathrm{HR}: 1.0 \quad \mathrm{Cl}: 0.7-1.4 \\
p=0.996\end{array}$ & $\begin{array}{l}\text { HR:1.3 Cl:0.7-2.6 } \\
p=0.397\end{array}$ & $\begin{array}{ll}\text { HR:1.0 Cl:0.7-1.5 } \\
p=0.813\end{array}$ \\
\hline History of Stroke & $\begin{array}{l}\mathrm{HR}: 1.9 \quad \mathrm{Cl}: 1.3-2.9 \\
\mathbf{p}=\mathbf{0 . 0 0 2} * *\end{array}$ & $\begin{array}{ll}\mathrm{HR}: 1.5 \quad \mathrm{Cl}: 0.8-2.8 \\
p=0.225\end{array}$ & $\begin{array}{l}\mathrm{HR}: 2.3 \quad \mathrm{Cl}: 1.3-3.9 \\
\mathbf{p}=\mathbf{0 . 0 0 4} * *\end{array}$ & $\begin{array}{ll}\mathrm{HR}: 1.8 \quad \mathrm{Cl}: 0.9-3.5 \\
p=0.088\end{array}$ & $\begin{array}{l}\text { HR:1.9 Cl:1.1-3.2 } \\
\mathbf{p}=\mathbf{0 . 0 1 3} *\end{array}$ \\
\hline Periodontitis & $\begin{array}{l}\mathrm{HR}: 1.4 \quad \mathrm{Cl}: 1.2-1.8 \\
\mathbf{p}=\mathbf{0 . 0 0 2} * *\end{array}$ & $\begin{array}{ll}\mathrm{HR}: 1.4 & \mathrm{Cl}: 1.0-1.9 \\
\mathrm{p}=0.055 & \end{array}$ & $\begin{array}{l}\mathrm{HR}: 1.5 \quad \mathrm{Cl}: 1.1-1.9 \\
\mathbf{p}=\mathbf{0 . 0 0 6} * *\end{array}$ & $\begin{array}{l}\mathrm{HR}: 2.2 \mathrm{Cl}: 1.5-3.2 \\
\mathbf{p}=\mathbf{0 . 0 0 0 * *}\end{array}$ & $\begin{array}{ll}\mathrm{HR}: 1.2 & \mathrm{Cl}: 1.0-1.6 \\
\mathrm{p}=0.102 & \end{array}$ \\
\hline Smoking & $\begin{array}{l}\mathrm{HR}: 1.0 \quad \mathrm{Cl}: 0.8-1.2 \\
\mathrm{p}=0.977\end{array}$ & $\begin{array}{l}\text { HR:0.9 Cl:0.6-1.2 } \\
p=0.333\end{array}$ & $\begin{array}{l}\mathrm{HR}: 1.1 \quad \mathrm{Cl}: 0.9-1.5 \\
p=0.321\end{array}$ & $\begin{array}{l}\mathrm{HR}: 1.1 \quad \mathrm{Cl}: 0.8-1.5 \\
\mathrm{p}=0.624\end{array}$ & $\begin{array}{ll}\text { HR:1.0 } & \mathrm{Cl}: 0.8-1.2 \\
p=0.810\end{array}$ \\
\hline
\end{tabular}

AMI $=$ Acute myocardial infarction, $\mathrm{BMI}=$ Body mass index,

Periodontitis $=$ Alveolar bone-loss $\geq 5 \mathrm{~mm}$ distance from CEJ to marginal bone level on $\geq 30 \%$ of sites

$*=\mathrm{p}<0.0 .5, * *=\mathrm{p}<0.01$ 


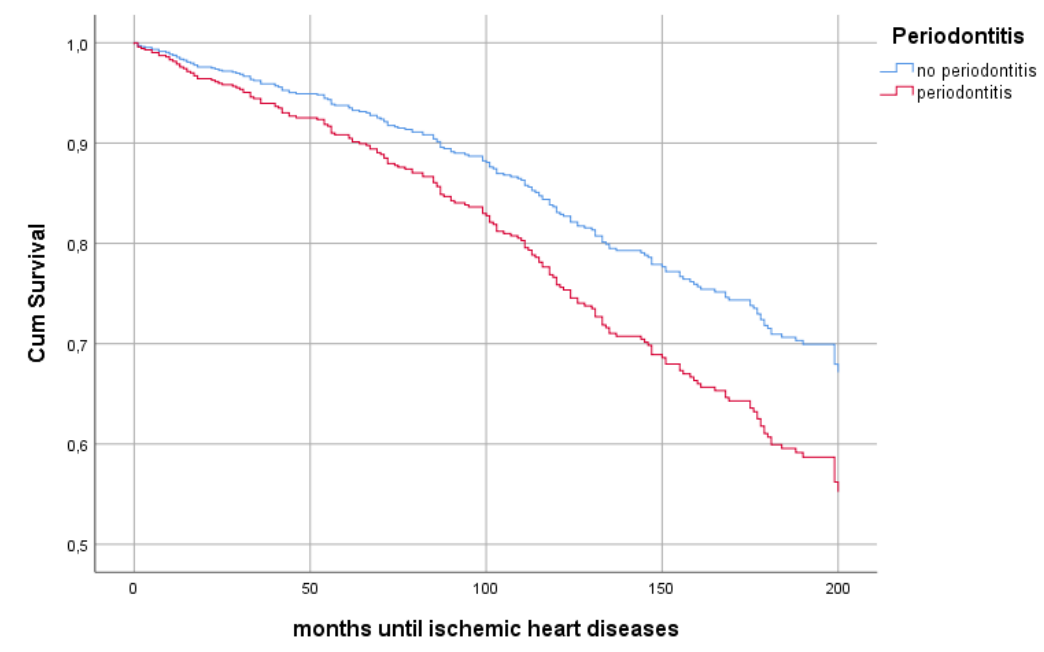

Figure 1 Cox regression curves: 17 year cumulative ischemic heart diseases survival of the total population, comparing individuals with and without periodontitis 


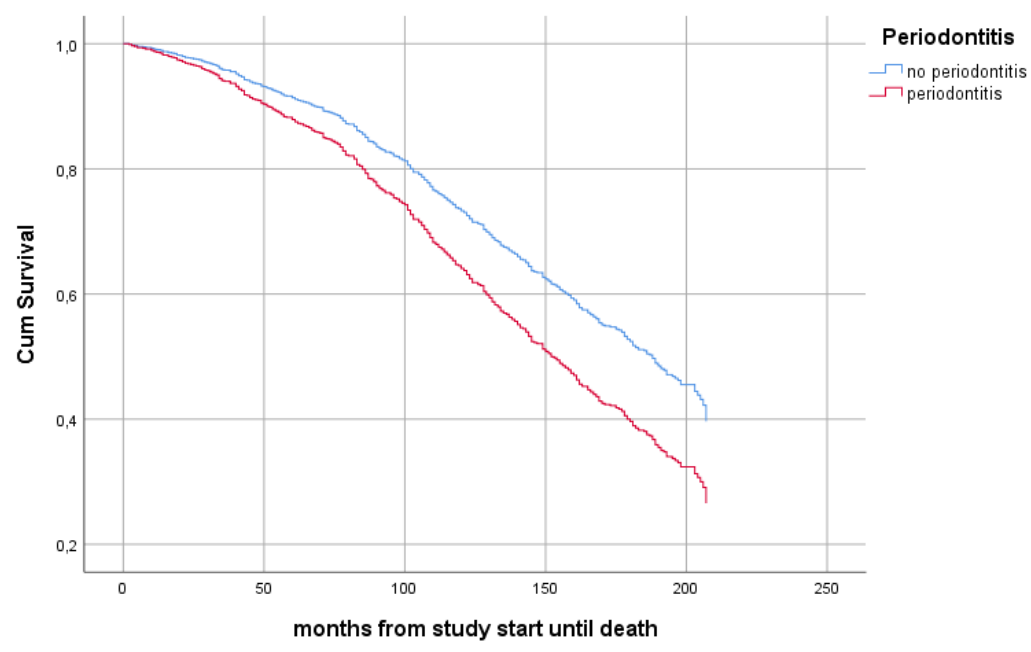

Figure 2 Cox regression curves: 17 year cumulative death survival of the total study population, comparing individuals with and without periodontitis 



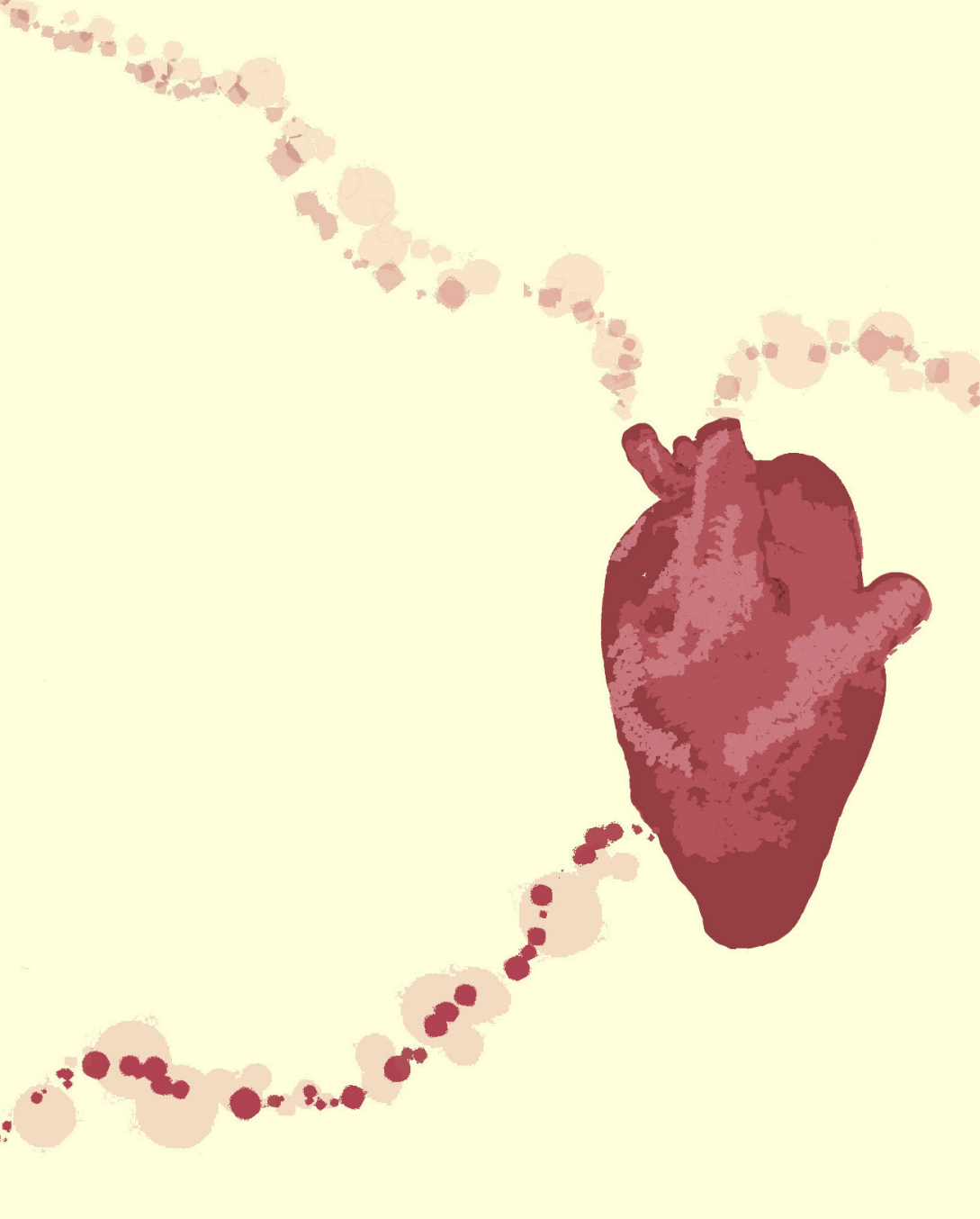

ISBN 978-9I-7877-020-5 (print)

ISBN 978-9I-7877-02I-2 (pdf)

ISBN 978-9I-87973-4 I-3 (Kristianstad)

MALMÖ UNIVERSITY 20506 MALMÖ, SWEDEN WWW.MAU.SE 